\title{
Modulation of the
}

\section{Hypothalamic-Pituitary-Adrenal Axis by Early Life Stress Exposure}

\author{
Miranda van Bodegom, Judith R. Homberg and Marloes J. A. G. Henckens*
}

Department of Cognitive Neuroscience, Centre for Neuroscience, Donders Institute for Brain, Cognition and Behaviour, Radboudumc, Nijmegen, Netherlands

Exposure to stress during critical periods in development can have severe long-term consequences, increasing overall risk on psychopathology. One of the key stress response systems mediating these long-term effects of stress is the hypothalamic-pituitary-adrenal (HPA) axis; a cascade of central and peripheral events resulting in the release of corticosteroids from the adrenal glands. Activation of the HPA-axis affects brain functioning to ensure a proper behavioral response to the stressor, but stress-induced (mal)adaptation of the HPA-axis' functional maturation may provide a mechanistic basis for the altered stress susceptibility later in life. Development of the HPA-axis and the brain regions involved in its regulation starts prenatally and continues after birth, and is protected by several mechanisms preventing corticosteroid over-exposure to the maturing brain. Nevertheless, early life stress (ELS) exposure has been reported to have numerous consequences on HPA-axis function in adulthood, affecting both its basal and stress-induced activity. According to the match/mismatch

OPEN ACCESS

Edited by:

Angela Sarabdjitsingh,

UMC Utrecht Brain Center Rudolf

Magnus, Netherlands

Reviewed by:

Chris Anthony Murgatroyd, Manchester Metropolitan University,

Eva Naninck

University of Amsterdam, Netherlands

*Correspondence:

Marloes J. A. G. Henckens marloes.henckens@radboudumc.nl

Received: 02 February 2017 Accepted: 13 March 2017

Published: 19 April 2017

Citation:

van Bodegom M, Homberg JR and Henckens MJAG (2017) Modulation of the Hypothalamic-Pituitary-Adrenal Axis by Early Life Stress Exposure.

Front. Cell. Neurosci. 11:87.

doi: 10.3389/fncel.2017.00087 theory, encountering ELS prepares an organism for similar ("matching") adversities during adulthood, while a mismatching environment results in an increased susceptibility to psychopathology, indicating that ELS can exert either beneficial or disadvantageous effects depending on the environmental context. Here, we review studies investigating the mechanistic underpinnings of the ELS-induced alterations in the structural and functional development of the HPA-axis and its key external regulators (amygdala, hippocampus, and prefrontal cortex). The effects of ELS appear highly dependent on the developmental time window affected, the sex of the offspring, and the developmental stage at which effects are assessed. Albeit by distinct mechanisms, ELS induced by prenatal stressors, maternal separation, or the limited nesting model inducing fragmented maternal care, typically results in HPA-axis hyper-reactivity in adulthood, as also found in major depression. This hyper-activity is related to increased corticotrophin-releasing hormone signaling and impaired glucocorticoid receptor-mediated negative feedback. In contrast, initial evidence for HPA-axis hypo-reactivity is observed for early social deprivation, potentially reflecting the abnormal HPA-axis function as observed in post-traumatic stress disorder, and future studies should investigate its neural/neuroendocrine foundation in further detail. Interestingly, experiencing additional (chronic) stress in adulthood seems to normalize these alterations in HPA-axis function, supporting the match/mismatch theory.

Keywords: HPA-axis, corticosteroids, prenatal stress, maternal separation, early social deprivation, limited nesting, match/mismatch theory, epigenetics 


\section{INTRODUCTION}

The neuroendocrine stress response is essential for adequate responding to, coping with, and subsequent recovery from environmental threats that disrupt homeostasis (McEwen, 2007; Joëls and Baram, 2009; Sandi and Haller, 2015). Activation of the hypothalamic-pituitary-adrenal (HPA) axis provides the metabolic support for the stress response by mobilizing stored energy, suppressing the immune response, and potentiating numerous sympathetically mediated effects (de Kloet et al., 2005; Ulrich-Lai and Herman, 2009). Moreover, corticosteroids (i.e., cortisol in humans, corticosterone in rodents), the end product of the HPA-axis, easily cross the blood-brain barrier to affect brain function and thereby behavior. Although this is a highly adaptive response, aberrant corticosteroid release, e.g., as a consequence of extreme or chronic stress exposure, can be damaging to the organism and contribute to psychopathology (McKay and Cidlowski, 2003). A wealth of evidence implicates deviant HPA-axis function in stress-related mental disorders (Varghese and Brown, 2001; Faravelli et al., 2012), suggesting that proper basal and stress-induced function of the HPA-axis is of critical importance to an organism's health. Evidence for the clinical relevance of aberrant HPA-axis function has accumulated over years. Elevated basal cortisol has for example been shown predictive of the risk for depressive episodes (Goodyer et al., 2001), whereas successful antidepressant treatment is associated with the resolution of the impaired HPA-axis negative feedback (Pariante, 2006) by restoring corticosteroid receptor expression in the brain (Pariante and Lightman, 2008) that also predicts the patient's long-term clinical outcome (Pariante, 2006).

The perinatal period, characterized by elevated synaptic plasticity, reflects a critical window of brain development, during which the brain is particularly sensitive to modulating external factors such as stress (Andersen, 2003; Lupien et al., 2009). Abundant evidence suggests that stress experienced during this sensitive period can have lasting effects on an individual's ability to cope with stressful situations throughout life. Childhood adversities such as emotional, physical or sexual abuse, and neglect have been reported to result in increased arousal (Jovanovic et al., 2009), enhanced processing of negative emotional information (Pollak and Sinha, 2002; Pollak and Tolley-Schell, 2003; Pollak et al., 2009), and cognitive deficits (including impaired working memory, long-term memory, and attention; Masson et al., 2015; Geoffroy et al., 2016); all contributing to a heightened sensitivity to stress and increased risk to develop e.g., major depressive disorder (MDD), substance abuse disorders, or post-traumatic stress disorder (PTSD) (Fergusson et al., 1996; Felitti et al., 1998; Chapman et al., 2004; Faravelli et al., 2012). These observations suggest that individuals are more likely to suffer from disease as life adversity accumulates; a theory known as the cumulative stress hypothesis (McEwen, 2003). However, another prominent theory, i.e., the match/mismatch hypothesis, suggests that early life adversity may prepare an organism for exposure to similar ("matching") adversity later in life and produce a predictive adaptive response (Gluckman et al., 2007) to optimize responses to future stressors. In line with this theory, adverse childhood events have been associated with blunted HPA-axis reactivity to acute stress experienced in adulthood (Elzinga et al., 2008). However, a mismatch between early- and later-life environments could render an organism more vulnerable to develop psychopathology (Bravo et al., 2011; Nederhof and Schmidt, 2012; Daskalakis et al., 2013; Fine et al., 2014). To understand the underlying mechanisms of vulnerability to stress-related disease and its interaction with the adult environment, it is essential to study the development of the central components of the stress system, and how this is modulated by ELS.

Here, we review existing literature describing the effects of ELS on adult HPA-axis function. As one relies on animal models to study the effects of ELS exposure prospectively, mechanistically, and in a controlled manner, this review mainly covers data from rodent studies. Like in humans, ELS in rodents has generally been shown to increase anxiety (Wigger and Neumann, 1999) and depressive symptoms (Weinstock, 2008), alter social behavior (Veenema et al., 2006; Lukas et al., 2011), impair learning and memory processes (Liu et al., 1997, 2000b), and attenuate sensorimotor gating (Ellenbroek et al., 1998; Zhang et al., 2005), seemingly in interaction with concurrent adult life stress levels (Oomen et al., 2010).

\section{The HPA-Axis}

Upon exposure to a stressor, corticotrophin-releasing hormone (CRH) and arginine vasopressin (AVP) are secreted by the paraventricular nucleus (PVN) of the hypothalamus (Stratakis and Chrousos, 1995). CRH and AVP activate the anterior pituitary to secrete adrenocorticotropic hormone (ACTH), which in turn stimulates the adrenal cortex to produce corticosteroids, the end product of the HPA-axis (Figure 1). CRH acts primarily through CRH receptor 1 (CRHR1; Refojo and Holsboer, 2009), which is not only abundantly expressed in the anterior pituitary, but also in the prefrontal cortex, hippocampus, PVN, and basolateral amygdala (BLA); all regions involved in mediating and regulating behavioral and neuroendocrine stress responsivity. CRH also binds to a lesser extent to CRHR2, expressed predominantly in the ventromedial hypothalamus, dorsal raphe nucleus, and medial amygdala (MeA) (Steckler and Holsboer, 1999), further endorsing CRH's potency in modulating brain function. CRHR1 activation by CRH, which is not only released by the PVN, but also e.g., by $\mathrm{CRH}$-expressing cells in the hippocampus and central amygdala (CeA), is generally thought mediate stress-initiation, whereas CRHR2 activation would moderate its termination, although recent work has emphasized that this dual, opposing role of CRHRs is overly simplified and highly brain-region specific (Henckens et al., 2016).

Corticosteroids easily cross the blood-brain barrier to influence brain function through the binding to two receptors: the glucocorticoid receptors (GRs) and mineralocorticoid receptors (MRs), differing both in distribution and in affinity for their ligand (Reul and de Kloet, 1985). GRs are widely expressed throughout the brain, but most abundant in the hypothalamic $\mathrm{CRH}$ neurons and pituitary corticotropes. MR expression is mainly restricted to the limbic areas, with highest expression levels found in the hippocampus (Sapolsky et al., 1983; Reul and 


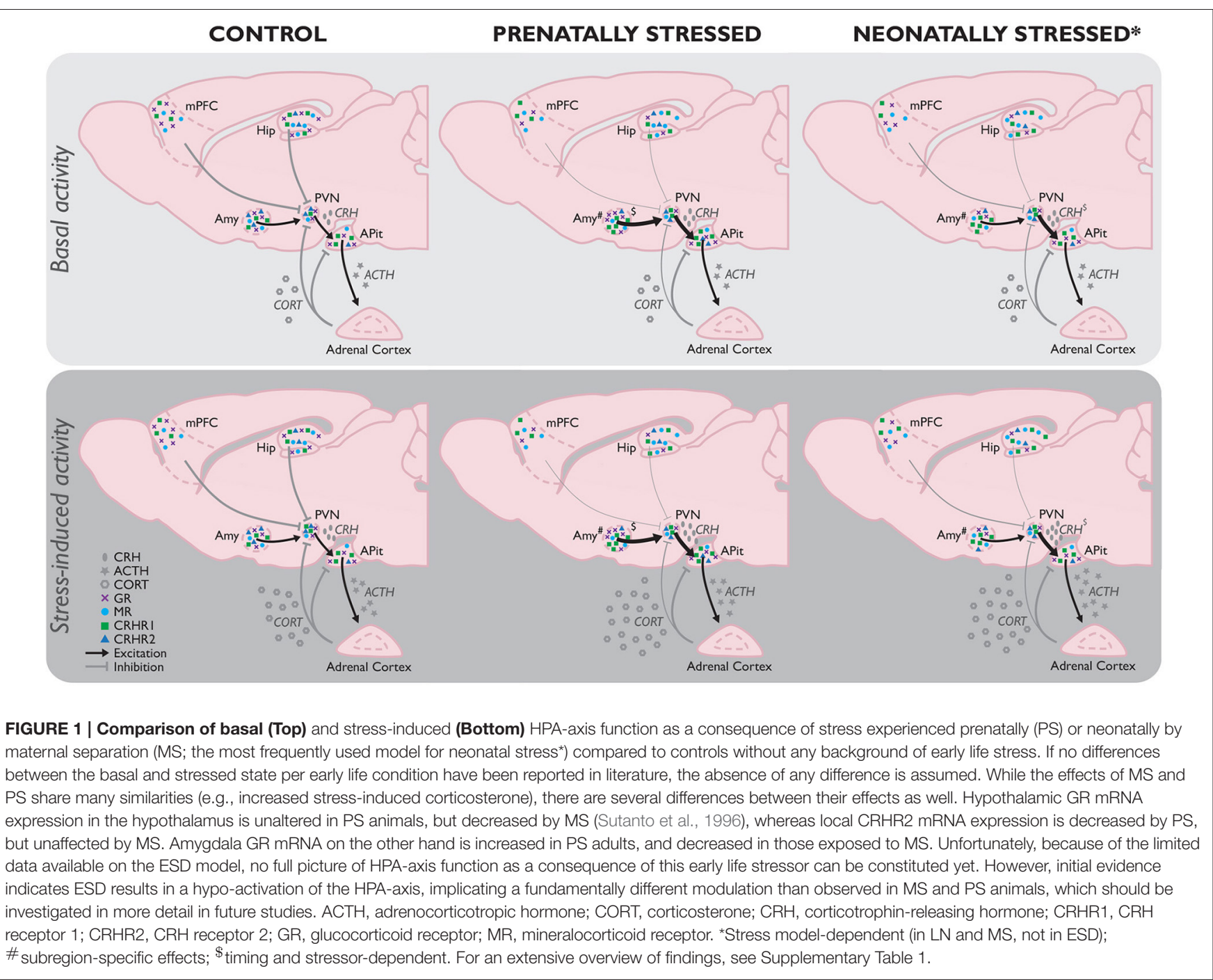

de Kloet, 1985; de Kloet, 1991). The most well-known route of action of corticosteroids involves their binding to intracellularly located receptors, which upon ligand-binding translocate to the nucleus to influence gene transcription both directly through the binding of their homo/heterodimers to glucocorticoid response elements in the DNA and the recruitment of co-repressors or coactivators, or indirectly by interacting with other stress-induced transcription factors to dampen their activity (De Bosscher et al., 2003). Thereby, corticosteroid receptor binding can lead to the induction or repression of the transcription of over 200 genes that are involved in a multitude of cellular processes (Datson et al., 2001). This provides a mechanism through which corticosteroids can modulate brain maturation; initiating terminal maturation, remodeling axons and dendrites, and affecting cell survival (Meyer, 1983).

As intracellularly located MRs have a 10-fold higher affinity for corticosteroids compared to the GRs residing in the cytoplasm (Reul and de Kloet, 1985; de Kloet, 1995), they have been hypothesized to be primarily involved in the ongoing transfer of information and stability of circuits, controlling the sensitivity and the threshold of the system's response to stress. For long, the intracellular GRs were assumed to be the main players in the stress response; mediating the negative feedback control on the HPA-axis (de Kloet et al., 1993; Herman and Cullinan, 1997), normalizing neuronal activity following stress exposure, and helping the organism cope with, adapt to, and recover from stress. However, the recent discovery of MRs and GRs residing on the cell membrane, both displaying comparable affinity to the intracellular GRs (Joëls, 2008) has forced researchers to amend this rather simplistic dualistic view. Corticosteroid-binding to these membrane receptors was shown to induce rapid changes in neuronal excitability and activity through non-genomic mechanisms (Groeneweg et al., 2011) and thereby seems to contribute to an acute state of arousal and hypervigilance (de Kloet et al., 2005). This multitude of functions affected by corticosteroids suggests that alterations in corticosteroid signaling, resulting for example from early life stress (ELS), can have enormous consequences. 


\section{HPA-AXIS PROGRAMMING BY EARLY LIFE STRESS (ELS)}

Because of its potent programming effects (e.g., lastingly influencing GR and $\mathrm{MR}$ expression levels, programming hypertension, and influencing hormone levels), excessive corticosteroid exposure to the developing brain is minimized by several mechanisms. Prenatally, fetal exposure to maternal corticosteroids is minimized by placental $11 \beta$-hydroxysteroid dehydrogenase type 2 (11 $\beta$-HSD2), which throughout the entire pregnancy rapidly inactivates corticosteroids (Shams et al., 1998; Maccari et al., 2014). During late-pregnancy, the mother's HPA-axis stress response is reduced (Maccari et al., 2014), and postnatally, corticosteroid exposure to the developing brain is minimized by the stress hyporesponsive period (SHRP) (Gos et al., 2008); a period [postnatal day (PND) 1-12 in mice and PND3/4-14 in rats] characterized by both low basal ACTH and corticosteroids levels and a relative unresponsiveness to external stressors (Schmidt et al., 2003; Box 1). While not entirely identical to rodents, humans also appear to experience a period of dampened HPA-axis responses. In humans the exact duration of the SHRP is not clearly specified, but seems to occur between 6 and 12 months of age, while the human HPA-axis is still quite responsive to stressful situations up to roughly 3 months after birth (Gunnar and Donzella, 2002; Gunnar, 2003). The exact duration of this period seems to be associated with the quality of care the infant receives, with a lower quality of care resulting in premature development of corticosterone responsivity even until 15 months (Gunnar and Cheatham, 2003).

However, these mechanisms cannot prevent corticosteroid exposure entirely, allowing ELS to affect brain and HPA-axis development. While $11 \beta$-HSD2 buffers corticosterone exposure to the fetus, a portion of it does pass the placenta, where it not only increases fetal exposure directly but also indirectly by inducing fetal HPA-axis activation (provided the fetal HPAaxis is functional yet; Ohkawa et al., 1991; Fujioka et al., 1999; Seckl, 2008). Moreover, repeated exposure of the mother to stress reduces $11 \beta$-HSD2 activity (Mairesse et al., 2007), further contributing to increased fetal corticosteroid exposure, reaching levels high enough to cause alterations in fetal programming (e.g., by influencing GR and MR expression levels and inducing increased HPA-axis activity; Levitt et al., 1996). Increased corticosteroid exposure seems to critically mediate these ELS effects, as they are prevented by adrenalectomy and hormone replacement in the dams (Barbazanges et al., 1996). Shortly after birth, prolonged stress exposure, e.g., by long separation periods ( $3 \mathrm{~h}$ or more each day) from the mother, can cause the neonate to emerge from the SHRP; increasing activity of the PVN (Smith et al., 1997) and elevating levels of basal and stressinduced corticosterone (Stanton et al., 1988). Short separation periods $(3 \min -3 \mathrm{~h}$ ) seem to be insufficient to do so, but when repeated daily, also induce sensitization of the neonate's corticosterone stress response and adrenal growth (Levine et al., 1991; D’Amato et al., 1992; McCormick et al., 1998; Schmidt et al., 2004).
Thereby, ELS is able to "imprint" or "program" an organism's neuroendocrine, neural and behavioral responses to stress. Although the exact underlying mechanisms by which ELS establishes these life-long effects still need to be resolved, research focuses along two complementary lines. Firstly, ELS during critical stages in brain maturation may disrupt specific developmental processes (by altered neurotransmitter exposure, gene transcription, or neuronal differentiation), leading to aberrant neural circuit function throughout life (Chen and Baram, 2016). Evidence for these mechanisms is derived from observations that corticosteroids in vitro decrease the rate of cell proliferation by preventing progression through the cell cycle (Fanger et al., 1987; Vintermyr et al., 1989; Hatakeyama et al., 1991; Sánchez et al., 1993), suggesting that endogenous corticosteroids play a role in differentiation and maturational events during late fetal brain development, promoting the transition between a proliferative and a differentiating stage by directly inhibiting cell division as well as activating the expression of specific genes characteristic of the differentiated mature phenotype. Secondly, ELS may induce modifications of the epigenome which lastingly affect brain function (Babenko et al., 2015). Briefly, epigenetics refers to mechanisms by which the environment interacts with the genome by the modification of chromatin structure or control of mRNA translation (Silberman et al., 2016). DNA methylation, post-translational histone modifications (methylation, phosphorylation, acetylation) and noncoding RNA activity are among the most studied epigenetic mechanisms that regulate gene expression. These epigenetic modifications are inducible, stable, and yet reversible, constituting an important emerging mechanism by which transient environmental stimuli can induce persistent changes in gene expression and ultimately behavior (Zovkic et al., 2013). Prenatal stress was for example shown to alter characteristic brain miRNA profiles and affect transcriptomic brain profiles in the offspring, including genes related to development, axonal guidance and neuropathology (Zucchi et al., 2013). Furthermore, increased DNA methylation of the Hsd11b2 gene promoter in the placenta was found (together with an increase in DNA methyltransferase DNMT3a mRNA levels) as a consequence of repeated stress exposure of the mother, which is held responsible for the reduction of $H s d 11 b 2$ mRNA expression and activity observed following repeated stress (Jensen Peña et al., 2012). Moreover, in the fetal hypothalamus, prenatal stress was found to decrease methylation within the Hsd11b2 promoter and increase methylation at sites within exon 1 of the gene, but these differences did not translate into differential mRNA expression levels of the gene.

To improve understanding of the life-time consequences of these ELS-induced mechanisms and their potential contribution to psychopathology, we here review the effects of ELS on the functional and structural integrity of the HPA-axis' endocrine glands, expression levels of neuroendocrine and growth hormones and neurotransmitters, as well as their receptors in several of the key brain regions regulating HPA-axis activity (i.e., the amygdala, hippocampus, and prefrontal cortex), and interpret their (mal)adaptive nature under either matching 


\section{BOX 1 | The developing HPA-axis.}

During pregnancy, the fetus is exposed to maternal corticosteroids which are to a great extend inactivated by placental $11 \beta$-hydroxysteroid dehydrogenase type $2(11 \beta-H S D 2)$. In the third trimester (in humans, this is slightly earlier in gestation; Murphy, 1973), the fetus becomes capable of secreting corticotrophin-releasing hormone (CRH) (Fujioka et al., 1999) and adrenocorticotropic hormone (ACTH) in response to stress experienced by the mother, leading to the production of fetal corticosterone (Gunn et al., 2013). Basal corticosterone levels of the fetal rat at the final week of gestation closely resemble the basal levels found in adults (Meaney et al., 1985b; Sapolsky and Meaney, 1986; Levine, 1994). However, around birth, corticosteroid levels start to drop, resulting in low basal levels of corticosteroids and a relative unresponsiveness to external stressors early in life; the stress hyporesponsive period (SHRP) (Gos et al., 2008). During this period, pups display low basal ACTH and corticosterone concentrations and an inability to induce a ACTH/corticosterone response to stress (Schmidt et al., 2003). The pattern of $\mathrm{CRH}$ expression differs slightly in that the robust $\mathrm{CRH}$ expression decreases perinatally to 20\% of the levels observed in adulthood (Walker et al., 1986a), but increases to reach adult levels at the end of the first postnatal week (Grino et al., 1989; Baram and Lerner, 1991) and do respond to stressors during the SHRP (Dent et al., 2000a,b). The expression of arginine vasopressin (AVP) is just detectable during the third trimester, but rises in the first 4 weeks of life, reaching $70 \%$ of adult levels by postnatal day (PND) (Almazan et al., 1989). During the SHRP, glucocorticoid (GR) and mineralocorticoid receptors (MR) mRNA expression levels are slightly higher than in the prenatal brain $\mathrm{Yi}$ et al., 1994), but low corticosterone levels prevent the feedback loops from functioning.

Concerning receptor expression, first $\mathrm{CRH}$ receptors (CRHRs) are observed in the brain from mid-gestation [ gestational day (GD)17] onwards, and reach particularly high levels early in development (stretching to $>300 \%$ of adult expression levels during the first post-natal week; Insel et al., 1988; AvishaiEliner et al., 1996). Moreover, during this stage CRHR2 is also temporarily expressed in the medial prefrontal cortex (MPFC), but has disappeared at the end of the SHRP (Eghbal-Ahmadi et al., 1998). Although, expression levels of CRHR1 in the fully developed mPFC are only moderate, and CRHR2 seems absent (Van Pett et al., 2000), initial expression levels during early development are thus much higher (Avishai-Eliner et al., 1996; Eghbal-Ahmadi et al., 1998). CRHR2 expression levels in the developing amygdala (Amy) are very subregiondependent, as the medial and basal nuclei express this receptor by GD17, and do so fairly stable until adulthood, whereas in the cortical amygdala this receptor will not be expressed until after birth. Expression has been observed on PND3, and will increase with age (Eghbal-Ahmadi et al., 1998). In the hippocampus, CRHR1 mRNA levels increase to maximal (300-600\% of adult levels) at PND6, after which levels slowly decrease (Avishai-Eliner et al., 1996). Hippocampal CRHR2 expression is observed as of PND1, and its expression remains fairly constant throughout development (Eghbal-Ahmadi et al., 1998). Prenatally, GR mRNA levels in the hippocampus, mPFC, amygdala, paraventricular nucleus (PVN), and anterior pituitary (APit) are relatively low compared to the adult situation (Bohn et al., 1994; Yi et al., 1994; Pryce, 2008) and thus, the HPAaxis has a relatively low sensitivity to negative feedback (Sapolsky et al., 1985). First GRs arise around mid-pregnancy (first in the PVN and pituitary, followed by the hippocampus) and levels rise toward the end of gestation (Matthews, 2002). Full development of GR expression only occurs after birth (when 20$50 \%$ of adult levels are observed; Sapolsky and Meaney, 1986; Levine, 1994) and continues into adulthood (Bohn et al., 1994; Pryce, 2008)\&. MR mRNA expression also arises around mid-pregnancy (first in the pituitary, followed by the hippocampus and hypothalamus), but levels remain rather low until the last few days of gestation (Diaz et al., 1998). The concentration of MR in the hippocampus is however largely indistinguishable from adult levels by the end of the first week of life, whereas local GR levels at that time are present at only $\sim 30 \%$ of adult levels (Meaney et al., 1985b; Sapolsky and Meaney, 1986; Sarrieau et al., 1988; Levine, 1994), making that the local ratio of MR/GR is much higher during the first weeks of life in the rodent. In the amygdala, GR and MR expression increases gradually over development in a region-specific manner $\left(\mathrm{Yi}_{\mathrm{i}}\right.$ et al., 1994; Diaz et al., 1998).

Upon adulthood, corticosteroid levels have increased significantly, as have GR and MR mRNA expression in the hippocampus, mPFC, amygdala, and PVN (Bohn et al., 1994; Yi et al., 1994; Pryce, 2008). CRH secreted by the pituitary stimulates the secretion of $\mathrm{ACTH}$, which in turn stimulates the production and secretion of corticosterone by the adrenal glands, which is now capable of taking part in the fully functional feedback loops of the HPAaxis. A critical period in HPA-axis development not covered by this review is adolescence (extensively reviewed elsewhere e.g., McCormick et al., 2010; Eiland and Romeo, 2013). Interestingly, recent investigations have indicated that (pharmacological) interventions targeting the GR during this period are able to revert the effects of ELS on the brain (Arp et al., 2016; Loi et al., 2017), making that this period-and its exact HPA-axis characteristics-deserves further study.

\&Development in the mouse brain differs slightly from that in the rat, with e.g., GR expression in the hippocampus not being observable until after birth (Noorlander et al., 2006), suggesting species-specific maturation of the HPA-axis.
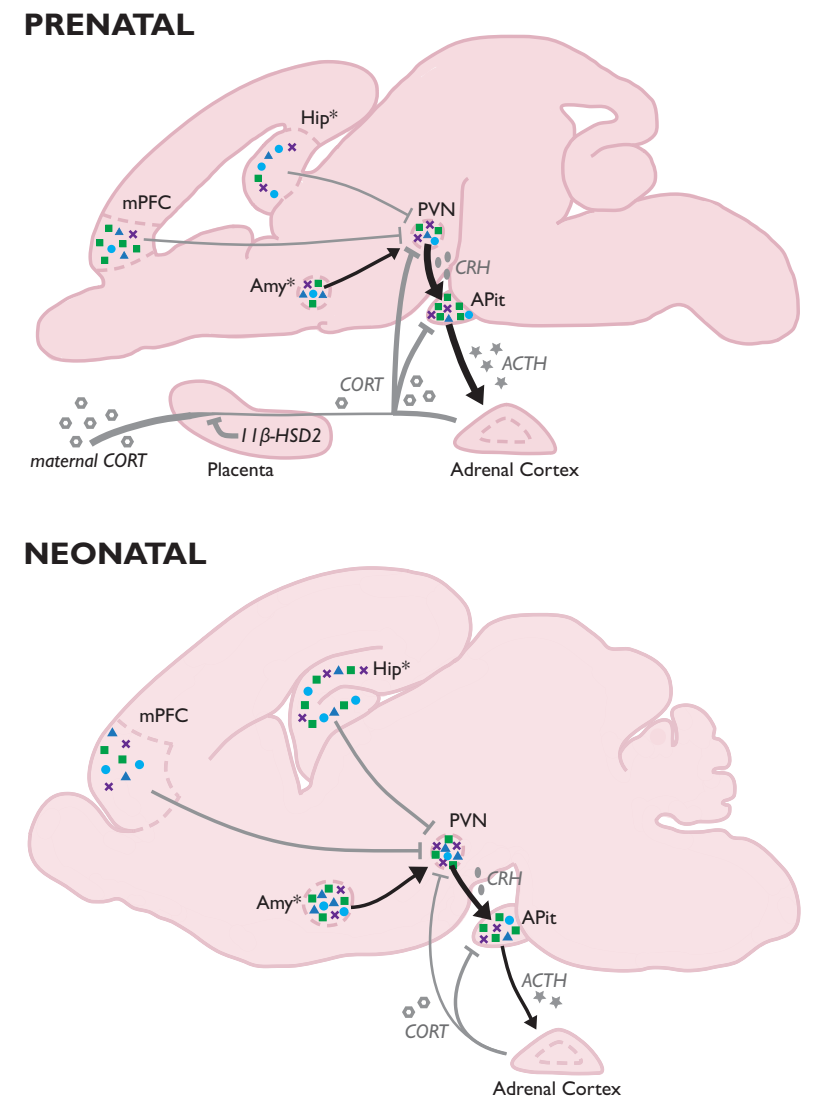

ADULT

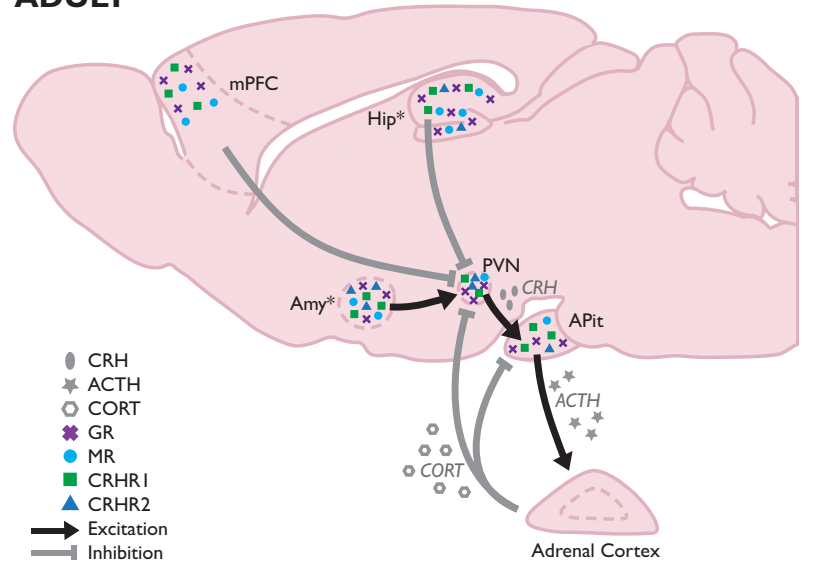


or non-matching adult life circumstances. Unless specified otherwise, the discussed data apply to animals in adulthood.

\section{ELS Induction}

To study the effects of prenatal stress (PS) exposure on the offspring, dams are most frequently stressed by physical restraint (Lemaire et al., 2000; Mandyam et al., 2008; Belnoue et al., 2013; de Souza et al., 2013; Madhyastha et al., 2013; Xu et al., 2014) or immobilization of the limbs (Liaudat et al., 2015), often for multiple times a day. Alternatively, exposure to foot shocks (Estanislau and Morato, 2005, 2006), hypoxia (Fan et al., 2009; Wang X. et al., 2013), or multiple variable stressors over the course of multiple days (Lee et al., 2007; Fan et al., 2009; Zohar and Weinstock, 2011) are applied. These stressors are most commonly applied during the second half of pregnancy, a critical moment in fetal brain development when the differentiation of several key regions in the regulation of the stress response initiates (i.e., hypothalamus, amygdala, and hippocampus; see Bayer et al., 1993 for a review concerning the human compared to the rat brain development), and ranges between a single stressor to repeated stress exposure until birth (Welberg et al., 2001; Fan et al., 2009).

To induce neonatal stress, maternal separation (MS) is often used, i.e., the temporary separation of the dam from her pups, which models maternal neglect. In the variant of early social deprivation (ESD), the pups are isolated from both their mother and littermates and temporarily housed in a novel environment
(Sandi and Haller, 2015). The separation duration, frequency and its timing, vary amongst studies, influencing their ultimate effect on HPA-axis function and brain development in the neonate. A third, relatively recent, neonatal stress model is the limited nesting model (LN; Rice et al., 2008), in which dams are housed in a cage with only limited nesting (or bedding) material available. The absence of sufficient material to build a proper nest induces chronic stress in the dam (Ivy et al., 2008), disrupts maternal behavior and fragments the dam's care for her pups (Rice et al., 2008), as opposed to the separation models, which typically cause a temporary increase in the dam's care upon their reunion (e.g., Pryce et al., 2001, see Box 2). As maternal care (mostly through feeding and tactile stimulation) suppresses pups' HPAaxis activity (e.g., Macrì et al., 2008), the LN model raises neonatal corticosteroid levels as well (Gilles et al., 1996; AvishaiEliner et al., 2001) by being a chronic stressor [whereas MS and ESD are more acute (recurrent) neonatal stressors]. Due to its resemblance of impoverished maternal care in human situations, the $\mathrm{LN}$ paradigm is a valuable addition to the earlier models of neonatal stress.

\section{Effects on the Endocrine Glands and Their Output Hypothalamus}

The hypothalamic PVN develops to a great extent prenatally, and seems to be part of a functioning HPA-axis from the third trimester onwards [gestational day (GD) 17 in rats], when

\section{BOX 2 | Stress-induced variations in maternal care and their impact.}

Maternal care has been shown to be a critical modulator in the effects of early life stress (ELS) on the developing offspring. Being either essential to the manipulation [e.g., in limited nesting (LN)] or an "unwanted side effect" [e.g., in the case of prenatal stress (PS)], the effect of the stressor on maternal behavior is a crucial denominator of its eventual effects on the offspring. Enhanced maternal care (arch back nursing and licking and grooming behavior) induced by neonatal handling of pups induces physiological responses related to reduced fearfulness, and improved emotional, behavioral, and neuroendocrine stress responses (see Francis et al., 1999 for a review of this work). Handled animals show reduced basal corticotrophin-releasing hormone (CRH) expression (Plotsky and Meaney, 1993; Plotsky et al., 2005), and reduced CRH receptor 1 expression in the paraventricular nucleus and locus coeruleus (contributing to the noradrenergic drive induced by stress; Plotsky et al., 2005), which is joined by increased negative feedback sensitivity to corticosteroids, related to increased hippocampal and frontal cortex glucocorticoid receptor (GR) expression (Meaney et al., 1985a; Sarrieau et al., 1988). Studies investigating the natural variation in nursing behavior observed similar changes in the offspring of high licking and grooming mothers (Liu et al., 1997), and showed that corticosterone responses to acute stress as well as hippocampal GR mRNA and hypothalamic CRH mRNA expression correlated with the nursing behavior of the dam. Moreover, maternal care was recently shown to exert major influence on the DNA methylation, histon acetylation and gene expression across large genomic regions (covering the NR3C1) in the hippocampi of adult animals (McGowan et al., 2011). Differences in transcription occurred in the context of hyperacetylation and hypomethylation of promoters and hypermethylation of exons. These studies suggest that the behavior of the mother toward her pups can program neuroendocrine responses to stress in adulthood. In the ELS paradigms altered care is crucial for many of the observed stress effects, as demonstrated by the use of foster-studies (Maccari et al., 1995; Huot et al., 2004; de Souza et al., 2013). As PS can also induce alterations in maternal behavior (de Souza et al., 2012; St-Cyr and McGowan, 2015), these paradigms may in fact model the effects of a both prenatal and neonatal stressful environment instead of looking at PS in isolation. Although, altered maternal care as a consequence of stress during pregnancy is not always observed (e.g., in Lee et al., 2007), cross-fostering studies emphasize the impact on the postnatal environment (i.e., maternal care). The effects of PS in terms of the stress-induced corticosterone response, anxiety, aggression, and social memory differed significantly in pups raised by either control foster mother, non-related stressed mothers, or their biological stressed mother (Maccari et al., 1995; de Souza et al., 2013).

In case of the LN model alterations in maternal behavior (Gilles et al., 1996; in terms of erratic and fragmented nurturing behavior) are in fact sufficient for longterm stress effects in the offspring (Brunson et al., 2005; Rice et al., 2008; Dalle Molle et al., 2012; Gunn et al., 2013). Similarly, maternal care seems to critically mediate the effects of maternal separation (MS) and early social deprivation (ESD), as in these paradigms not only the pups are stressed by the absence of their mother, but the mothers as well. The amount of stress experienced by the dam (and the compensatory care she can perform) however, greatly varies amongst the separation procedures implemented, influencing her behavior toward the litter. Besides the obvious differences in separation frequency and duration, some MS studies leave the litter in the home cage (Sutanto et al., 1996; Vázquez et al., 2003), removing the mum, whilst others place the litter in a new, clean cage (Aisa et al., 2008). Understandably, the exposure to a novel environment might cause additional stress in either the dam or pups, causing variable stress levels between studies. Amongst ESD studies similar variations arise, as they either allow the mother to keep part of her litter by her side (Barna et al., 2003) or separate her from all her pups (Irles et al., 2014), which is evidently more stressful. Potentially depending on the amount of stress experienced by the dam, temporary compensatory increases in nurturing behavior following the reunion with her pups are also observed (Macri et al., 2008), which might modulate the impact of the stressful separation on the offspring. 
regional CRH mRNA responses are observed to maternal stress (Fujioka et al., 1999). The observation that CRH synthesis and mRNA expression in the fetal hypothalamus are not yet regulated by corticosteroids until the end of the first postnatal week (Grino et al., 1989; Baram and Schultz, 1992; Yi and Baram, 1993), and local CRHR expression levels are particularly high early in development (Insel et al., 1988), implicates an important role for the stress-induced elevations in CRH signaling mediating the effects of ELS on PVN function.

On the structural level, previous work has indicated that PS increases apoptosis in the fetal hypothalamus (Fujioka et al., 1999; Tobe et al., 2005), but decreases apoptosis in adulthood (Baquedano et al., 2011). Although MS was not found to affect local neuronal density during the SHRP, it increased neuronal density afterwards, which was joined by decreased levels of apoptosis-stimulating proteins and enzymes, whilst cell survival-stimulating protein levels were increased (Irles et al., 2014). These data indicate that ELS influences the structural reorganization of the PVN throughout development, and thereby likely alters its role in HPA-axis regulation.

On the functional level, the effects of ELS on both basal and stress-induced CRH release by the PVN seem to heavily depend on the precise developmental period affected by ELS, the stressor applied, and the age at which the effects are assessed (see Table 1 for an overview of findings). Moreover, the effect of ELS on local CRH signaling might be sex-specific, as PVN
CRHR1 mRNA and protein levels were reported to be increased as a consequence of PS in males, but decreased in females (Fan et al., 2009; Wang X. et al., 2013; see Box 3 for an overview of sex-specific modulatory effects of ELS). However, these findings are in contrast with another study reporting no ELS-effects on PVN CRHR1 expression in either sex (Zohar and Weinstock, 2011). As CRHR1-activation in the PVN has been associated with anxiogenic effects (Fan et al., 2013), elevated CRHR1 levels in PS males could underlie the anxious behavioral profile resulting from ELS (Huot et al., 2002; Kalinichev et al., 2002; Daniels et al., 2004; Rees et al., 2006; Aisa et al., 2007; Trujillo et al., 2016). In contrast to potentially increased PVN CRHR1 levels, local CRHR2 expression is unchanged or reduced in both sexes as a consequence of PS (Fan et al., 2009; Zohar and Weinstock, 2011; Wang X. et al., 2013) or MS (Bravo et al., 2011; O’Malley et al., 2011).

In addition to $\mathrm{CRH}$, hypothalamic AVP has subtle stimulating effects on ACTH secretion as well (Gillies et al., 1982) and potentiates the effects of CRH (Giguere and Labrie, 1982; Gillies et al., 1982; Lolait et al., 2007). MS has been found to increase local basal AVP mRNA expression at PND14 (Vázquez et al., 2003), PND21 (Zhang et al., 2012), and PND35 (Veenema and Neumann, 2009), and to elevate local stress-induced AVP mRNA levels at PND6 and PND12 in rats (Dent et al., 2000a), whereas it increases stress-induced fos expression in AVP-positive PVN cells (Zhang et al., 2012). In adults, local stress-induced AVP mRNA

\section{BOX 3 | Sex-differences in ELS effects.}

There is a considerable sex-bias in the prevalence of stress-related mental disorders linked to early life adversity (Tolin and Foa, 2006; American Psychiatric Association, 2013). The increased susceptibility of women to stress-related psychopathology may be may be (partially) mediated by sex-specific (vulnerable) responses to early life stress (ELS). Females experiencing trauma, physical abuse, or maternal distress during infancy show higher rates of depression, anxiety, and post-traumatic stress disorder than males (Baker and Shalhoub-Kevorkian, 1999; MacMillan et al., 2001; Pitzer et al., 2011). Sex also seems to be a significant modulator of the relationship between childhood adversity and HPA-axis activity later in life. Exposure to early trauma is associated with higher basal corticotrophin-releasing hormone $(\mathrm{CRH})$ levels in women, but lower levels in men, whereas severe trauma is linked to an increased response to a CRH challenge in men only (DeSantis et al., 2011). There is also evidence from rodent studies indicating sex-specific effects of ELS on neuroendocrine function. Prenatally stressed (PS) females were shown to display a higher peak corticosterone plasma levels to stress in adulthood compared to males (Brunton and Russell, 2010). They display increased fetal paraventricular nucleus (PVN) apoptosis in response to acute immobilization (Tobe et al., 2005), as well as higher basal PVN CRH (though inconsistently) and arginine vasopressin mRNA expression levels (Brunton and Russell, 2010; Zohar and Weinstock, 2011), and higher basal adrenocorticotropic hormone plasma levels as a result of PS compared to males. However, females do not display a significantly higher acute stress-induced increase in POMC mRNA expression in the anterior pituitary compared to non-stressed controls, while males do (Brunton and Russell, 2010). CRH receptor 2 mRNA expression in the basomedial amygdala is increased in PS females, whereas it is decreased in PS males. Meanwhile, effects of PS on CRH receptor 1 mRNA expression in the amygdala appear to be both sex-and subregion-specific; mRNA expression was found to be significantly elevated in the central amygdala and basolateral amygdala of males as a consequence of PS, but in the medial amygdala of females (Brunton et al., 2011). PS induces reductions in adult neurogenesis in males (Lemaire et al., 2000; Mandyam et al., 2008; Morley-Fletcher et al., 2011; Belnoue et al., 2013; Madhyastha et al., 2013), but does not seem to affect neurogenesis in females (Mandyam et al., 2008; Zuena et al., 2008), which might be related to overall lower basal levels of neurogenesis in adult females (Mandyam et al., 2008; Oomen et al., 2009). Some of these effects might be related to sex-specific epigenetic regulation of gene expression during development. PS was shown to cause significant elevations in DNA methyltransferase 1 expression in the placenta of females, but not in males, but only male brains displayed reduced hippocampal glucocorticoid receptor and increased amygdalar $\mathrm{CRH}$ expression, which was related to changes in Crh and NR3C1 methylation (Mueller and Bale, 2008).

Neonatal stress studies have indicated similar sex-differences. Female rats were found to overall display higher basal plasma corticosterone levels than males, but these were reduced by maternal separation (MS) (Slotten et al., 2006). Similarly, basal corticosterone levels of female mice have been found to be reduced as a consequence of limited nesting (LN), in contrast to increased basal level in males (Arp et al., 2016). However, such sex differences are not consistently found (Table 3). MS also affects adult neurogenesis differently in males and females, depending on the age of assessment. At the age of weaning, male rats were found to display increased neurogenesis, whereas MS female rats displayed decreased levels (Oomen et al., 2009), but these effects changed at adulthood, when neurogenesis was found to be reduced in MS and LN males (Oomen et al., 2010; Lajud et al., 2012; Naninck et al., 2015), but unaffected in females (Oomen et al., 2011; Naninck et al., 2015).

Unfortunately, most of what is known about the effects of ELS on brain maturation is derived from studies using male individuals, particularly in rodent research, illustrating the necessity of the more thorough investigation of sex differences in neuroscience research (Beery and Zucker, 2011). Moreover, one should take the oestrous cycle phase at the moment of testing of females into account, as it seems to be an important modulating factor when assessing the effects of ELS (Romeo et al., 2003), but is often ignored. 
TABLE 1 | CRH mRNA expression in the PVN both under basal conditions and in response to stress in ELS animals compared to non-stressed controls.

\begin{tabular}{|c|c|c|c|c|c|c|c|}
\hline Period & Stress paradigm & Duration & Age at testing & Basal CRH & $\begin{array}{l}\text { Stress-induced } \\
\text { CRH }\end{array}$ & Species (strain) & References \\
\hline GD1-21 & CBX & daily & Adult & $\uparrow \sigma^{\pi}$ & & Rats (Wistar) & Welberg et al., 2000 \\
\hline GD1-21 & Hypoxia and/or restraint & $4 \mathrm{~h}$ & Adult & $\uparrow \sigma^{\pi *}$ & & Rats (SD) & Fan et al., 2009 \\
\hline GD1-21 & Hypoxia & $4 \mathrm{~h}$ & Adult & $\uparrow 0^{\pi} /-++$ & & Rats (SD) & Wang X. et al., 2013 \\
\hline GD4-10 & Defeat or restraint $\#$ & 45 or $60 \mathrm{~min}$ & Adult & $\uparrow+$ & & Rats (Wistar) & Bosch et al., 2007 \\
\hline GD11-18 & Defeat & $1 \mathrm{~h}$ & & & & & \\
\hline GD9-20 & Restraint & $6 \mathrm{~h}$ & Adult & $-\sigma^{x} *$ & & Mice (ICR) & Chung et al., 2005 \\
\hline GD13-21 & Variable & daily & Adult & $-\sigma^{\pi} / \uparrow+$ & $-\sigma^{x} / \uparrow+q$ & Rats (Wistar) & $\begin{array}{l}\text { Zohar and Weinstock, } \\
2011\end{array}$ \\
\hline GD16-20 & Defeat & $10 \min$ & Adult & - & $\uparrow$ & Rats (SD) & Brunton and Russell, 2010 \\
\hline PND2-9 & LN & & PND9 & $\downarrow$ & & Rats (SD) & Avishai-Eliner et al., 2001 \\
\hline PND2-9 & LN & & PND9 & $\downarrow$ & & Mice (C57BL/6J) & Rice et al., 2008 \\
\hline PND3 & MS & $24 \mathrm{~h}$ & PND20 & - & & Rats (SD-LE hybrids) & van Oers et al., 1997 \\
\hline PND3 & MS & $24 \mathrm{~h}$ & PND20 & - & $\uparrow$ & Rats (SD-LE hybrids) & van Oers et al., 1998b \\
\hline PND5 & MS & $24 \mathrm{~h}$ & PND 6 & $\downarrow$ & $\downarrow$ & Rats (SD-LE hybrids) & Dent et al., 2000a \\
\hline PND7 & MS & $24 \mathrm{~h}$ & PND20 & - & & Rats (SD-LE hybrids) & van Oers et al., 1997 \\
\hline PND8 & MS & $24 \mathrm{~h}$ & PND9 & - & - & Rats (SD) & Avishai-Eliner et al., 1995 \\
\hline PND8 & ESD & $24 \mathrm{~h}$ & PND9 & - & - & Rats (SD) & Avishai-Eliner et al., 1995 \\
\hline PND11 & MS & $24 \mathrm{~h}$ & PND12 & $\downarrow$ & $\downarrow$ & Rats (SD-LE hybrids) & $\begin{array}{l}\text { Smith et al., 1997; van } \\
\text { Oers et al., 1998a }\end{array}$ \\
\hline PND11 & MS & $24 \mathrm{~h}$ & PND12 & - & $\downarrow^{\$}$ & Rats (SD-LE hybrids) & Dent et al., 2000a \\
\hline PND11 & MS & $24 \mathrm{~h}$ & PND20 & - & & Rats (SD-LE hybrids) & van Oers et al., 1997 \\
\hline PND11 & MS & $24 \mathrm{~h}$ & PND20 & - & $\downarrow$ & Rats (SD-LE hybrids) & van Oers et al., 1998b \\
\hline PND17 & MS & $24 \mathrm{~h}$ & PND18 & - & $\uparrow$ & Rats (SD-LE hybrids) & Dent et al., 2000a \\
\hline PND19 & MS & $24 \mathrm{~h}$ & PND20 & $\downarrow$ & $\downarrow$ & Rats (SD-LE hybrids) & Smith et al., 1997 \\
\hline PND1-14 & ESD & $4 \mathrm{~h}$ & Adult & - & & Rats (Ficher) & $\begin{array}{l}\text { Rüedi-Bettschen et al., } \\
2006\end{array}$ \\
\hline PND2-8 & MS & $15 \min$ & Adult & $\downarrow$ & & Rats (SD) & Korosi et al., 2010 \\
\hline PND2-9 & LN & & Adult & $\downarrow^{0^{\top}}$ & & Mice (C57BL/6J & Rice et al., 2008 \\
\hline PND2-9 & LN & & Adult & $-0^{\pi}$ & & Mice (129S2/Sv × C57BL/6J) & Wang et al., 2012 \\
\hline PND2-13 & MS & $4 \mathrm{~h}$ & Adult & - & - & Rats (SD) & Chen et al., 2012 \\
\hline PND2-14 & MS & $3 \mathrm{~h}$ & Adult & $\uparrow \sigma^{\pi}$ & $\uparrow \sigma^{\pi}$ & Rats (LE) & Plotsky and Meaney, 1993 \\
\hline PND2-14 & MS & $3 \mathrm{~h}$ & Adult & $\uparrow \sigma^{\top}$ & & Rats (LE) & Plotsky et al., 2005 \\
\hline PND2-21 & MS & $3 \mathrm{~h}$ & Adult & $\uparrow \uparrow$ & & Rats (Wistar) & Aisa et al., 2008 \\
\hline PND3 & MS & $24 \mathrm{~h}$ & Adult & $\downarrow^{0^{\pi}}$ & & Rats (Brown Norway) & Workel et al., 2001 \\
\hline PND3-15 & MS & $3 \mathrm{~h}$ & Adult & $-0^{\pi}$ & & Rats (LE) & Slotten et al., 2006 \\
\hline PND9 & ESD & $24 \mathrm{~h}$ & Adult & & - & Rats (n.s.) & Barna et al., 2003 \\
\hline
\end{tabular}

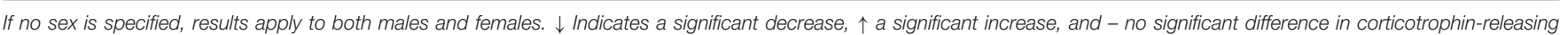

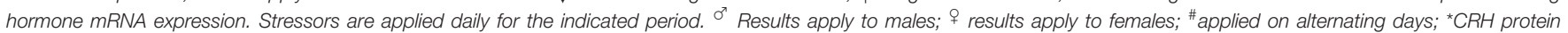

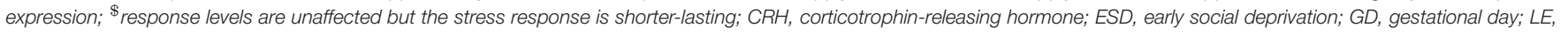
Long Evans rats; LN, limited nesting; MS, maternal separation; n.s., not specified; PND, postnatal day; SD, Sprague Dawley rats.

and protein levels are higher in both PS (Brunton and Russell, 2010) and MS (Veenema et al., 2006, 2007) offspring compared to controls, although effects might be sex- and stressor-specific (Desbonnet et al., 2008; Brunton and Russell, 2010). Like for $\mathrm{CRH}$, effects of ELS on basal PVN AVP expression are rather heterogeneous. While PS exposure does not affect basal AVP mRNA expression in the male PVN (Lee et al., 2007; Brunton and Russell, 2010), it increases local levels in the females (Bosch et al., 2007; Brunton and Russell, 2010). The number of local AVP-expressing cells has however been found to be decreased due to PS (de Souza et al., 2013) in both sexes. Moreover, effects of PS on AVP expression might be depending on genetic background. Basal PVN AVP mRNA expression in rats bred for low levels of anxiety-related behavior (LAB) were found to be lower compared to rats bred for high levels of anxiety-related behavior ( $\mathrm{HAB})$, but PS increased AVP mRNA expression in the $\mathrm{LAB}$ rats to levels observed in $\mathrm{HAB}$ rats, the latter being not affected by PS (Bosch et al., 2006). Neonatal stress was found to either not affect (Veenema et al., 2006), increase (Veenema et al., 2007; Desbonnet et al., 2008; Murgatroyd et al., 2009; Zhang et al., 2012), or decrease (in females) (Desbonnet et al., 2008) basal expression levels compared to unstressed controls. In one of the studies, increased AVP signaling induced by neonatal stress exposure was associated with a sustained DNA hypomethylation of the Avp gene in the PVN, and turned out to critically mediate the observed hypersecretion of corticosterone 
TABLE 2 | ACTH plasma levels in ELS animals as compared to non-stressed controls.

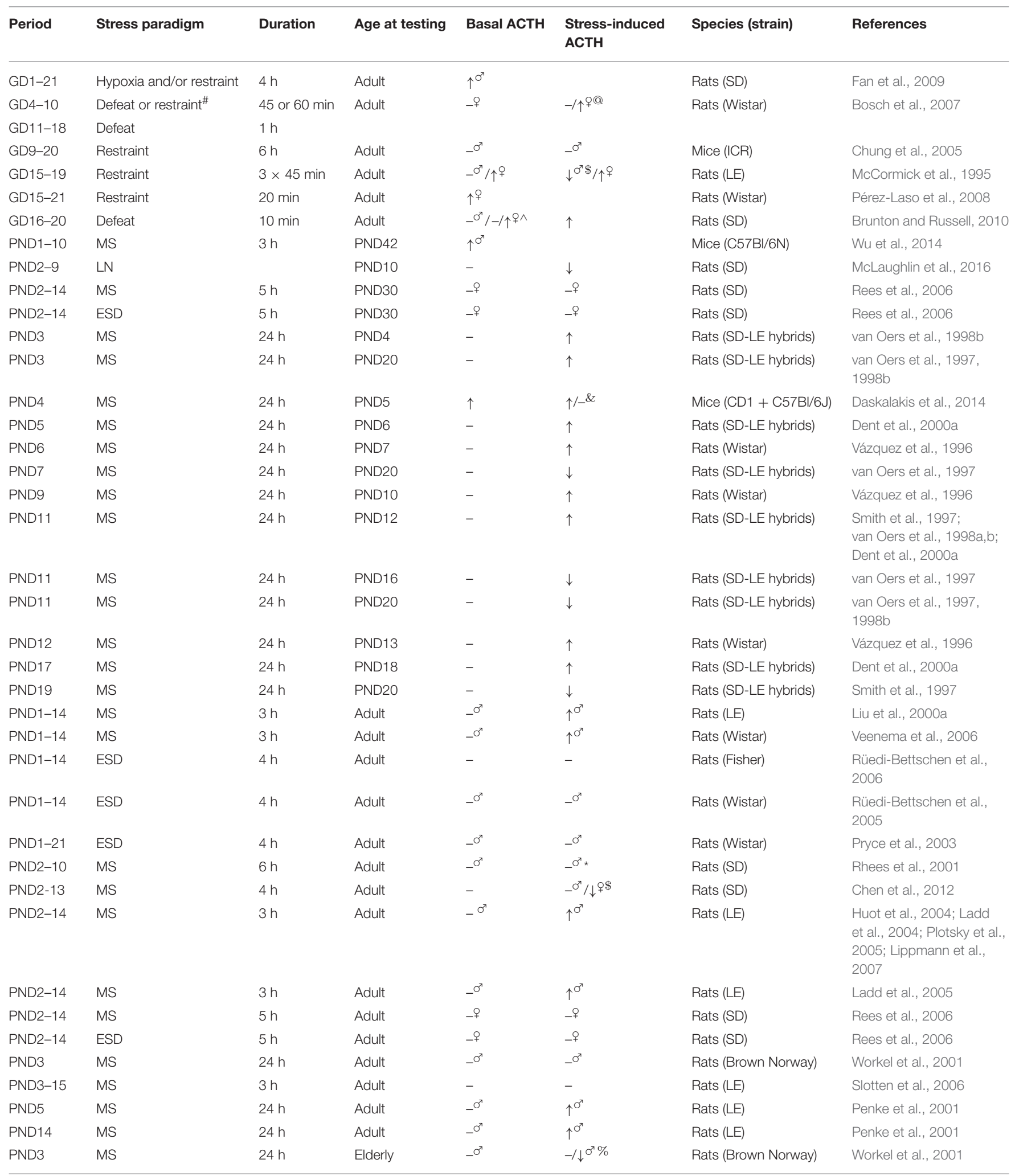

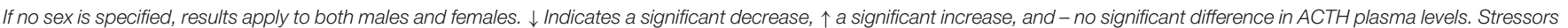

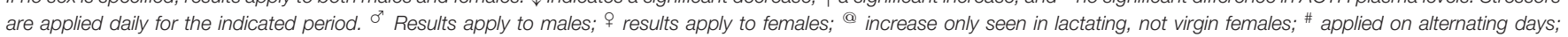

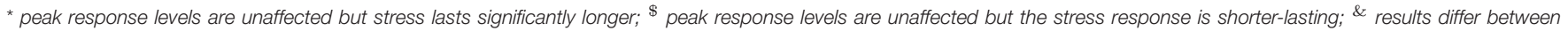

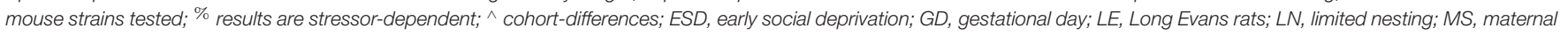
separation; PND, postnatal day; SD, Sprague Dawley rats. 
and alterations in passive stress coping and memory observed in the offspring (Murgatroyd et al., 2009). However, further research seems necessary to elucidate the exact effects of ELS on AVP signaling.

In the adult PVN, GR mRNA has been localized to cells expressing CRH (Swanson and Simmons, 1989), where GR moderates the glucocorticoid-mediated negative feedback on the HPA-axis by regulating CRH gene expression (Majzoub et al., 1993). Both prenatal exposure to exogenous corticosterone and PS have been shown to decrease local GR expression (Bingham et al., 2013). Inhibition of $11 \beta$-HSD2 during pregnancy, raising prenatal corticosterone exposure, also induced reduced GR mRNA expression in the PVN (while it locally increased CRH mRNA levels; Welberg et al., 2000), whereas MS attenuated GRbinding in young rats and decreased GR mRNA levels in adult (Arnett et al., 2015) and senescent animals (Workel et al., 2001). These findings suggest that ELS attenuates HPA-axis regulation at the level of the PVN by reducing GR-mediated negative feedback.

\section{Anterior Pituitary}

Both corticosteroid and CRH receptors are present in the pituitary from the third trimester onwards (Insel et al., 1988). In contrast to the PVN, pro-opiomelanocortin (POMC; the precursor for ACTH) transcription is already stimulated by $\mathrm{CRH}$ and inhibited by corticosteroid administration at this age, implicating functional receptors and local negative feedback regulation well before birth (Scott and Pintar, 1993). However, soon after birth, the pituitary shows a time-limited, reduced response to $\mathrm{CRH}$, which could either be the result of a reduced sensitivity to CRH (Dent et al., 2000b) (although CRHR expression is high at that time) or a reduction in the size and number of ACTH-secreting cells in the pituitary (Sapolsky and Meaney, 1986). Exaggerated negative feedback-sensitivity to corticosteroids (Walker et al., 1986b) might further contribute to this non-responsiveness, but this cannot be readily explained by altered corticosteroid receptor expression levels (which are relatively stable prenatally, and only slowly increase after birth to reach adult levels; Keller-Wood et al., 2006).

Similar to the PVN, the pituitary of PS animals is characterized by decreased cell proliferation and cell death in adulthood (Baquedano et al., 2011). Basal ACTH and POMC expression levels seem to be rather unaffected by ELS in the adult offspring (see Table 2 for an overview of findings). While increased basal ACTH levels have been reported for PS females, ACTH plasma levels seem to be unaffected by neonatal stress. Interestingly, though basal POMC mRNA levels are not influenced by PS (Brunton and Russell, 2010), they are elevated by MS (Murgatroyd et al., 2009), associated with an enduring hypomethylation of the POMC gene (Wu et al., 2014), indicating alterations in ACTH turnover. Concerning stressinduced responses, PS seems to increase the POMC mRNA (in males) and ACTH response to stress (Fan et al., 2009; Brunton and Russell, 2010), at least partially by increasing CRHR expression in the anterior pituitary (Fan et al., 2009). The effects of neonatal stressors on stress-induced ACTH release however seem to again greatly depend on the type of stressor, its timing and duration, and the age of the animal at which the effects are assessed (Table 2). Generally, MS for $24 \mathrm{~h}$ both before the onset of and early with in the SHRP is found to increase offspring's ACTH plasma levels in response to stress. However, MS during the second half of the SHRP increases ACTH response to stress only if tested during the SHRP (Smith et al., 1997; van Oers et al., 1998b), whereas it reduces ACTH stress responses measured at an older age (Smith et al., 1997; van Oers et al., 1997, 1998b). AVP seems to play an important role in mediating these effects, as the increase in ACTH levels as a consequence of $24 \mathrm{~h}$ MS on PND9 was not observed in AVP deficient animals (Zelena et al., 2015). Since AVP deficiency or AVPR1b antagonist pretreatment diminished ACTH responses to stress only in pups but no longer in adults (Zelena et al., 2011), AVP seems to be particularly important in regulating ACTH-secretion in the neonate. LN seems to reduce ACTH stress-induced responses during the SHRP, though data is limited. Both multiple-day MS and $24 \mathrm{~h}$ MS during the SHRP seem to increase ACTH stress responses in adulthood, but not consistently. ESD does not exert any obvious effect (Table 2). Stressor- and age-dependent alterations in local CRHR binding capacity may contribute to the diversity of these effects. ESD and LN are for example found to reduce CRHR binding capacity (Ladd et al., 1996; Avishai-Eliner et al., 2001), and thereby limit the ACTH-releasing potential of CRH.

\section{Adrenals}

PS (or prenatal corticosterone) generally increases corticosterone stress responses by elevating peak levels or increasing the total duration of the response (see Table 3), which both appear indicative of impaired negative feedback. Overall, these effects appear slightly stronger in PS females than males (Brunton and Russell, 2010; Table 3, Box 3). Basal corticosterone levels seem to be either increased or unaffected by PS (Table 3 ).

Effects of neonatal stress on adrenal function are again stressor-specific, and depending on the developmental period affected and the age at which they are assessed (Table 3). The LN model generally induces elevated basal corticosterone levels during the SHRP, which can be prevented by either GR- (in females) or CRHR1- blockage (in both sexes; Liao et al., 2014). However, these levels (as well as adrenal weight) seem to have normalized in adulthood (Naninck et al., 2015), although sex-specific effects might exist; whereas some studies observed increased corticosterone levels and adrenal weight in LN males (Rice et al., 2008; Arp et al., 2016), decreased levels were observed in females (Arp et al., 2016). Corticosterone stress responses have been shown to be either prolonged (Gilles et al., 1996), unaffected (Wang et al., 2012), or reduced (McLaughlin et al., 2016) as a consequence of LN. The effects of $24 \mathrm{~h}$ MS seem to be strongly age-dependent as well. MS applied during the SHRP increases both basal and stress-induced corticosterone levels observed during the SHRP (Table 3), without affecting basal corticosterone levels and exerting only minimal effect on stress-induced corticosterone levels when assessed later during infancy. Increased basal levels, but reduced stress-response levels are observed in 3 month-old rats (Workel et al., 2001), whereas in 5 and 12 month-olds basal levels are unaltered, but stressresponse levels increased as a consequence of MS (Workel et al., 2001; Lehmann et al., 2002). In elderly rats (20 months), basal 
TABLE 3 | Overview of corticosterone plasma levels in prenatally and neonatally stressed animals as compared to non-stressed controls.

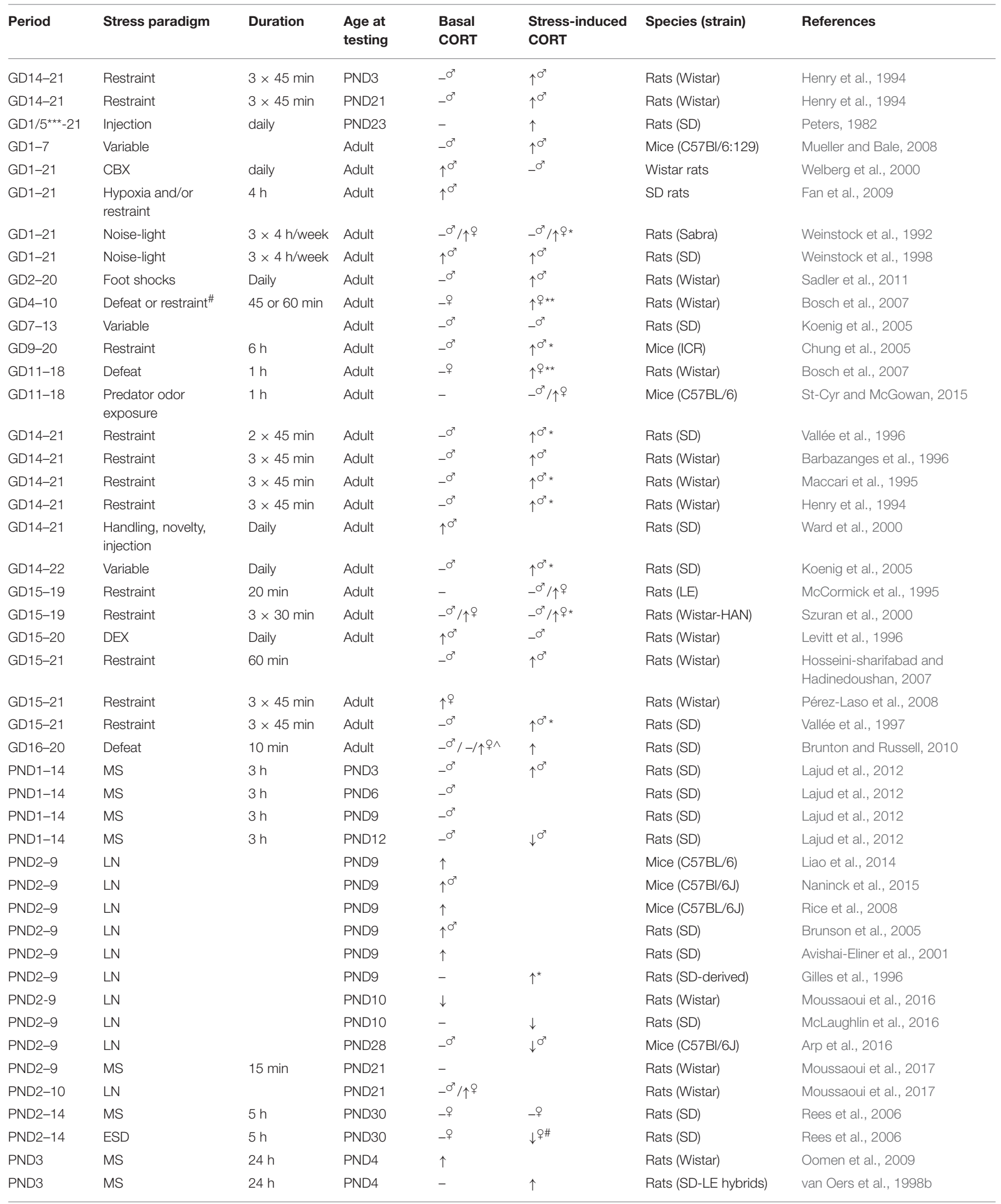


TABLE 3 | Continued

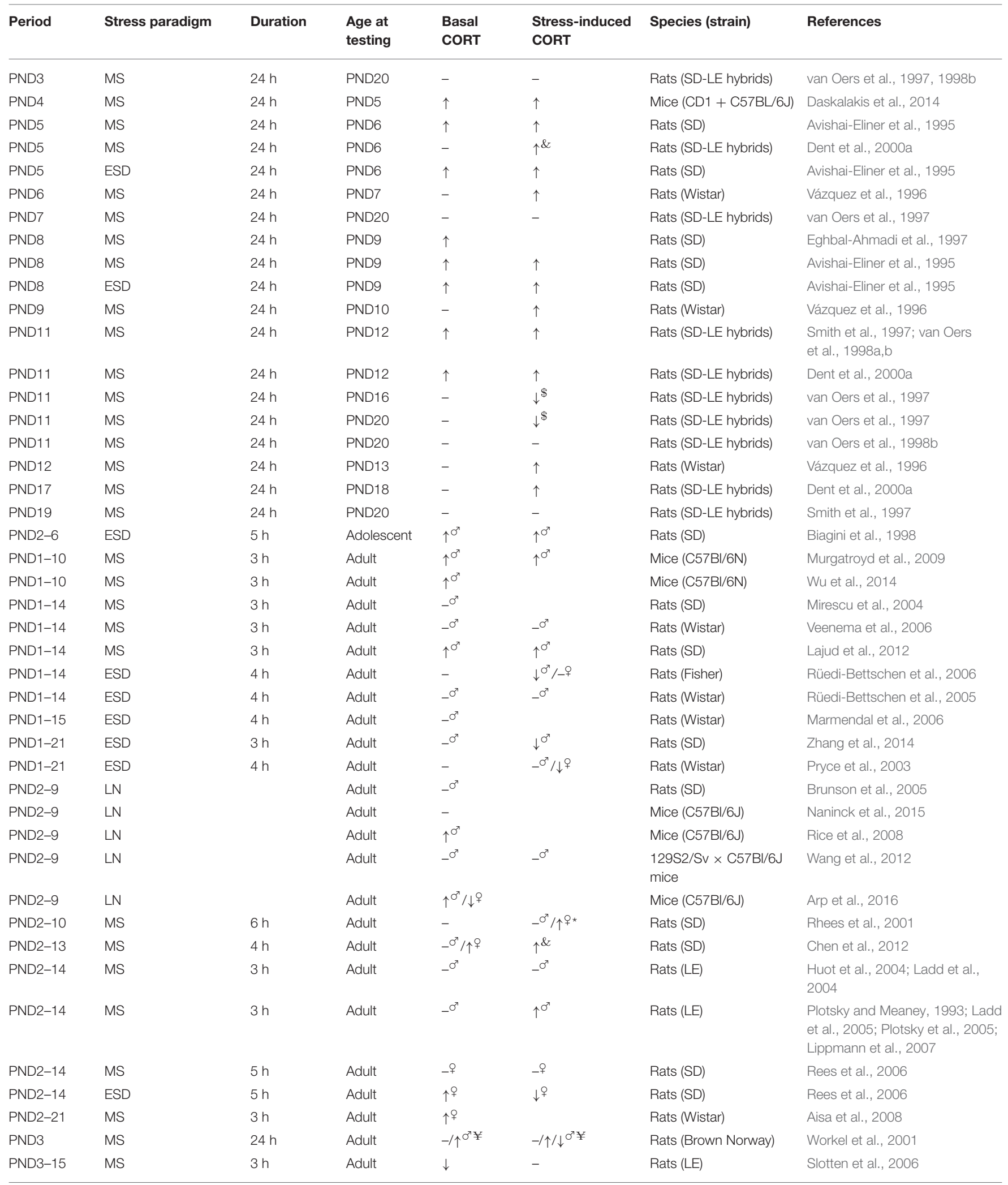


TABLE 3 | Continued

\begin{tabular}{|c|c|c|c|c|c|c|c|}
\hline Period & Stress paradigm & Duration & $\begin{array}{l}\text { Age at } \\
\text { testing }\end{array}$ & $\begin{array}{l}\text { Basal } \\
\text { CORT }\end{array}$ & $\begin{array}{l}\text { Stress-induced } \\
\text { CORT }\end{array}$ & Species (strain) & References \\
\hline PND4 & MS & $24 \mathrm{~h}$ & Adult & $-\sigma^{\pi}$ & $\uparrow /-\sigma^{\lambda} ¥$ & Rats (Wistar) & Lehmann et al., 2002 \\
\hline PND5 & MS & $24 \mathrm{~h}$ & Adult & $-0^{\pi}$ & $\uparrow \sigma^{\top}$ & Rats (LE) & Penke et al., 2001 \\
\hline PND9 & MS & $24 \mathrm{~h}$ & Adult & $-0^{\pi}$ & $\uparrow / \sigma^{\top} ¥$ & Rats (Wistar) & Lehmann et al., 2002 \\
\hline PND14 & MS & $24 \mathrm{~h}$ & Adult & $\downarrow^{\sigma^{2}}$ & $\uparrow \sigma^{x} *$ & Rats (LE) & Penke et al., 2001 \\
\hline PND18 & MS & $24 \mathrm{~h}$ & Adult & $-0^{\pi}$ & $\uparrow / \sigma^{\top} ¥$ & Rats (Wistar) & Lehmann et al., 2002 \\
\hline
\end{tabular}

If no sex is specified, results apply to both males and females. $\downarrow$ Indicates a significant decrease, $\uparrow$ a significant increase, and - no significant difference in corticosterone plasma levels.

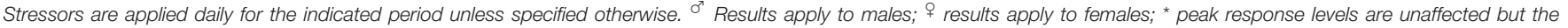

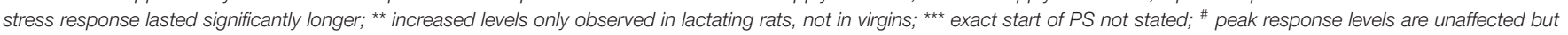

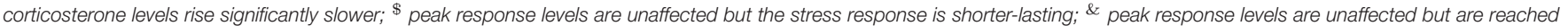

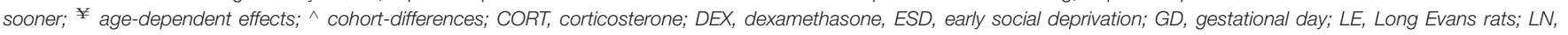
limited nesting; MS, maternal separation; PND, postnatal day; SD, Sprague Dawley rats.

and stress-induced levels are again unaffected (Lehmann et al., 2002), whereas stress-induced levels are reduced at senescent age (Workel et al., 2001). Similarly, multiple-day MS does not seem to induce any consistent alterations in basal corticosterone levels either during the SHRP or adulthood (Table 3). Corticosterone stress responses are however typically increased as a consequence of this repeated stressor. Lastly, ESD has been shown to increase basal and stress-induced corticosterone levels during the SHRP (24 h ESD) and in adolescence (PND45) (multipleday ESD), though in juveniles (PND30) multiple-day ESD was not found to affect basal corticosterone levels, and slowed down stress-induced release. In adulthood, basal corticosterone levels generally are similar to levels observed in non-stressed controls. Interestingly and in contrast to MS, ESD seems to induce reduced stress-response corticosterone levels in adulthood (Table 3).

These ELS-induced alterations in corticosterone plasma levels could obviously be caused by the earlier mentioned alterations in $\mathrm{CRH}$ and ACTH release, but could also be attributed to abnormal function of the adrenal gland itself, as increases in adrenal weight and cortex-to-medulla ratio have been reported as a consequence of PS (Ward et al., 2000; Fan et al., 2009; Liaudat et al., 2015). However, the frequent inconsistencies in findings emphasize the extremely complex modulatory effects ELS exerts on the HPA-axis, depending on the precise developmental stage affected, the exact stressor used (its frequency, duration, etc.), age of testing, sex of the offspring, and also the genetic background of the animals. Structured assessment of these effects is absolutely necessary to increase understanding of the underlying mechanisms of aberrant corticosteroid signaling later in life.

\section{Developmental Effects of ELS on HPA-Axis Modulators \\ Amygdala}

The amygdala plays a prominent role in the behavioral fear response and the regulation of emotional processing (Akirav and Maroun, 2007). CRH-expressing cells (first detected at PND6, after which they gradually increase with age; Vazquez et al., 2006) are quite abundant, particularly in the CeA, a major output site which projects to the hypothalamus (LeDoux et al., 1988; Gray et al., 1989). Activation of GRs expressed on CeA CRH-neurons increases local CRH mRNA expression (Makino et al., 1994), which directly contributes to a state of fear (Kolber et al., 2008). These CRH-containing neurons project through the bed nucleus in the stria terminalis to the PVN, and are believed to stimulate the HPA-axis and induce anxiety-like behavior (Feldman et al., 1994; Brunson et al., 2001a). Simultaneously, CRH released by the PVN activates the amygdala to increase anxiety (Schulkin, 2006), forming a potent feed-forward loop in stress signaling.

The amygdala develops both pre- and postnatally. It emerges during the third week of gestation, but matures prominently throughout infancy and adolescence (Berdel et al., 1997), changing neuronal morphology (Ryan et al., 2016), intrinsic membrane properties, action potential kinetics, and the synaptic and voltage-gated currents (Ehrlich et al., 2012, 2013). From PND7-21 in rats, regional soma volume doubles, spine density increases nearly five-fold, whereas dendritic arbors expand throughout the first postnatal month (Ryan et al., 2016). Neuronal density however reduces postnatally (Berdel et al., 1997).

PS influences the developmental trajectories of the rats' amygdalar subnuclei; the BLA, CeA, and lateral (LA) amygdala. Development of these regions was shown to be temporarily impeded by PS, with at offspring displaying significant reductions in regional volume and neuronal and glial number at PND25, which normalized at PND60 (Kraszpulski et al., 2006). In line with this, increased apoptosis was observed in the amygdala of pups (at PND7) as a consequence of prenatal corticosteroid treatment (Zuloaga et al., 2011), and an altered balance in subunit expression of glutamatergic and GABAergic receptors was observed at PND14-22 following prenatal restraint (Laloux et al., 2012). However, in another study the same stressor increased the volume and neuronal and glial number of the LA-the subregion serving as the site of signal-input from the sensory processing systems (LeDoux, 1994)-at PND80120, without affecting the other subregions (Salm et al., 2004), suggesting age-dependent effects. Cell proliferation in the infant amygdala showed a non-significant reduction as a consequence 
of PS (Kawamura et al., 2006), whereas electrophysiological recordings from BLA excitatory principal neurons revealed a hyperpolarized resting membrane potential, larger action potential after-hyperpolarizations and $\mathrm{H}$-currents in $\mathrm{PS}$ rat offspring compared to controls, reducing neuronal excitability throughout development from infancy into young adulthood (PND60; Ehrlich and Rainnie, 2015).

Whereas PS thus appears to transiently impede amygdala development, stress applied to the neonate seems to hasten amygdala maturation. Typically, the amygdala is not activated by aversive experiences shortly after birth (until PND8) and pups show attenuated learning of fear (and an approach response to aversively conditioned stimuli; Sullivan et al., 2000), which seems to be crucial for forming dam-pup attachment (Sullivan and Holman, 2010). Neonatal stress however accelerates the development of an aversive response and precocious activation of the amygdala, with pups expressing aversive learning and significant corticosterone stress responses at PND8 when reared in the LN model (Moriceau et al., 2006, 2009). This acceleration seems to be mediated by increased corticosteroid exposure, as corticosteroid infusion in the amygdala mimics the effects (Moriceau et al., 2006) and the administration of a corticosteroid receptor antagonist prevents them (Moriceau et al., 2009). In fact, suppressed aversion learning may be another reason for the SHRP, reducing corticosterone exposure to allow proper dam-pup attachment to occur. Neonatal stress also leads to longer fear retention (Callaghan and Richardson, 2012) and precocious expression of the mature form of extinction learning (Callaghan and Richardson, 2011; Cowan et al., 2013); all suggesting a (premature) acceleration in amygdala development of the stressed neonate. Amygdalar connectivity is affected by this early "maturation," as myelination is expedited due to ELS (Ono et al., 2008). Potentially, this strengthening of early connections (e.g., those to the thalamus and nucleus accumbens) comes at the expense of the connections that form later in development, including those to the frontal cortex (Bouwmeester et al., 2002). Support for this idea comes from the preclinical observation of aberrant functional amygdala-frontal cortex connectivity in adolescents and adults that experienced childhood adversity (Birn et al., 2014; Fan et al., 2014; Lee et al., 2015). Alternatively, these changes in connectivity could derive from the precocious closing of a critical period of plasticity through neonatal stress. Closure of such critical periods has been shown to coincide with the emergence of perineuronal nets on parvalbumin interneurons (Pizzorusso et al., 2002; Hensch, 2005; Dityatev et al., 2007; Nowicka et al., 2009), stabilizing synapses. MS was shown to increase the number of parvalbumin neurons in the periadolescent LA (Giachino et al., 2007; Seidel et al., 2008), but the effects of stress on the perineuronal nets still have to be characterized. Gross amygdala morphology however does not seem to be affected by MS (Krugers et al., 2012).

Functionally, the adult amygdala seems to be come "overactive" as a consequence of ELS. Assessment of regional cerebral blood flow (CBF) by autoradiography revealed an increased cerebral activation of the amygdala in adult ( $\sim$ PND100) PS offspring to a fear-conditioned stimulus (Laviola et al., 2004), which was accompanied by heightened fear responsivity (i.e., freezing behavior; Sadler et al., 2011). However, also increased amygdala and fear responsivity to the tone was observed without any prior conditioning, suggesting general amygdala hyperactivity and increased anxiety in the PS animals (Sadler et al., 2011). In line with elevated amygdala activity, PS or exposure to elevated corticosteroid levels during gestation was shown to increase amygdala's basal CRH mRNA levels (Welberg et al., 2001; Brunton and Russell, 2010), as well as local CRH release in adult animals (Cratty et al., 1995). MS was found to leave local basal CRH mRNA expression unaffected (Bravo et al., 2011), but ESD, a more severe stressor, was shown to increase stress-induced levels (Barna et al., 2003). These findings may be related to local changes in the inhibition of CRH-induced activation as regulated by local GABAergic signaling. GABAa receptor binding was found to be reduced in the CeA and BLA as a consequence of MS (Caldji et al., 2000 ), joined by an increase in $\alpha 2 / \alpha 3$ and decrease in $\alpha 1$ subunit mRNA expression; a profile associated with decreased GABA binding (Wilson, 1996). Moreover, these findings might relate to the altered methylation patterns of the $\mathrm{Crh}$ promoter as a consequence of ELS, which correlated with CRH mRNA levels in the central amygdala in a learned helplessness paradigm, but their direction depends on the genetic background of the animal (van der Doelen et al., 2015). The influence of ELS on local CRHR expression seems to be age-, sex-, and subregionspecific. PS was found to elevate CRHR1 mRNA expression in the CeA and BLA of males, and in the MeA of females (Brunton et al., 2011), whereas CRHR2 mRNA expression was not affected in the BLA and MeA, but reduced in the basomedial amygdala of males and increased in females (Brunton et al., 2011). MS was found to increase CRHR1 mRNA expression in the MeA during infancy, and decrease CRHR1 and CRHR2 mRNA levels in the CeA (Vázquez et al., 2003). However, in adulthood CeA and BLA CRHR1 mRNA expression levels are actually elevated in MS offspring, and BLA CRHR2 mRNA expression is reduced (Bravo et al., 2011). Importantly, no effects of neonatal stress on CRHR1/2 mRNA expression levels in adulthood are observed when the amygdala is considered as a whole (O'Malley et al., 2011), emphasizing the relevance of studying subregion-specific expression profiles. MS also affects the rather immediate alterations in receptor expression typically observed following acute stress. It attenuates the typical decrease in CRHR1 mRNA expression and raises CRHR2 mRNA levels in response to an acute psychological stressor (O'Malley et al., 2011). As CRHR1 activation by CRH in the amygdala typically serves an activating, anxiogenic role (Dunn and Berridge, 1990; Henckens et al., 2016), elevated expression levels match the overall increase in anxiety-like behavior of ELS animals. In line with this, injection of a CRHR antagonist abolished the increased fear and sensitivity to the environment of the PS offspring (Ward et al., 2000).

ELS also affects corticosteroid signaling in the amygdala. PS was found to increase CeA GR mRNA levels (Brunton and Russell, 2010) and overall GR-binding (McCormick et al., 1995). These effects might be mediated by elevated corticosteroid exposure of the fetus, as GR (but not MR) mRNA levels in the BLA, CeA, and MeA were found to be increased by the 
inhibition of 11ß-HSD2 (Welberg et al., 2000), and BLA MR and GR mRNA expression were increased as a consequence of dexamethasone administration during pregnancy (Welberg et al., 2001). Remarkably, GR expression in the amygdala was found to be reduced in MS offspring, although this effect might be strain-specific. MS reduced amygdala basal GR mRNA expression during the SHRP in C57Bl/6J mice, but not in CD1s (Daskalakis et al., 2014), and this decrease remained present until adulthood (Arnett et al., 2015). Despite the fact that neonatal stress typically induces an anxiogenic phenotype (Huot et al., 2002; Kalinichev et al., 2002; Daniels et al., 2004; Rees et al., 2006; Aisa et al., 2007; Trujillo et al., 2016), this apparent decrease in GR expression was associated with reduced anxiety of the ELS animals compared to controls, which was normalized by lentiviral-mediated restoration of GR levels (Arnett et al., 2015).

\section{Hippocampus}

The hippocampus, best-known for its role in spatial learning and memory (Block and Schwarz, 1997), plays an important inhibitory role in the regulation of the HPA-axis by its direct and indirect polysynaptic connections to the PVN. Electric stimulation of hippocampal subfields [CA3, dentate gyrus (DG), and subiculum] reduces corticosteroid release (Dunn and Orr, 1984), whereas hippocampal lesions and those of the ventral subiculum increase CRH mRNA levels in the PVN (Herman et al., 1989), and prolong the corticosterone stress response (Herman et al., 1995), respectively. This feedback seems to be relayed to the hypothalamus by indirect projections through the bed nucleus stria terminalis (Herman et al., 2003). Because of its high local GR/MR expression levels, moderate CRHR1/2 levels, and local CRH-expression, the hippocampus is however highly sensitive to the influences of stress (de Kloet et al., 1990; Maras and Baram, 2012). The first 2 postnatal weeks comprise a crucial period in hippocampal maturation (Frotscher and Seress, 2007), as this is when the hippocampal commissural/associational (C/A) pathways establish their synaptic connections on CA3 pyramidal cell dendrites (Bayer, 1980). Disruption of this process can only be partially restored beyond the third postnatal week (Gall and Lynch, 1978), making that stress experienced during this period can profoundly affect hippocampal structure and function.

ELS has been shown to slow the acquisition of spatial learning and/or impair memory under both moderately stressful and relatively stress-free conditions (Lemaire et al., 2000; Huot et al., 2002; Brunson et al., 2005; Ishiwata et al., 2005; Yang et al., 2006b; Aisa et al., 2007; Kosten et al., 2007; Rice et al., 2008; Ivy et al., 2010; Hulshof et al., 2011). In one of these studies, PS-induced learning deficits were associated with a reduction in spine density of pyramidal neuron dendrites in the hippocampal CA3 region (Ishiwata et al., 2005). Other studies confirmed this PS-reduced spine density not only in the CA3, but also the CA1 subregion of the hippocampus (Martínez-Téllez et al., 2009). Besides, PS reduced dendritic length and branching of CA3, but not CA1, neurons (Hosseini-sharifabad and Hadinedoushan, 2007). Similar reductions in spine density of CA1 neurons were observed as a consequence of ESD and LN, which was, in contrast to the case of PS, joined by CA1 dendritic atrophy (Ivy et al., 2010; Monroy et al., 2010). Moreover, LN was found to reduce apical dendritic length and neuronal complexity in CA3 neurons in infants (Liao et al., 2014). Whereas MS decreased the density of mossy fibers in the stratum oriens (Huot et al., 2002), no changes in apical dendritic length and neuronal complexity have been found in the DG (Oomen et al., 2011).

These structural alterations affect local synaptic plasticity; PS impairs long-term potentiation (LTP) in the CA1 (which is associated with a decreased expression and impaired interaction of the NR1 and NR2B subunits of the NMDA receptor in hippocampal synapses; Son et al., 2006), whereas long-term depression (LTD) is facilitated. Furthermore, PS was shown to enhance the effects of acute stress on impairing hippocampal LTP and facilitating LTD (Yang et al., 2006a). Cross-fostering the neonate offspring with control mothers did not change these effects on hippocampal LTP and LTD, implicating they resulted directly from the prenatal manipulation and not altered maternal care (see Box 2; Yang et al., 2006a). However, environmental enrichment after weaning restored plasticity in PS animals, as well as the associated impairments in spatial memory (Yang et al., 2007), emphasizing the impact of the neonate's environment on PS effects. Not surprisingly, disturbed LTP in the CA1, CA3, and DG is also observed as a consequence of stress in the neonate (by both LN and MS; Brunson et al., 2005; Cui et al., 2006; Ivy et al., 2010; Batalha et al., 2013; Cao et al., 2014; Xiong et al., 2014). However, these perturbations are not always found and may depend on the developmental stage affected by stress (Gruss et al., 2008), the sex of the animal (Oomen et al., 2011), and the age of testing (Brunson et al., 2005). Moreover, they might depend on the exact ELS model implemented, since ESD has been found to enhance DG LTP induction and duration in juvenile (Kehoe et al., 1995; Bronzino et al., 1996) and adult (Kehoe and Bronzino, 1999) offspring. Potentially in line with this ESD-boosted hippocampal LTP is the observation that neonatal isolation accelerates the developmental switch in the signaling cascades for local LTP induction (Huang et al., 2005). However, ESD was also shown to prevent acute stress-induced potentiation of LTP in the DG (Wang H. et al., 2013). Future studies should further elucidate the critical dependables in the modulation of the effects of ELS on hippocampal plasticity.

Although several studies have attributed these effects to elevated corticosteroid exposure of the hippocampus (Brunson et al., 2005), suppressing dendritic growth and branching (Alfarez et al., 2009; Liston and Gan, 2011), the presence of both elevated levels of CRH and CRHR1 (with CRHR1 mRNA expression detected at $\sim 300-600 \%$ of adult levels at PND6; AvishaiEliner et al., 1996) during early developmental stages points toward their critical role in development (and thereby particular sensitivity of the brain to their dysregulation). Hippocampal CRH-immunoreactive neurons are already detected at PND1 (Yan et al., 1998; Chen et al., 2001) and numbers increase to peak levels at PND18, after which levels reduce to those observed in adulthood (Chen et al., 2001). Interestingly, at this initial stage of development, hippocampal CRH mRNA is not only detected in basket- and chandelier-type GABAergic interneurons (Yan et al., 1998; Chen et al., 2001) synapsing on somata of hippocampal pyramidal neurons, but also a second population of $\mathrm{CRH}-$ expressing neurons is present, possessing the morphology of 
hippocampal Cajal-Retzius cells. These non-GABAergic neurons disappear by the end of the second postnatal week (Chen et al., 2001), but emphasize the potential modulatory role CRH can have during early development. $\mathrm{CRH}$ is tonically released in the hippocampus, as becomes apparent from the abnormal dendritic structure (i.e., hypertrophy), spine morphology, and impaired synaptic potentiation and spatial learning observed when CRHR1s are chronically blocked (Chen et al., 2004) and in mice lacking CRHR1 (Contarino et al., 1999; Schierloh et al., 2007; Wang et al., 2011). However, the balance seems to be critical. CRH applied to slice cultures was shown to reduce spine density (Chen et al., 2008) and induce dendritic atrophy (Lin and Koleske, 2010), whereas CRH administration into the hippocampus recapitulated the learning and memory problems associated with ELS (Brunson et al., 2001b). Importantly, all these effects are observed when corticosteroid levels are maintained at basal levels. Additionally, both CRH mRNA and protein levels are generally upregulated in ELS animals (Wang et al., 2014), the number of CRH expressing interneurons in the CA1 and CA3 is increased (Ivy et al., 2010), and blockage of CRHR1 prevents dendritic atrophy and LTP attenuation, as well as the impairment in memory performance observed in neonatally stressed animals (Ivy et al., 2010). Therefore, elevated CRHR1activation has been suggested to mediate the ELS effects on hippocampal function (Maras and Baram, 2012); a hypothesis that was further corroborated by the observation that mice lacking CRHR1 are resistant to the detrimental effects of ELS on hippocampal function (Wang et al., 2011).

ELS also affects neurogenesis in the DG, one of the brain's only sites that displays neurogenesis well into adulthood (Drew et al., 2013). Reductions in adult neurogenesis and cell proliferation are observed as a consequence of PS (Lemaire et al., 2000; Morley-Fletcher et al., 2011; Belnoue et al., 2013), with the severity of the reduction depending on the severity of the PS paradigm and gestational stage affected (Mandyam et al., 2008; Madhyastha et al., 2013), with stress later in pregnancy inducing stronger effects. As the DG for the larger part develops postnatally (Altman and Bayer, 1990a,b), this structure may be particularly sensitive to stress during the first weeks of life. In line with this, it was shown that neonatal stress strongly affects DG neurogenesis in a sex-, age-, and possibly species-specific manner. When assessed at the end of the SHRP, neurogenesis was found to be reduced in rats as a consequence of MS (Lajud et al., 2012), but increased in mice exposed to LN (Naninck et al., 2015). At the age of weaning, sex-specific effects were observed following MS, with male rats showing increased neurogenesis, whereas female rats displayed decreased levels (Oomen et al., 2009). Sex-specific effects of ELS were also observed in adulthood, but in an opposite direction; adult neurogenesis was reduced in MS and LN males (Oomen et al., 2010; Lajud et al., 2012; Naninck et al., 2015), whereas no effects were found in females (Oomen et al., 2011; Naninck et al., 2015). For cell death, conflicting results have been found, ranging from unaffected levels in both sexes (Lemaire et al., 2000; Mandyam et al., 2008), to increased levels in PS males (Mandyam et al., 2008).

Potentially related to these effects on neurogenesis and cell survival, volume reductions have been observed in the DG as a consequence of LN (Naninck et al., 2015), but not MS (Huot et al., 2002). ELS is also reported to locally decrease neuron and glia cell numbers (Leventopoulos et al., 2007; Fabricius et al., 2008; Oomen et al., 2011). Other hippocampal regions were not found to be reduced in volume by ELS (Fabricius et al., 2008; Hui et al., 2011; Zalosnik et al., 2014). Cell proliferation seems to be particularly affected in the caudal/ventral part of the DG (Oomen et al., 2010; Hulshof et al., 2011), implying altered hippocampal contribution to emotional behaviors (Bannerman et al., 2004; Fanselow and Dong, 2010) as a consequence of ELS. Alterations in expression levels of the neurotrophic factor BDNF, which stimulates the survival of newborn cells and is involved in cell proliferation, might be mediating these effects on cell proliferation. Hippocampal BDNF levels in female adult offspring were found to be reduced as a consequence of PS, which was related to a decreased DNA methylation in $b d n f$ exon IV. No such effects were however observed in the male offspring (St-Cyr and McGowan, 2015) and another study even reported on increased BDNF levels in PS males (Zuena et al., 2008). Reports on the effects of neonatal stress on BDNF are conflicting, as both increased (Roceri et al., 2004) and decreased BDNF mRNA expression (Kuma et al., 2004) have been observed in MS-exposed infants, and either similar BDNF mRNA (Roceri et al., 2004; Greisen et al., 2005) accompanied by increased BDNF protein levels (Greisen et al., 2005), decreased BDNF mRNA (Aisa et al., 2009), or increased BDNF mRNA levels (Kuma et al., 2004) have been observed in MS adults. Differences in duration and developmental phase affected by the MS paradigm might be responsible for these inconsistencies, although differences in rat strain might contribute as well.

Interestingly, although adult MS animals mostly show normal basal levels of corticosterone (see Table 3), depleting corticosterone (by adrenalectomy) can reverse this suppression of cell proliferation and neurogenesis, implicating inhibited cellular plasticity due to hypersensitivity to corticosterone signaling in the hippocampus (Mirescu et al., 2004). This abnormal sensitivity to corticosterone might be mediated by altered corticosteroid receptor expression or MR/GR balance as a consequence of ELS. PS has been found to decrease hippocampal MR mRNA levels, density, and binding capacity (Henry et al., 1994; Maccari et al., 1995; Koehl et al., 1999; Van Waes et al., 2006; Brunton and Russell, 2010), which could relate to the increased basal $\mathrm{CRH}$ levels in the PVN. Moreover, PS was shown to reduce hippocampal GR levels (Henry et al., 1994; Barbazanges et al., 1996; Koehl et al., 1999; Szuran et al., 2000; Chung et al., 2005; Van Waes et al., 2006; Mueller and Bale, 2008; Green et al., 2011; Bingham et al., 2013), attenuating its negative feedback on the HPA-axis, potentially explaining the stronger and prolonged corticosterone responses in PS animals (Chung et al., 2005; Koenig et al., 2005). These effects seemed to be mediated by increased prenatal corticosteroid exposure of the pups, as they were prevented by adrenalectomy in the mothers and reinstated by corticosterone injection in adrenalectomized dams (Barbazanges et al., 1996). MS during the SHRP induced an immediate decrease in CA1 MR (but not GR) mRNA expression in rat pups (Vázquez et al., 1996), whereas MS toward the end of the SHRP induced an immediate downregulation of both CA1 
MR and GR mRNA expression (van Oers et al., 1998a). No effects were observed in the other hippocampal subregions in these studies. In adulthood, mixed effects of MS on hippocampal MR mRNA expression are found, with levels found to be either increased in all hippocampal subregions (Ladd et al., 2004), in the DG only (Workel et al., 2001), or unaffected (Ladd et al., 2005; Batalha et al., 2013). GR protein levels are however univocally downregulated in the hippocampus in neonatally stressed adults (Weaver et al., 2004; Aisa et al., 2007, 2008; Batalha et al., 2013; Arnett et al., 2015) although these effects not always translate to the mRNA level (Ladd et al., 2004, 2005; Brunson et al., 2005). Moreover, these effects may be sex-specific and occur only upon repeated stress exposures, as downregulation in GR and MR expression were observed in males, but upregulation of GR was observed in females as a consequence of $24 \mathrm{~h}$ MS (Sutanto et al., 1996). Overall, these alterations might result in an increased MR/GR ratio in the hippocampus (Ladd et al., 2004), which may result in an amplified initial stress reaction by increased activation of the membrane MR in a feed-forward fashion, and an impaired containment of this response by reduced membrane and genomic GR-mediated negative feedback (Oitzl et al., 2010).

Studies have recently focused on the putative association between DNA methylation at the GR gene (NR3C1) and ELS, mediating this reduction in GR expression (in males at least). This line of work started with the discovery by Weaver and colleagues that differential levels of maternal care critically modulated methylation levels of the GR promoter exon $1_{7}$, influencing local transcription factor (NGF1-A) binding, histone acetylation, and ultimately hippocampal GR expression and corticosterone responding in the offspring (Weaver et al., 2004). These differences emerged over the first week of life, were reversed by cross-fostering, and persisted into adulthood. Moreover, they were prevented by the central infusion of a histone deacetylase inhibitor, suggesting a causal relation among epigenomic state, GR expression and the maternal effect on stress responses in the offspring. These findings were replicated in a study in human suicide victims with a history of childhood abuse; the hippocampi of early life abuse victims were characterized by decreased GR mRNA levels, GR transcripts of the GR 1F-splice variant, as well as increased methylation of the NR3C1 promoter (McGowan et al., 2009). Another recent study replicated this finding of enhanced DNA methylation at this splice variant and additionally identified altered DNA methylation in other splice variants of the GR promoter (Labonte et al., 2012). Moreover, it showed that this epigenetic response to ELS is brain regionspecific, not occurring in the anterior cingulate. Studies like this, as well as the observation that epigenetic mechanisms critically contribute to conferring cell-type identity during development and cell division, suggest that the impact of environmental factors on epigenetic marks is likely to be to some extent celltype specific, emphasizing the relevance of limiting analysis to appropriate tissues of interest instead of mere analyses of leukocytes (please see McGowan, 2013 for an extensive review on this issue). Nevertheless, these initial human data translate rodent findings to humans, suggesting a common effect of early life environment on the epigenetic regulation of hippocampal GR expression.

\section{Prefrontal Cortex}

The PFC is key to stress coping and emotion regulation (Arnsten, 2009) through its inhibitory connections to both the amygdala (Banks et al., 2007) and the PVN, where it inhibits CRH release (Radley et al., 2006). It represses the HPA-axis predominantly through inhibitory projections from the infralimbic (IL), prelimbic (PL), and anterior cingulate cortex (ACC) that target HPA-axis neurons directly or indirectly (Heidbreder and Groenewegen, 2003), although the exact functional implications for the HPA-axis seem to be subregion-specific (Radley et al., 2006). It represents the functionally most advanced area of the brain with the longest period of maturation. This prolonged development allows for the acquisition of complex cognitive abilities through experience, but also makes it susceptible to factors that can lead to abnormal functioning, which is often manifested in neuropsychiatric disorders (Schubert et al., 2015). Its development starts prenatally with the proliferation and migration of neurons, growth of dendrites, the formation of neural micro- and macro-circuits through efferent/afferent axonal projections, but continues after birth with the initial overproduction of neurons and their connection being finetuned by reducing synaptic contacts (e.g., by the pruning and cell death of unused connections; Kolb et al., 2012) and neuronal density steered by experience.

ELS typically impairs PFC function in adulthood, as is exemplified by increased impulsivity (Gondré-Lewis et al., 2016), deficits in extradimensional shifts of attention (Mehta and Schmauss, 2011), and impaired working, short-term, and longterm memory (Gué et al., 2004; Markham et al., 2010; NegrónOyarzo et al., 2015; Alteba et al., 2016). In line with this, PS has been shown to impair prefrontal LTP, which was accompanied by an increase in the mean frequency of spontaneous excitatory postsynaptic currents (sEPSCs) in layer II/III pyramidal neurons (Sowa et al., 2015). Similar results have been observed in rats following chronic corticosterone treatment (Bartosz et al., 2011), suggesting a role for glucocorticoids in this impaired LTP. MS has been shown to result in LTP impairment in the IL layer II/III-layer V (Xiong et al., 2014), and ELS to impair extinction retrieval of context-dependent fear memories by preventing the synaptic potentiation of hippocampal-PL cortex neural pathway, which displayed synaptic inhibition rather than potentiation (Judo et al., 2010). Another study into the effects of PS confirmed this aberrant hippocampal-PFC functional connectivity as the temporal coupling between neuronal discharge in the medial PFC (mPFC) and hippocampal sharp-wave ripples was decreased by PS (Negrón-Oyarzo et al., 2015). In line with this, decreased regional $\mathrm{CBF}$ was elicited in the dorsal mid-cingulate and posterior cingulate cortex in MS rats in response to a conditioned tone compared to controls (Sadler et al., 2011).

These functional changes in the frontal cortex might be mediated by structural alterations caused by ELS. Comprehensive insight into the modulatory role of ELS on PFC neural morphology is derived from a series of experiments in a precocious rodent, the degu. In contrast to classical laboratory rats and mice, degus (like human babies) are born with relatively mature sensory systems and can thus perceive and more elaborately interact with their early life environment, making 
them a very suitable model to study the impact of neonatal stress (Bock and Braun, 2011; Braun and Bock, 2011). Brief MS increases corticosterone levels (Gruss et al., 2006) and both MS and ESD downregulate PFC activity during the separation period (Bock et al., 2012). Repeated separation has been shown to increase spine density in the basal dendrites of layer III dorsal ACC neurons in adolescent animals when compared to nonstressed controls (Helmeke et al., 2001). This finding could potentially be explained by either delayed or permanently impaired synaptic pruning during PFC development. The effect of this increased excitatory spine density may even be exaggerated by a decrease of inhibitory shaft synapses on the neurons by stress (Ovtscharoff and Braun, 2001), inducing a dysbalance of PFC synaptic input and neuronal output. Besides altering synaptic contacts, neonatal stress was shown to also affect the number and type of inhibitory interneurons in the ACC (Helmeke et al., 2008), as wells as reduce mPFC GABAa receptor binding (Caldji et al., 2000), further substantiating evidence for a transient dysbalance in small neuronal feedback loops, and potentially providing a substrate for the development of dysfunctional large-scale neuronal networks. Work in the classical rodent models has substantiated these findings of altered PFC development by ELS, reporting on alterations in both dendritic length and regional spine density depending on the age (developmental stage) and the molecular layer in which they are assessed. Mild PS was found to increase spine density in layer III cingulate cortex neurons at weaning (Mychasiuk et al., 2012), and a mild postnatal stressor caused similar effects assessed pre-puberty (PND35; Monroy et al., 2010). However, in adulthood, PS was found to reduce spine density and dendritic branching and length in AACC and orbitofrontal cortex layer II/III pyramidal neurons (Murmu et al., 2006), and to reduce the ratio of mushroom spines; the type forming the most strong and stable synapses (Michelsen et al., 2007). ESD was also found to reduce apical dendritic length in several PFC subregions in the adult offspring, and reduce spine density in frontal cortex layer III neurons (Monroy et al., 2010; Romano-López et al., 2016). Reduced local expression of BDNF mRNA in adult MS (Roceri et al., 2004), LN (Roth et al., 2009), and PS offspring due to increased $B d n f$ DNA methylation [associated with an increase in DNA methyltransferase 1 (DNMT1) expression; Roth et al., 2009; Dong et al., 2015], may relate to these changes. However, findings are not indisputable (Muhammad et al., 2012; Boersma et al., 2014), and it has been suggested that the extent and direction of the effects of ELS on frontal neuronal morphology may depend on the developmental status of the neuronal layer at the time the stress is experienced. ESD on PND1-3 was shown to decrease dendritic spine density in layer II/III neurons of the ACC, but failed to have an effect when applied on PND5-7. ESD on PND14-16 however increased spine density on these neurons (Bock et al., 2005). Conversely, ESD on PND5-7 reduced spine density on layer $\mathrm{V}$ pyramidal neurons, whereas ESD during the other time intervals did not induce any effects (Gos et al., 2008). As pyramidal cells in layers V/VI are ontogenetically older and therefore establish their synaptic connections earlier than layer II/III pyramidal neurons (Zhang, 2004), these neuron-specific responses to ELS may be due to their different degree of maturity at the time the stressor is experienced. The differential innervation and receptor patterns amongst neuronal layers may be an alternative explanation for their differential sensitivity toward stress (e.g., Zilles et al., 1993). Furthermore, the effects of stress exposure might critically depend on its intensity. Supporting this idea, stressor intensity was found to critically modulate frontal cortex global methylation levels; mild PS increased overall methylation levels at PND21, whereas intense PS induced the opposite effect (Mychasiuk et al., 2011).

Prefrontal CRHR1s have been associated with anxiety (Sotnikov et al., 2014), contribute to the HPA-axis stress response (Jaferi and Bhatnagar, 2007) and were recently found to mediate acute stress-induced executive dysfunction (Uribe-Marino et al., 2016). MS has been observed to significantly increase CRHR1 protein levels in response to acute stress, compared to non-MS controls (O’Malley et al., 2011). However, reported effects of MS on basal CRHR1 expression levels have been mixed, with both no effects (O'Malley et al., 2011) and decreases reported (Ladd et al., 2005). Importantly, ELS reduces GR expression in the PFC, and thereby compromises its negative feedback function on the HPA-axis (Diorio et al., 1993). PS was shown to reduce PFC GR protein levels (Green et al., 2011; Bingham et al., 2013) and binding capacity (McCormick et al., 1995). Also LN and MS induce a significant reduction in PFC GR density (Avishai-Eliner et al., 2001; Ladd et al., 2004, 2005), although this effect is not consistently observed (Huot et al., 2004). Interestingly, a study in which monkeys were prenatally treated with the synthetic glucocorticoid dexamethasone did not observe a decrease in GR expression (Heijtz et al., 2010), suggesting that increased corticosterone exposure in itself is not sufficient to establish these effects. Instead, findings in MS pups of which the dam was given a foster nest for the duration of the separation period implicated a critical role for maternal stress (and potentially care) in influencing GR expression; MS pups from a dam with a foster nest showed increased instead of decreased GR density, accompanied by an (albeit partial) restoration of PVN CRH mRNA levels and ACTH response to stress (Huot et al., 2004). Future research should investigate the exact aspects of the maternal behavior that mediate these normative effects.

\section{EARLY LIFE STRESS EFFECTS IN A "MATCHING" STRESSFUL ADULT ENVIRONMENT}

Although findings on basal neuroendocrine function as a consequence of ELS are rather inconsistent, general consensus points toward exaggerated neuroendocrine responses upon the encounter of an acute stressor in most ELS models. Such increased responsivity to environmental challenges is typically considered to be maladaptive, as maladaptation is often defined as deviation from the norm. However, we would like to argue that this increased environmental sensitivity can be both adaptive and maladaptive depending on the context at which it is displayed. Enhanced attention to threat (Pollak and TolleySchell, 2003; Shackman et al., 2007) for example, might be 
very adaptive in dangerous environments, but maladaptive in a save, non-threatening context. Evidence supporting this interpretation of an adaptive role for ELS in case of exposure to adult life stressors has been accumulating. Offspring receiving relatively poor maternal care (low licking/grooming) not only displays impaired spatial learning (Liu et al., 2000b), deficits in long term neutral memory (Bredy et al., 2003), and increased acoustic startle and pre-pulse inhibition (PPI) (Daskalakis et al., 2012), but also enhanced memory for stressful events (i.e., contextual fear-conditioning; Champagne et al., 2008; Bagot et al., 2009). Similarly, MD offspring showed impaired spatial learning in the water maze (Oomen et al., 2010), but improved cue fear-conditioned memory (Oomen et al., 2011) and contextual learning in a high-stress environment (Oomen et al., 2010). In line with this, mild ELS reduced responsiveness to acute stress exposure (acoustic and restraint) in terms of corticosteroid release and reduction in body weight (Kiank et al., 2009). Some studies even indicated anxiolytic effects of mild-moderate ELS (Cannizzaro et al., 2006; Ehrlich and Rainnie, 2015). Besides this enhanced coping with acutely stressful conditions, ELS also seems to "protect" against the detrimental effects of prolonged stress exposure in adulthood. Isolation rearing was shown to significantly disrupt PPI in control animals but not in those that were maternally deprived (Ellenbroek and Cools, 2002), and to more severely affect anxious, social, and depressive phenotypes in controls compared to LN offspring (Santarelli et al., 2014). Moreover, offspring that received enhanced maternal care (high licking/grooming) reared in isolation displayed lower PPI levels and the highest apomorphine-induced gnawing, a measure marking psychosis susceptibility, compared to offspring that received low maternal care (Daskalakis et al., 2012). Even the effects of severe prolonged stress (i.e., 24 days of chronic unpredictable stress) were buffered by ELS; whereas this stressor induced a significant impairment in contextual fear memory in control animals, stressed MD rats displayed similar performance to non-stressed control animals (Zalosnik et al., 2014). All these findings seem to support the match-mismatch theory, proposing adaptive effects of ELS exposure in a matching stressful environment in adulthood. Importantly, the adaptive potential of ELS seems to interact with an individual's programming sensitivity (or early plasticity), which might be determined by three factors; heritable variation, developmental experience, and the timing of the experience (Nederhof and Schmidt, 2012). Animals exposed to inescapable shock stress for example showed reduced escape latencies to escapable stress when they experienced MS early in life, and this effect was more pronounced in animals with reduced expression levels of the serotonin transporter (van der Doelen et al., 2013), supposedly reflecting higher susceptibility to environmental factors ("programming sensitivity"). Another study showed that MS decreased anxiety- and depressive-like behaviors and enhanced social interaction in rats with heightened inborn stress-susceptibility (i.e., Wistar-Kyoto rats), whereas MS induced opposite effects in Wistar MS offspring (Rana et al., 2015).

Similar protective effects of ELS to stress exposure in adulthood are emerging in terms of neuroendocrine responding.
While MS seems to result in significantly higher corticosterone stress responses in adulthood (Ladd et al., 2004, 2005; Plotsky et al., 2005; Lippmann et al., 2007; Lajud et al., 2012), the additional experience of chronic stress in adult life has been shown to normalize these responses to the level observed in non-stressed non-MS controls (Ladd et al., 2005) or to even reduce basal ACTH and corticosterone levels compared to stressed non-MS animals (Renard et al., 2007). These effects were associated with an upregulation in hippocampal GR expression, and a normalization of GR levels in the PVN (Renard et al., 2010). Moreover, exposure to chronic stress reduced amygdala CRH mRNA expression in MS offspring and did not induce an increase in PVN expression levels (as observed in the stressed control animals; Ladd et al., 2005). At the same time, acute stress exposure reduced PVN CRHR1 mRNA expression specifically in MS animals, returning them to similar levels as those in non-MS controls (O'Malley et al., 2011). In terms of the HPA-axis' external modulators, PS has been found to protect rats from the degenerating effects of chronic stress on spine density and morphology (reducing the density of mushroom spines in particular) of mPFC neurons (Michelsen et al., 2007). Additionally, MS was shown to prevent the observed reduction in mPFC BDNF mRNA expression in response to acute stress (Roceri et al., 2004). Furthermore, exposure of MS animals to chronic stress later in life was shown to significantly increase frontal cortex GR mRNA expression levels, eliminating the significant difference in expression with the non-stressed non-MS controls (Ladd et al., 2005). In the hippocampus, corticosterone administration enhanced CA1 LTP in offspring that received low maternal care, whereas significant impairments due to corticosterone were observed in high licking/grooming (LG) offspring (Champagne et al., 2008). This CORT-induced impairment in LTP in the high LG offspring was associated with increased NMDA receptor function in these animals, and was also observed in low LG offspring under basal conditions (Bagot et al., 2012). Moreover, corticosterone was shown to enhance DG LTP in MS animals compared to their non-MS controls, even though the MS caused a reduction of neurogenesis and an altered dendritic complexity (Oomen et al., 2010). These studies imply that chronic stress in adulthood actually restores PFC and hippocampal function and their inhibition of the HPA-axis.

Although still preliminary, first evidence in humans supporting the adaptive effects of early life adversity under matching situations later in life has also become apparent. Stress during pregnancy was shown to be a consistent predictor of cortisol reactivity in infants; although PS increased overall basal cortisol levels in children, it decreased cortisol reactivity to maternal separation (Tollenaar et al., 2011). Another study showed that moderate ELS was associated with lower implicit anxiety than low ELS (Edge et al., 2009), whereas neuroimaging work indicated that ELS was not only associated with a reduced cortisol response to psychosocial stress, but also with an attenuated stress-induced limbic deactivation, reflecting relative stress resilience (Grimm et al., 2014). 
However, the interaction between stress in early life and adulthood is not always as straightforward. Acute stress exposure was also shown to induce an increase in prefrontal CRHR1 expression in MS animals (compared to a decrease in controls), but not a reduction in amygdala CRHR1 expression (as seen in controls), and to induce significant increased amygdalar CRHR2 and hippocampal CRHR1 expression in MS animals specifically (O'Malley et al., 2011). Moreover, chronic stress has been shown to add to the effects of MS in terms of decreasing CRHR1 mRNA expression in the frontal and parietal cortex, whereas it normalized CRHR1 binding potential in these regions to the level of non-stressed controls (Ladd et al., 2005). The exact meaning of these findings should be assessed in further studies. Moreover, in contrast to these adaptive/protective effects of ELS, other findings support the so-called "two/three-hit hypothesis," in which later life stressors worsen the effects of ELS and genetic predispositions sensitize an animal to these detrimental effects (Daskalakis et al., 2013). For example, a combination of MS and later life corticosterone treatment or chronic stress exaggerated the impairing effects of either treatment alone on learning and memory, PPI, and hippocampal BDNF expression (Choy et al., 2008, 2009; Llorente et al., 2011). Moreover, PS appeared to increase vulnerability to chronic restraint stress in adulthood, elevating anxiety and basal hypothalamic $\mathrm{CRH}$ and ACTH levels, although basal corticosteroid levels were remarkably reduced (Chung et al., 2005). Behaviorally, MS animals were found more sensitive to social-defeat anhedonia (Der-Avakian and Markou, 2010), and to display elevated corticosterone stress responses and increased depression-like behavior as a consequence of repeated restraint stress in adulthood (Uchida et al., 2010). In line with these behavioral findings, MS was shown to decrease overall hippocampal GR levels (Aisa et al., 2007, 2008), and even more so in case of adult chronic stress (Aisa et al., 2008).

Finally, more ambiguous findings in support of both theories have been reported. Chronic stress exposure induced a smaller reduction in CA3 dendritic length and a blunted response on thymus and adrenal weight in MS animals compared to controls (Eiland and McEwen, 2012). However, at the same time, MS animals displayed increased chronic stressinduced anxiety and novelty-induced corticosterone secretion (Eiland and McEwen, 2012). Again, it seems important to note that all of the abovementioned phenotypic alterations should be interpreted in the light of the specific environmental context. While deviations from the norm (such as increased anxiety and heightened corticosterone responses) are usually seen as maladaptive, they could be highly adaptive if the context requires. Moreover, besides the test context, the exact extent of programming by ELS may critically determine how individuals function in adult life. The match-mismatch theory may apply to individuals that are sensitively programmed (by a combination of genetic makeup and strong developmental experience at a vulnerable time point in development) for an adverse environment, while the cumulative stress (2/3-hit) hypothesis might apply to individuals that did not undergo such strong programming effects (Nederhof and Schmidt, 2012).

\section{CONCLUSION AND DISCUSSION}

As described in this review, ELS induces enduring neuroplasticity of the HPA-axis by influencing the developmental trajectories of brain maturation, and exerting a wide range of long-lasting effects, encompassing alterations in neuroendocrine signaling, neuronal morphology and plasticity, and regional brain volume and function. Both PS and MS seem to induce a hyperresponsive HPA-axis, boosting the amygdala's excitatory drive, while impairing regulatory negative feedback function of the hippocampus and PFC. Human findings are in line with such HPA-axis hyperactivity due to prenatal and "mild-moderate" neonatal stress. Prenatal stress and anxiety were shown to increase stress-induced cortisol responses in pre-adolescent children (Gutteling et al., 2005; O'Connor et al., 2005), and also adversity in early life (e.g., interparental aggression, corporal punishment, or frequent emotional maternal withdrawal) was found to increase basal cortisol levels (Davies et al., 2009), as well as cortisol stress responses (Bugental et al., 2003). Conversily, child-reported maternal warmth predicted lower cortisol stress responses (Luecken et al., 2016). However, more severe stress, ESD, seems to exert different effects as stress-induced corticosterone levels in ESD animals are either unaffected or decreased as compared to non-stressed controls. Similarly, studies in human children exposed to severe stress (due to severe neglect, abuse, or deprivation e.g., in orphanages or institutions, or involvement with child protective services) report on lower basal levels of corticosteroids (e.g., Carlson and Earls, 1997; Gunnar and Donzella, 2002; Bruce et al., 2009; Bernard et al., 2015). This hypocortisolism might either be caused by a reduced response of the pituitary to the CRH-drive from the hypothalamus (Fries et al., 2005) or by target tissue hypersensitivity to corticosteroids (Yehuda et al., 2006). Interestingly, hypocortisolism is also observed in PTSD patients, in combination with increased glucocorticoid sensitivity (Rohleder et al., 2004). However, similar to the described preclinical rodent studies, many discrepancies regarding altered HPA-axis function as observed in ELS-related psychopathology remain. Future dedicated research into the exact nature, duration, and developmental period affected by the early life adversity may shed light on these obscurities.

Overall, many conflicting results have been reported for the effects of ELS in rodents. Results may vary due to the use of different stressors, their distinct severity, and differential duration and frequency. Moreover, differences in testing conditions, such as the time of the day (influencing concurrent circulating corticosterone levels; Dickmeis, 2009), or relatively stressful context of testing or sacrifice may affect the outcome. Furthermore, the effects of stress exposure may critically depend on the (additive or compensatory changes in) alterations in maternal care caused by the stressor (Box 2). As the developmental trajectories of brain regions and systems are affected (either delayed or characterized by temporary attempts to compensation), the age at which ELS effects are assessed is also a critical factor. Moreover, gene $\mathrm{x}$ environment interactions (Nugent et al., 2011) may underlie the differential 
effects observed for different strains of the animals (e.g., Long Evans, Wistar, Sprague-Dawley, Brattleboro rats, CD1, C57BL/6J, $\mathrm{C} 57 \mathrm{Bl} / 6 \mathrm{~N}, \mathrm{BALB} / \mathrm{C}$ mice). Another important factor is sex (see Box 3). Sexually dimprophic gonadal hormones critically interact with the stress response (reviewed in Kajantie and Phillips, 2006). The biological substrates of sex dimorphisms pertaining to stress however remain understudied and require further investigation. Lastly, the exact outcome of stress exposure seems to depend on the maturational status of a given brain region at the time of the stressor, e.g., the experience of adversity at times of frontal cortex development induce differential effects from those experienced during those of the hippocampus or amygdala (Lupien et al., 2009). In line with this, experiments in rats revealed that MS between PND2-20 was shown to exert negative effects on the spine density in hippocampus (Andersen and Teicher, 2004), whereas stress experienced later in development, i.e., PND3035 , affected synaptic density in the prefrontal cortex (Leussis et al., 2008). Findings in humans further corroborate this by showing that the repeated experience of sexual abuse was related to decreased hippocampal volume when it occurred early in childhood, but with reduced prefrontal cortex volume if it occurred during adolescence (Teicher et al., 2006; Andersen et al., 2008). Similarly, the psychopathology developed as a consequence of ELS may depend on the developmental stage affected. Women were for example shown to display increased risk for major depression when they experienced a trauma before the age of 12, but to PTSD when the trauma occurred between 12 and 18 years of age (Maercker et al., 2004). As the hippocampus in humans develops till 2 years of age, whereas that of the amygdala continues until the late $20 \mathrm{~s}$ and that of the frontal cortex primarily takes place between 8 and 14 years of age (Giedd et al., 1996), the hippocampus might be the brain area most vulnerable to the effects of stress early in life.

\section{REFERENCES}

Aisa, B., Elizalde, N., Tordera, R., Lasheras, B., Del Río, J., and Ramírez, M. J. (2009). Effects of neonatal stress on markers of synaptic plasticity in the hippocampus: implications for spatial memory. Hippocampus 19, 1222-1231. doi: 10.1002/hipo.20586

Aisa, B., Tordera, R., Lasheras, B., Del Río, J., and Ramírez, M. J. (2007). Cognitive impairment associated to HPA axis hyperactivity after maternal separation in rats. Psychoneuroendocrinology 32, 256-266. doi: 10.1016/j.psyneuen.2006.12.013

Aisa, B., Tordera, R., Lasheras, B., Del Río, J., and Ramírez, M. J. (2008). Effects of maternal separation on hypothalamic-pituitary-adrenal responses, cognition and vulnerability to stress in adult female rats. Neuroscience 154, 1218-1226. doi: 10.1016/j.neuroscience.2008.05.011

Akirav, I., and Maroun, M. (2007). The role of the medial prefrontal cortexamygdala circuit in stress effects on the extinction of fear. Neural Plast. 2007:30873. doi: 10.1155/2007/30873

Alfarez, D. N., De Simoni, A., Velzing, E. H., Bracey, E., Joels, M., Edwards, F. A., et al. (2009). Corticosterone reduces dendritic complexity in developing hippocampal CA1 neurons. Hippocampus 19, 828-836. doi: 10.1002/hipo.20566

Almazan, G., Lefebvre, D. L., and Zingg, H. H. (1989). Ontogeny of hypothalamic vasopressin, oxytocin and somatostatin gene expression. Dev. Brain Res. 45, 69-75. doi: 10.1016/0165-3806(89)90008-4

\section{Concluding}

Thus, stress exposure during early life can have severe consequences on our health during later life and increase susceptibility to psychopathology. However, the severe, longlasting changes in the reactivity of the HPA-axis to stress are not necessarily maladaptive. In this review we point toward several factors that seem to be highly relevant in determining the eventual outcome. Firstly, the nature and timing and duration (Andersen, 2003) of the stressor in combination with the genetic background of the individual, determine how well an individual can adapt to it. Secondly, it depends on the specific endophenotype tested and the context in which it is assessed. High levels of anxiety could for example be adaptive in certain environmental context, whereas impaired spatial memory is not. The latter suggests that even within the same individual evidence for the match/mismatch and cumulative stress hypothesis can be obtained.

\section{AUTHOR CONTRIBUTIONS}

$\mathrm{MvB}$ and $\mathrm{MH}$ have reviewed literature and wrote the manuscript. $\mathrm{JH}$ read and revised the manuscript.

\section{FUNDING}

This work was supported by the Netherlands Organization for Scientific Research (NWO), grant \#864.10.003 awarded to JH and Veni grant \#863.15.008 awarded to $\mathrm{MH}$.

\section{SUPPLEMENTARY MATERIAL}

The Supplementary Material for this article can be found online at: http://journal.frontiersin.org/article/10.3389/fncel. 2017.00087/full\#supplementary-material

Alteba, S., Korem, N., and Akirav, I. (2016). Cannabinoids reverse the effects of early stress on neurocognitive performance in adulthood. Learn. Mem. 23, 349-358. doi: 10.1101/lm.041608.116

Altman, J., and Bayer, S. A. (1990a). Migration and distribution of two populations of hippocampal granule cell precursors during the perinatal and postnatal periods. J. Comp. Neurol. 301, 365-381. doi: 10.1002/cne.9030 10304

Altman, J., and Bayer, S. A. (1990b). Mosaic organization of the hippocampal neuroepithelium and the multiple germinal sources of dentate granule cells. J. Comp. Neurol. 301, 325-342. doi: 10.1002/cne.903010302

Andersen, S. L. (2003). Trajectories of brain development: point of vulnerability or window of opportunity? Neurosci. Biobehav. Rev. 27, 3-18. doi: 10.1016/S0149-7634(03)00005-8

Andersen, S. L., and Teicher, M. H. (2004). Delayed effects of early stress on hippocampal development. Neuropsychopharmacology 29, 1988-1993. doi: 10.1038/sj.npp.1300528

Andersen, S. L., Tomada, A., Vincow, E. S., Valente, E., Polcari, A., and Teicher, M. H. (2008). Preliminary evidence for sensitive periods in the effect of childhood sexual abuse on regional brain development. J. Neuropsychiatry Clin. Neurosci. 20, 292-301. doi: 10.1176/jnp.2008.20.3.292

Arnett, M. G., Pan, M. S., Doak, W., Cyr, P. E., Muglia, L. M., and Muglia, L. J. (2015). The role of glucocorticoid receptor-dependent activity in the amygdala central nucleus and reversibility of early-life stress programmed behavior. Transl. Psychiatry 5:e542. doi: 10.1038/tp.2015.35 
Arp, J. M., Ter Horst, J. P., Loi, M., den Blaauwen, J., Bangert, E., Fernández, G., et al. (2016). Blocking glucocorticoid receptors at adolescent age prevents enhanced freezing between repeated cue-exposures after conditioned fear in adult mice raised under chronic early life stress. Neurobiol. Learn. Mem. 133, 30-38. doi: 10.1016/j.nlm.2016.05.009

Arnsten, A. F. (2009). Stress signalling pathways that impair prefrontal cortex structure and function. Nat. Rev. Neurosci. 10, 410-422. doi: 10.1038/nrn2648

American Psychiatric Association (2013). Diagnostic and Statistical Manual of Mental Disorders, 5th Edn. Arlington, VA: American Psychiatric Association.

Avishai-Eliner, S., Gilles, E. E., Eghbal-Ahmadi, M., Bar-El, Y., and Baram, T. Z. (2001). Altered regulation of gene and protein expression of hypothalamicpituitary-adrenal axis components in an immature rat model of chronic stress. J. Neuroendocrinol. 13, 799-807. doi: 10.1046/j.1365-2826.2001.00698.x

Avishai-Eliner, S., Yi, S.-J., and Baram, T. Z. (1996). Developmental profile of messenger RNA for the corticotropin-releasing hormone receptor in the rat limbic system. Dev. Brain Res. 91, 159-163. doi: 10.1016/0165-3806(95)00158-1

Avishai-Eliner, S., Yi, S.-J., Newth, C. J. L., and Baram, T. Z. (1995). Effects of maternal and sibling deprivation on basal and stress induced hypothalamicpituitary-adrenal components in the infant rat. Neurosci. Lett. 192, 49-52. doi: 10.1016/0304-3940(95)11606-W

Babenko, O., Kovalchuk, I., and Metz, G. A. (2015). Stress-induced perinatal and transgenerational epigenetic programming of brain development and mental health. Neurosci. Biobehav. Rev. 48, 70-91. doi: 10.1016/j.neubiorev.2014.11.013

Bagot, R. C., Tse, Y. C., Nguyen, H. B., Wong, A. S., Meaney, M. J., and Wong, T. P. (2012). Maternal care influences hippocampal N-methyl-D-aspartate receptor function and dynamic regulation by corticosterone in adulthood. Biol. Psychiatry 72, 491-498. doi: 10.1016/j.biopsych.2012.03.016

Bagot, R. C., van Hasselt, F. N., Champagne, D. L., Meaney, M. J., Krugers, H. J., and Joëls, M. (2009). Maternal care determines rapid effects of stress mediators on synaptic plasticity in adult rat hippocampal dentate gyrus. Neurobiol. Learn. Mem. 92, 292-300. doi: 10.1016/j.nlm.2009.03.004

Baker, A., and Shalhoub-Kevorkian, N. (1999). Effects of political and military traumas on children: the Palestinian case. Clin. Psychol. Rev. 19, 935-950. doi: 10.1016/S0272-7358(99)00004-5

Bannerman, D. M., Rawlins, J. N. P., McHugh, S. B., Deacon, R. M. J., Yee, B. K., Bast, T., et al. (2004). Regional dissociations within the hippocampus-memory and anxiety. Neurosci. Biobehav. Rev. 28, 273-283. doi: 10.1016/j.neubiorev.2004.03.004

Banks, S. J., Eddy, K. T., Angstadt, M., Nathan, P. J., and Phan, K. L. (2007). Amygdala-frontal connectivity during emotion regulation. Soc. Cogn. Affect Neurosci. 2, 303-312. doi: 10.1093/scan/nsm029

Baquedano, E., García-Cáceres, C., Diz-Chaves, Y., Lagunas, N., Calmarza-Font, I., Azcoitia, I., et al. (2011). Prenatal stress induces long-term effects in cell turnover in the hippocampus-hypothalamus-pituitary axis in adult male rats. PLoS ONE 6:e27549. doi: 10.1371/journal.pone.0027549

Baram, T. Z., and Lerner, S. P. (1991). Ontogeny of corticotropin releasing hormone gene expression in rat hypothalamus-comparison with somatostatin. Int. J. Dev. Neurosci. 9, 473-478. doi: 10.1016/0736-5748 (91)90033-I

Baram, T. Z., and Schultz, L. (1992). CRH gene expression in the fetal rat is not increased after pharmacological adrenalectomy. Neurosci. Lett. 142, 215-218. doi: 10.1016/0304-3940(92)90376-I

Barbazanges, A., Piazza, P. V., Le Moal, M., and Maccari, S. (1996). Maternal glucocorticoid secretion mediates long-term effects of prenatal stress. J. Neurosci. 16, 3943-3949.

Barna, I., Bálint, E., Baranyi, J., Bakos, N., Makara, G. B., and Haller, J. (2003). Gender-specific effect of maternal deprivation on anxiety and corticotropinreleasing hormone mRNA expression in rats. Brain Res. Bull. 62, 85-91. doi: 10.1016/S0361-9230(03)00216-8

Bartosz, B., Joanna, W., and Grzegorz, H. (2011). Imipramine counteracts corticosterone-induced enhancement of glutamatergic transmission and impairment of long-term potentiation in the rat frontal cortex. Pharmacol. Rep. 63, 1404-1412. doi: 10.1016/S1734-1140(11)70704-6

Batalha, V. L., Pego, J. M., Fontinha, B. M., Costenla, A. R., Valadas, J. S., Baqi, Y., et al. (2013). Adenosine A(2A) receptor blockade reverts hippocampal stress-induced deficits and restores corticosterone circadian oscillation. Mol. Psychiatry 18, 320-331. doi: 10.1038/mp.2012.8
Bayer, S. A. (1980). Development of the hippocampal region in the rat. II. Morphogenesis during embryonic and early postnatal life. J. Comp. Neurol. 190, 115-134. doi: 10.1002/cne.901900108

Bayer, S. A., Altman, J., Russo, R. J., and Zhang, X. (1993). Timetables of neurogenesis in the human brain based on experimentally determined patterns in the rat. Neurotoxicology 14, 83-144.

Beery, A. K., and Zucker, I. (2011). Sex bias in neuroscience and biomedical research. Neurosci. Biobehav. Rev. 35, 565-572. doi: 10.1016/j.neubiorev.2010.07.002

Belnoue, L., Grosjean, N., Ladevèze, E., Abrous, D. N., and Koehl, M. (2013). Prenatal stress inhibits hippocampal neurogenesis but spares olfactory bulb neurogenesis. PLoS ONE 8:e72972. doi: 10.1371/journal.pone.0072972

Berdel, B., Morys, J., and MacIejewska, B. (1997). Neuronal changes in the basolateral complex during development of the amygdala of the rat. Int. J. Dev. Neurosci. 15, 755-765. doi: 10.1016/S0736-5748(97)00022-1

Bernard, K., Zwerling, J., and Dozier, M. (2015). Effects of early adversity on young children's diurnal cortisol rhythms and externalizing behavior. Dev. Psychobiol. 57, 935-947. doi: 10.1002/dev.21324

Biagini, G., Pich, E. M., Carani, C., Marrama, P., and Agnati, L. F. (1998). Postnatal maternal separation during the stress hyporesponsive period enhances the adrenocortical response to novelty in adult rats by affecting feedback regulation in the CA1 hippocampal field. Int. J. Dev. Neurosci. 16, 187-197. doi: 10.1016/S0736-5748(98)00019-7

Bingham, B. C., Sheela Rani, C. S., Frazer, A., Strong, R., and Morilak, D. A. (2013). Exogenous prenatal corticosterone exposure mimics the effects of prenatal stress on adult brain stress response systems and fear extinction behavior. Psychoneuroendocrinology 38, 2746-2757. doi: 10.1016/j.psyneuen.2013.07.003

Birn, R. M., Patriat, R., Phillips, M. L., Germain, A., and Herringa, R. J. (2014). Childhood maltreatment and combat posttraumatic stress differentially predict fear-related fronto-subcortical connectivity. Depress. Anxiety 31, 880-892. doi: 10.1002/da.22291

Block, F., and Schwarz, M. (1997). Correlation between hippocampal neuronal damage and spatial learning deficit due to global ischemia. Pharmacol. Biochem. Behav. 56, 755-761. doi: 10.1016/S0091-3057(96)00484-4

Bock, J., and Braun, K. (2011). The impact of perinatal stress on the functional maturation of prefronto-cortical synaptic circuits: implications for the pathophysiology of ADHD? Prog. Brain Res. 189, 155-169. doi: 10.1016/B978-0-444-53884-0.00023-3

Bock, J., Gruss, M., Becker, S., and Braun, K. (2005). Experience-induced changes of dendritic spine densities in the prefrontal and sensory cortex: correlation with developmental time windows. Cereb. Cortex 15, 802-808. doi: 10.1093/cercor/bhh181

Bock, J., Riedel, A., and Braun, K. (2012). Differential changes of metabolic brain activity and interregional functional coupling in prefronto-limbic pathways during different stress conditions: functional imaging in freely behaving rodent pups. Front. Cell. Neurosci. 6:19. doi: 10.3389/fncel.2012.00019

Boersma, G. J., Lee, R. S., Cordner, Z. A., Ewald, E. R., Purcell, R. H., Moghadam, A. A., et al. (2014). Prenatal stress decreases Bdnf expression and increases methylation of Bdnf exon IV in rats. Epigenetics 9, 437-447. doi: 10.4161/epi.27558

Bohn, M. C., Dean, D., Hussain, S., and Giuliano, R. (1994). Development of mRNAs for glucocorticoid and mineralocorticoid receptors in rat hippocampus. Dev. Brain Res. 77, 157-162. doi: 10.1016/0165-3806(94) 90192-9

Bosch, O. J., Krömer, S. A., and Neumann, I. D. (2006). Prenatal stress: opposite effects on anxiety and hypothalamic expression of vasopressin and corticotropin-releasing hormone in rats selectively bred for high and low anxiety. Eur. J. Neurosci. 23, 541-551. doi: 10.1111/j.1460-9568.2005.04576.x

Bosch, O. J., Müsch, W., Bredewold, R., Slattery, D. A., and Neumann, I. D. (2007). Prenatal stress increases HPA axis activity and impairs maternal care in lactating female offspring: implications for postpartum mood disorder. Psychoneuroendocrinology 32, 267-278. doi: 10.1016/j.psyneuen.2006.12.012

Bouwmeester, H., Wolterink, G., and van Ree, J. M. (2002). Neonatal development of projections from the basolateral amygdala to prefrontal, striatal, and thalamic structures in the rat. J. Comp. Neurol. 442, 239-249. doi: $10.1002 /$ cne. 10084

Braun, K., and Bock, J. (2011). The experience-dependent maturation of prefrontolimbic circuits and the origin of developmental psychopathology: implications 
for the pathogenesis and therapy of behavioural disorders. Dev. Med. Child. Neurol. 53(Suppl. 4), 14-18. doi: 10.1111/j.1469-8749.2011.04056.x

Bravo, J. A., Dinan, T. G., and Cryan, J. F. (2011). Alterations in the central CRF system of two different rat models of comorbid depression and functional gastrointestinal disorders. Int. J. Neuropsychopharmacol. 14, 666-683. doi: 10.1017/S1461145710000994

Bredy, T. W., Humpartzoomian, R. A., Cain, D. P., and Meaney, M. J. (2003). Partial reversal of the effect of maternal care on cognitive function through environmental enrichment. Neuroscience 118, 571-576. doi: 10.1016/S0306-4522(02)00918-1

Bronzino, J. D., Kehoe, P., Austin-LaFrance, R. J., Rushmore, R. J., and Kurdian, J. (1996). Neonatal isolation alters LTP in freely moving juvenile rats: sex differences. Brain Res. Bull. 41, 175-183. doi: 10.1016/0361-9230(96)00166-9

Bruce, J., Fisher, P. A., Pears, K. C., and Levine, S. (2009). Morning cortisol Levels in preschool-aged foster children: differential effects of maltreatment type. Dev. Psychobiol. 51, 14-23. doi: 10.1002/dev.20333

Brunson, K. L., Avishai-Eliner, S., Hatalski, C. G., and Baram, T. Z. (2001a). Neurobiology of the stress response early in life: evolution of a concept and the role of corticotropin releasing hormone. Mol. Psychiatry 6, 647-656. doi: 10.1038/sj.mp.4000942

Brunson, K. L., Eghbal-Ahmadi, M., Bender, R., Chen, Y., and Baram, T. Z. (2001b). Long-term, progressive hippocampal cell loss and dysfunction induced by early-life administration of corticotropin-releasing hormone reproduce the effects of early-life stress. Proc. Natl. Acad. Sci. U.S.A. 98, 8856-8861. doi: $10.1073 /$ pnas. 151224898

Brunson, K. L., Kramár, E., Lin, B., Chen, Y., Colgin, L. L., Yanagihara, T. K., et al. (2005). Mechanisms of late-onset cognitive decline after early-life stress. J. Neurosci. 25, 9328-9338. doi: 10.1523/JNEUROSCI.2281-05.2005

Brunton, P. J., Donadio, M. V., and Russell, J. A. (2011). Sex differences in prenatally programmed anxiety behaviour in rats: differential corticotropinreleasing hormone receptor mRNA expression in the amygdaloid complex. Stress 14, 634-643. doi: 10.3109/10253890.2011.604750

Brunton, P. J., and Russell, J. A. (2010). Prenatal social stress in the rat programmes neuroendocrine and behavioural responses to stress in the adult offspring: sex-specific effects. J. Neuroendocrinol. 22, 258-271. doi: $10.1111 /$ j.1365-2826.2010.01969.x

Bugental, D. B., Martorell, G. A., and Barraza, V. (2003). The hormonal costs of subtle forms of infant maltreatment. Horm. Behav. 43, 237-244. doi: 10.1016/S0018-506X(02)00008-9

Caldji, C., Francis, D., Sharma, S., Plotsky, P. M., and Meaney, M. J. (2000). The effects of early rearing environment on the development of GABAA and central benzodiazepine receptor levels and novelty-induced fearfulness in the rat. Neuropsychopharmacology 22, 219-229. doi: 10.1016/S0893-133X(99)00110-4

Callaghan, B. L., and Richardson, R. (2011). Maternal separation results in early emergence of adult-like fear and extinction learning in infant rats. Behav. Neurosci. 125, 20-28. doi: 10.1037/a0022008

Callaghan, B. L., and Richardson, R. (2012). The effect of adverse rearing environments on persistent memories in young rats: removing the brakes on infant fear memories. Transl. Psychiatry 2:e138. doi: 10.1038/tp.2012.65

Cannizzaro, C., Plescia, F., Martire, M., Gagliano, M., Cannizzaro, G., Mantia, G., et al. (2006). Single, intense prenatal stress decreases emotionality and enhances learning performance in the adolescent rat offspring: interaction with a brief, daily maternal separation. Behav. Brain Res. 169, 128-136. doi: 10.1016/j.bbr.2005.12.010

Cao, X., Huang, S., Cao, J., Chen, T., Zhu, P., Zhu, R., et al. (2014). The timing of maternal separation affects morris water maze performance and long-term potentiation in male rats. Dev. Psychobiol. 56, 1102-1109. doi: $10.1002 /$ dev. 21130

Carlson, M., and Earls, F. (1997). Psychological and neuroendocrinological sequelae of early social deprivation in institutionalized children in Romania. Ann. N.Y. Acad. Sci. 807, 419-428. doi: 10.1111/j.1749-6632.1997.tb51936.x

Champagne, D. L., Bagot, R. C., van Hasselt, F., Ramakers, G., Meaney, M. J., de Kloet, E. R., et al. (2008). Maternal care and hippocampal plasticity: evidence for experience-dependent structural plasticity, altered synaptic functioning, and differential responsiveness to glucocorticoids and stress. J. Neurosci. 28, 6037-6045. doi: 10.1523/JNEUROSCI.0526-08.2008

Chapman, D. P., Whitfield, C. L., Felitti, V. J., Dube, S. R., Edwards, V. J., and Anda, R. F. (2004). Adverse childhood experiences and the risk of depressive disorders in adulthood. J. Affect. Disord. 82, 217-225. doi: 10.1016/j.jad.2003. 12.013

Chen, J., Evans, A. N., Liu, Y., Honda, M., Saavedra, J. M., and Aguilera, G. (2012). Maternal deprivation in rats is associated with corticotrophinreleasing hormone $(\mathrm{CRH})$ promoter hypomethylation and enhances $\mathrm{CRH}$ transcriptional responses to stress in adulthood. J. Neuroendocrinol. 24, 1055-1064. doi: 10.1111/j.1365-2826.2012.02306.x

Chen, Y., and Baram, T. Z. (2016). Toward understanding how earlylife stress reprograms cognitive and emotional brain networks. Neuropsychopharmacology 41, 197-206. doi: 10.1038/npp.2015.181

Chen, Y., Bender, R. A., Brunson, K. L., Pomper, J. K., Grigoriadis, D. E., Wurst, W., et al. (2004). Modulation of dendritic differentiation by corticotropinreleasing factor in the developing hippocampus. Proc. Natl. Acad. Sci. U.S.A. 101, 15782-15787. doi: 10.1073/pnas.0403975101

Chen, Y., Bender, R. A., Frotscher, M., and Baram, T. Z. (2001). Novel and transient populations of corticotropin-releasing hormone-expressing neurons in developing hippocampus suggest unique functional roles: a quantitative spatiotemporal analysis. J. Neurosci. 21, 7171-7181.

Chen, Y., Dube, C. M., Rice, C. J., and Baram, T. Z. (2008). Rapid loss of dendritic spines after stress involves derangement of spine dynamics by corticotropin-releasing hormone. J. Neurosci. 28, 2903-2911. doi: 10.1523/JNEUROSCI.0225-08.2008

Choy, K. H., de Visser, Y. P., and van den Buuse, M. (2009). The effect of 'two hit' neonatal and young-adult stress on dopaminergic modulation of prepulse inhibition and dopamine receptor density. Br. J. Pharmacol. 156, 388-396. doi: 10.1111/j.1476-5381.2008.00008.x

Choy, K. H., de Visser, Y., Nichols, N. R., and van den Buuse, M. (2008). Combined neonatal stress and young-adult glucocorticoid stimulation in rats reduce BDNF expression in hippocampus: effects on learning and memory. Hippocampus 18, 655-667. doi: 10.1002/hipo.20425

Chung, S., Son, G. H., Park, S. H., Park, E., Lee, K. H., Geum, D., et al. (2005). Differential adaptive responses to chronic stress of maternally stressed male mice offspring. Endocrinology 146, 3202-3210. doi: 10.1210/en.2004-1458

Contarino, A., Dellu, F., Koob, G. F., Smith, G. W., Lee, K. F., Vale, W., et al. (1999). Reduced anxiety-like and cognitive performance in mice lacking the corticotropin-releasing factor receptor 1. Brain Res. 835, 1-9. doi: 10.1016/S0006-8993(98)01158-5

Cowan, C. S., Callaghan, B. L., and Richardson, R. (2013). Acute early-life stress results in premature emergence of adult-like fear retention and extinction relapse in infant rats. Behav. Neurosci. 127, 703-711. doi: 10.1037/a0034118

Cratty, M. S., Ward, H. E., Johnson, E. A., Azzaro, A. J., and Birkle, D. L. (1995). Prenatal stress increases corticotropin-releasing factor (CRF) content and release in rat amygdala minces. Brain Res. 675, 297-302. doi: 10.1016/0006-8993(95)00087-7

Cui, M., Yang, Y., Yang, J., Zhang, J., Han, H., Ma, W., et al. (2006). Enriched environment experience overcomes the memory deficits and depressivelike behavior induced by early life stress. Neurosci. Lett. 404, 208-212. doi: 10.1016/j.neulet.2006.05.048

Dalle Molle, R., Portella, A., Goldani, M., Kapczinski, F., Leistner-Segala, S., Salum, G., et al. (2012). Associations between parenting behavior and anxiety in a rodent model and a clinical sample: relationship to peripheral BDNF levels. Transl. Psychiatry 2:e195. doi: 10.1038/tp.2012.126

D’Amato, F. R., Cabib, S., Puglisi-Allegra, S., Patacchioli, F. R., Cigliana, G., MacCari, S., et al. (1992). Effects of acute and repeated exposure to stress on the hypothalamo-pituitary-adrenocortical activity in mice during postnatal development. Horm. Behav. 26, 474-485. doi: 10.1016/0018-506X(92)90015-N

Daniels, W. M., Pietersen, C. Y., Carstens, M. E., and Stein, D. J. (2004). Maternal separation in rats leads to anxiety-like behavior and a blunted ACTH response and altered neurotransmitter levels in response to a subsequent stressor. Metab. Brain Dis. 19, 3-14. doi: 10.1023/B:MEBR.0000027412.19664.b3

Daskalakis, N. P., Bagot, R. C., Parker, K. J., Vinkers, C. H., and de Kloet, E. R. (2013). The three-hit concept of vulnerability and resilience: toward understanding adaptation to early-life adversity outcome. Psychoneuroendocrinology 38, 1858-1873. doi: 10.1016/j.psyneuen.2013.06.008

Daskalakis, N. P., Enthoven, L., Schoonheere, E., de Kloet, E. R., and Oitzl, M. S. (2014). Immediate effects of maternal deprivation on the (re)activity of the HPA-axis differ in CD1 and C57Bl/6J mouse pups. Front. Endocrinol. 5:190. doi: $10.3389 /$ fendo. 2014.00190 
Daskalakis, N. P., Oitzl, M. S., Schachinger, H., Champagne, D. L., and de Kloet, E. R. (2012). Testing the cumulative stress and mismatch hypotheses of psychopathology in a rat model of early-life adversity. Physiol. Behav. 106, 707-721. doi: 10.1016/j.physbeh.2012.01.015

Datson, N. A., van der Perk, J., de Kloet, E. R., and Vreugdenhil, E. (2001). Identification of corticosteroid-responsive genes in rat hippocampus using serial analysis of gene expression. Eur. J. Neurosci. 14, 675-689. doi: 10.1046/j.0953-816x.2001.01685.x

Davies, P. T., Sturge-Apple, M. L., Cicchetti, D., Manning, L. G., and Zale, E. (2009). Children's patterns of emotional reactivity to conflict as explanatory mechanisms in links between interpartner aggression and child physiological functioning. J. Child Psychol. Psychiatry 50, 1384-1391. doi: 10.1111/j.1469-7610.2009.02154.x

De Bosscher, K., Vanden Berghe, W., and Haegeman, G. (2003). The interplay between the glucocorticoid receptor and nuclear factor-kappaB or activator protein-1: molecular mechanisms for gene repression. Endocr. Rev. 24, 488-522. doi: 10.1210/er.2002-0006

de Kloet, E. R. (1991). Brain corticosteroid receptor balance and homeostatic control. Front. Neuroendocrinol. 12, 95-164.

de Kloet, E. R. (1995). Steroids, stability and stress. Front. Neuroendocrinol. 16, 416-425. doi: 10.1006/frne.1995.1015

de Kloet, E. R., Joëls, M., and Holsboer, F. (2005). Stress and the brain: from adaptation to disease. Nat. Rev. Neurosci. 6, 463-475. doi: 10.1038/nrn1683

de Kloet, E. R., Reul, J. M., and Sutanto, W. (1990). Corticosteroids and the brain. J. Steroid Biochem. Mol. Biol. 37, 387-394. doi: 10.1016/0960-0760(90) 90489-8

de Kloet, E. R., Sutanto, W., van den Berg, D. T., Carey, M. P., van Haarst, A. D., Hornsby, C. D., et al. (1993). Brain mineralocorticoid receptor diversity: functional implications. J. Steroid Biochem. Mol. Biol. 47, 183-190. doi: 10.1016/0960-0760(93)90073-6

de Souza, M. A., Centenaro, L. A., Menegotto, P. R., Henriques, T. P., Bonini, J., Achaval, M., et al. (2013). Prenatal stress produces social behavior deficits and alters the number of oxytocin and vasopressin neurons in adult rats. Neurochem. Res. 38, 1479-1489. doi: 10.1007/s11064-013-1049-5

de Souza, M. A., Szawka, R. E., Centenaro, L. A., Diehl, L. A., and Lucion, A. B. (2012). Prenatal stress produces sex differences in nest odor preference. Physiol. Behav. 105, 850-855. doi: 10.1016/j.physbeh.2011.10.012

Dent, G. W., Okimoto, D. K., Smith, M. A., and Levine, S. (2000a). Stressinduced alterations in corticotropin-releasing hormone and vasopressin gene expression in the paraventricular nucleus during ontogeny. Neuroendocrinology 71, 333-342. doi: 10.1159/000054554

Dent, G. W., Smith, M. A., and Levine, S. (2000b). Rapid induction of corticotropin-releasing hormone gene transcription in the paraventricular nucleus of the developing rat 1. Endocrinology 141, 1593-1598. doi: 10.1210/en.141.5.1593

Der-Avakian, A., and Markou, A. (2010). Neonatal maternal separation exacerbates the reward-enhancing effect of acute amphetamine administration and the anhedonic effect of repeated social defeat in adult rats. Neuroscience 170, 1189-1198. doi: 10.1016/j.neuroscience.2010.08.002

DeSantis, S. M., Baker, N. L., Back, S. E., Spratt, E., Ciolino, J. D., Moran-Santa Maria, M., et al. (2011). Gender differences in the effect of early life trauma on hypothalamic-pituitary-adrenal axis functioning. Depress. Anxiety 28, 383-392. doi: 10.1002/da.20795

Desbonnet, L., Garrett, L., Daly, E., McDermott, K. W., and Dinan, T. G. (2008). Sexually dimorphic effects of maternal separation stress on corticotrophinreleasing factor and vasopressin systems in the adult rat brain. Int. J. Dev. Neurosci. 26, 259-268. doi: 10.1016/j.ijdevneu.2008.02.004

Diaz, R., Brown, R. W., and Seckl, J. R. (1998). Distinct ontogeny of glucocorticoid and mineralocorticoid receptor and $11 \beta$-hydroxysteroid dehydrogenase types I and II mRNAs in the fetal rat brain suggest a complex control of glucocorticoid actions. J. Neurosci. 18, 2570-2580.

Dickmeis, T. (2009). Glucocorticoids and the circadian clock. J. Endocrinol. 200, 3-22. doi: 10.1677/JOE-08-0415

Diorio, D., Viau, V., and Meaney, M. J. (1993). The role of the medial prefrontal cortex (cingulate gyrus) in the regulation of hypothalamic-pituitary-adrenal responses to stress. J. Neurosci. 13, 3839-3847.

Dityatev, A., Bruckner, G., Dityateva, G., Grosche, J., Kleene, R., and Schachner, M. (2007). Activity-dependent formation and functions of chondroitin sulfate-rich extracellular matrix of perineuronal nets. Dev. Neurobiol. 67, 570-588. doi: 10.1002/dneu.20361

Dong, E., Dzitoyeva, S. G., Matrisciano, F., Tueting, P., Grayson, D. R., and Guidotti, A. (2015). Brain-derived neurotrophic factor epigenetic modifications associated with schizophrenia-like phenotype induced by prenatal stress in mice. Biol. Psychiatry 77, 589-596. doi: 10.1016/j.biopsych.2014.08.012

Drew, L. J., Fusi, S., and Hen, R. (2013). Adult neurogenesis in the mammalian hippocampus: why the dentate gyrus? Learn. Mem. 20, 710-729. doi: $10.1101 / \mathrm{lm} .026542 .112$

Dunn, A. J., and Berridge, C. W. (1990). Is corticotropin-releasing factor a mediator of stress responses? Ann. N.Y. Acad. Sci. 579, 183-191. doi: 10.1111/j.1749-6632.1990.tb48360.x

Dunn, J. D., and Orr, S. E. (1984). Differential plasma corticosterone responses to hippocampal stimulation. Exp. Brain Res. 54, 1-6. doi: 10.1007/BF00235813

Edge, M. D., Ramel, W., Drabant, E. M., Kuo, J. R., Parker, K. J., and Gross, J. J. (2009). For better or worse? Stress inoculation effects for implicit but not explicit anxiety. Depress. Anxiety 26, 831-837. doi: 10.1002/da.20592

Eghbal-Ahmadi, M., Hatalski, C. G., Avishai-Eliner, S., and Baram, T. Z. (1997). Corticotropin releasing factor receptor type II (CRF2) messenger ribonucleic acid levels in the hypothalamic ventromedial nucleus of the infant rat are reduced by maternal deprivation. Endocrinology 138, 5048-5051. doi: 10.1210/endo.138.11.5647

Eghbal-Ahmadi, M., Hatalski, C. G., Lovenberg, T. W., Avishai-Eliner, S., Chalmers, D. T., and Baram, T. Z. (1998). The developmental profile of the corticotropin releasing factor receptor $\left(\mathrm{CRF}_{2}\right)$ in rat brain predicts distinct age-specific functions. Brain Res. Dev. Brain Res. 107, 81-90. doi: 10.1016/S0165-3806(98)00002-9

Ehrlich, D. E., and Rainnie, D. G. (2015). Prenatal stress alters the development of socioemotional behavior and amygdala neuron excitability in rats. Neuropsychopharmacology 40, 2135-2145. doi: 10.1038/npp.2015.55

Ehrlich, D. E., Ryan, S. J., and Rainnie, D. G. (2012). Postnatal development of electrophysiological properties of principal neurons in the rat basolateral amygdala. J. Physiol. 590, 4819-4838. doi: 10.1113/jphysiol.2012.237453

Ehrlich, D. E., Ryan, S. J., Hazra, R., Guo, J. D., and Rainnie, D. G. (2013). Postnatal maturation of GABAergic transmission in the rat basolateral amygdala. $J$. Neurophysiol. 110, 926-941. doi: 10.1152/jn.01105.2012

Eiland, L., and McEwen, B. S. (2012). Early life stress followed by subsequent adult chronic stress potentiates anxiety and blunts hippocampal structural remodeling. Hippocampus 22, 82-91. doi: 10.1002/hipo.20862

Eiland, L., and Romeo, R. D. (2013). Stress and the developing adolescent brain. Neuroscience 249, 162-171. doi: 10.1016/j.neuroscience.2012.10.048

Ellenbroek, B. A., and Cools, A. R. (2002). Early maternal deprivation and prepulse inhibition: the role of the postdeprivation environment. Pharmacol. Biochem. Behav. 73, 177-184. doi: 10.1016/S0091-3057(02)00794-3

Ellenbroek, B. A., van den Kroonenberg, P. T., and Cools, A. R. (1998). The effects of an early stressful life event on sensorimotor gating in adult rats. Schizophr. Res. 30, 251-260. doi: 10.1016/S0920-9964(97)00149-7

Elzinga, B. M., Roelofs, K., Tollenaar, M. S., Bakvis, P., van Pelt, J., and Spinhoven, P. (2008). Diminished cortisol responses to psychosocial stress associated with lifetime adverse events: a study among healthy young subjects. Psychoneuroendocrinology 33, 227-237. doi: 10.1016/j.psyneuen.2007. 11.004

Estanislau, C., and Morato, S. (2005). Prenatal stress produces more behavioral alterations than maternal separation in the elevated plus-maze and in the elevated T-maze. Behav. Brain Res. 163, 70-77. doi: 10.1016/j.bbr.2005.04.003

Estanislau, C., and Morato, S. (2006). Behavior ontogeny in the elevated plus-maze: prenatal stress effects. Int. J. Dev. Neurosci. 24, 255-262. doi: 10.1016/j.ijdevneu.2006.03.001

Fabricius, K., Wörtwein, G., and Pakkenberg, B. (2008). The impact of maternal separation on adult mouse behaviour and on the total neuron number in the mouse hippocampus. Brain Struct. Funct. 212, 403-416. doi: 10.1007/s00429-007-0169-6

Fan, J. M., Chen, X. Q., Jin, H., and Du, J. Z. (2009). Gestational hypoxia alone or combined with restraint sensitizes the hypothalamic-pituitary-adrenal axis and induces anxiety-like behavior in adult male rat offspring. Neuroscience 159, 1363-1373. doi: 10.1016/j.neuroscience.2009.02.009

Fan, J.-M., Wang, X., Hao, K., Yuan, Y., Chen, X.-Q., and Du, J.-Z. (2013). Upregulation of PVN CRHR1 by gestational intermittent hypoxia selectively 
triggers a male-specific anxiogenic effect in rat offspring. Horm. Behav. 63, 25-31. doi: 10.1016/j.yhbeh.2012.11.005

Fan, Y., Herrera-Melendez, A. L., Pestke, K., Feeser, M., Aust, S., Otte, C., et al. (2014). Early life stress modulates amygdala-prefrontal functional connectivity: implications for oxytocin effects. Hum. Brain Mapp. 35, 5328-5339. doi: 10.1002/hbm.22553

Fanger, B. O., Schreifer, J., and Cidlowski, J. A. (1987). Glucocorticoids increase the length of the G2 and M phases of the HeLa S3 cell cycle. J. Steroid Biochem. 28, 345-347. doi: 10.1016/0022-4731(87)91029-6

Fanselow, M. S., and Dong, H. W. (2010). Are the dorsal and ventral hippocampus functionally distinct structures? Neuron 65, 7-19. doi: 10.1016/j.neuron.2009.11.031

Faravelli, C., Lo Sauro, C., Godini, L., Lelli, L., Benni, L., Pietrini, F., et al. (2012). Childhood stressful events, HPA axis and anxiety disorders. World J. Psychiatry 2, 13-25. doi: 10.5498/wjp.v2.i1.13

Feldman, S., Conforti, N., Itzik, A., and Weidenfeld, J. (1994). Differential effect of amygdaloid lesions on CRF-41, ACTH and corticosterone responses following neural stimuli. Brain Res. 658, 21-26. doi: 10.1016/S0006-8993(09)90005-1

Felitti, V. J., Anda, R. F., Nordenberg, D., Williamson, D. F., Spitz, A. M., Edwards, V., et al. (1998). Relationship of childhood abuse and household dysfunction to many of the leading causes of death in adults. Am. J. Prev. Med. 14, 245-258. doi: 10.1016/S0749-3797(98)00017-8

Fergusson, D. M., Horwood, L. J., and Lynskey, M. T. (1996). Childhood sexual abuse and psychiatric disorder in young adulthood: II. Psychiatric outcomes of childhood sexual abuse. J. Am. Acad. Child Adolesc. Psychiatry 35, 1365-1374. doi: 10.1097/00004583-199610000-00024

Fine, R., Zhang, J., and Stevens, H. E. (2014). Prenatal stress and inhibitory neuron systems: implications for neuropsychiatric disorders. Mol. Psychiatry 19, 641-651. doi: 10.1038/mp.2014.35

Francis, D. D., Caldji, C., Champagne, F., Plotsky, P. M., and Meaney, M. J. (1999). The role of corticotropin-releasing factor-norepinephrine systems in mediating the effects of early experience on the development of behavioral and endocrine responses to stress. Biol. Psychiatry 46, 1153-1166. doi: 10.1016/S0006-3223(99)00237-1

Fries, E., Hesse, J., Hellhammer, J., and Hellhammer, D. H. (2005). A new view on hypocortisolism. Psychoneuroendocrinology 30, 1010-1016. doi: 10.1016/j.psyneuen.2005.04.006

Frotscher, M., and Seress, L. (2007). "Morphological development of the hippocampus," in The Hippocampus Book, eds P. Andersen, R. Morris, D. Amaral, T. Bliss, and J. O'Keefe (Oxford, UK: Oxford University Press), 115-131.

Fujioka, T., Sakata, Y., Yamaguchi, K., Shibasaki, T., Kato, H., and Nakamura, S. (1999). The effects of prenatal stress on the development of hypothalamic paraventricular neurons in fetal rats. Neuroscience 92, 1079-1088. doi: 10.1016/S0306-4522(99)00073-1

Gall, C., and Lynch, G. (1978). Rapid axon sprouting in the neonatal rat hippocampus. Brain Res. 153, 357-362. doi: 10.1016/0006-8993(78)90415-8

Geoffroy, M.-C., Pinto Pereira, S., Li, L., and Power, C. (2016). Child neglect and maltreatment and childhood-to-adulthood cognition and mental health in a prospective birth cohort. J. Am. Acad. Child Adolesc. Psychiatry 55, 33.e33-40.e33. doi: 10.1016/j.jaac.2015.10.012

Giachino, C., Canalia, N., Capone, F., Fasolo, A., Alleva, E., Riva, M. A., et al. (2007). Maternal deprivation and early handling affect density of calcium binding protein-containing neurons in selected brain regions and emotional behavior in periadolescent rats. Neuroscience 145, 568-578. doi: 10.1016/j.neuroscience.2006.12.042

Giedd, J. N., Snell, J. W., Lange, N., Rajapakse, J. C., Casey, B. J., Kozuch, P. L., et al. (1996). Quantitative magnetic resonance imaging of human brain development: ages 4-18. Cereb. Cortex 6, 551-560. doi: 10.1093/cercor/6.4.551

Giguere, V., and Labrie, F. (1982). Vasopressin potentiates cyclic AMP accumulation and ACTH release induced by corticotropin-releasing factor (CRF) in rat anterior pituitary cells in culture. Endocrinology 111, 1752-1754. doi: 10.1210/endo-111-5-1752

Gilles, E. E., Schultz, L., and Baram, T. Z. (1996). Abnormal corticosterone regulation in an immature rat model of continuous chronic stress. Pediatr. Neurol. 15, 114-119. doi: 10.1016/0887-8994(96)00153-1

Gillies, G. E., Linton, E. A., and Lowry, P. J. (1982). Corticotropin releasing activity of the new CRF is potentiated several times by vasopressin. Nature 299, 355-357. doi: 10.1038/29 $9355 \mathrm{a} 0$

Gluckman, P. D., Hanson, M. A., and Beedle, A. S. (2007). Early life events and their consequences for later disease: a life history and evolutionary perspective. Am. J. Hum. Biol. 19, 1-19. doi: 10.1002/ajhb.20590

Gondré-Lewis, M. C., Warnock, K. T., Wang, H., June, H. L. Jr., Bell, K. A., Rabe, H., et al. (2016). Early life stress is a risk factor for excessive alcohol drinking and impulsivity in adults and is mediated via a CRF/GABA(A) mechanism. Stress 19, 235-247. doi: 10.3109/10253890.2016.1160280

Goodyer, I. M., Park, R. J., and Herbert, J. (2001). Psychosocial and endocrine features of chronic first-episode major depression in 8-16 year olds. Biol. Psychiatry 50, 351-357. doi: 10.1016/S0006-3223(01)01120-9

Gos, T., Bock, J., Poeggel, G., and Braun, K. (2008). Stress-induced synaptic changes in the rat anterior cingulate cortex are dependent on endocrine developmental time windows. Synapse 62, 229-232. doi: 10.1002/syn.20477

Gray, T. S., Carney, M. E., and Magnuson, D. J. (1989). Direct projections from the central amygdaloid nucleus to the hypothalamic paraventricular nucleus: possible role in stress-induced adrenocorticotropin release. Neuroendocrinology 50, 433-446. doi: 10.1159/000125260

Green, M. K., Rani, C. S. S., Joshi, A., Soto-Pi-a, A. E., Martinez, P. A., Frazer, A., et al. (2011). Prenatal stress induces long term stress vulnerability, compromising stress response systems in the brain and impairing extinction of conditioned fear after adult stress. Neuroscience 192, 438-451. doi: 10.1016/j.neuroscience.2011.06.041

Greisen, M. H., Altar, C. A., Bolwig, T. G., Whitehead, R., and Wörtwein, G. (2005). Increased adult hippocampal brain-derived neurotrophic factor and normal levels of neurogenesis in maternal separation rats. J. Neurosci. Res. 79, 772-778. doi: 10.1002/jnr.20418

Grimm, S., Pestke, K., Feeser, M., Aust, S., Weigand, A., Wang, J., et al (2014). Early life stress modulates oxytocin effects on limbic system during acute psychosocial stress. Soc. Cogn. Affect. Neurosci. 9, 1828-1835. doi: 10.1093/scan/nsu020

Grino, M., Young, W. S. III, and Burgunder, J.-M. (1989). Ontogeny of expression of the corticotropin-releasing factor gene in the hypothalamic paraventricular nucleus and of the proopiomelanocortin gene in rat pituitary. Endocrinology 124, 60-68. doi: 10.1210/endo-124-1-60

Groeneweg, F. L., Karst, H., de Kloet, E. R., and Joëls, M. (2011). Rapid nongenomic effects of corticosteroids and their role in the central stress response. J. Endocrinol. 209, 153-167. doi: 10.1530/JOE-10-0472

Gruss, M., Braun, K., Frey, J. U., and Korz, V. (2008). Maternal separation during a specific postnatal time window prevents reinforcement of hippocampal long-term potentiation in adolescent rats. Neuroscience 152, 1-7. doi: 10.1016/j.neuroscience.2007.12.033

Gruss, M., Westphal, S., Luley, C., and Braun, K. (2006). Endocrine and behavioural plasticity in response to juvenile stress in the semiprecocial rodent Octodon degus. Psychoneuroendocrinology 31, 361-372. doi: 10.1016/j.psyneuen.2005.08.017

Gué, M., Bravard, A., Meunier, J., Veyrier, R., Gaillet, S., Recasens, M., et al. (2004). Sex differences in learning deficits induced by prenatal stress in juvenile rats. Behav. Brain Res. 150, 149-157. doi: 10.1016/S0166-4328(03) 00250-X

Gunn, B. G., Cunningham, L., Cooper, M. A., Corteen, N. L., Seifi, M., Swinny, J. D., et al. (2013). Dysfunctional astrocytic and synaptic regulation of hypothalamic glutamatergic transmission in a mouse model of early-life adversity: relevance to neurosteroids and programming of the stress response. J. Neurosci. 33, 19534-19554. doi: 10.1523/JNEUROSCI.1337-13.2013

Gunnar, M. R. (2003). Integrating neuroscience and psychological approaches in the study of early experiences. Ann. N.Y. Acad. Sci. 1008, 238-247. doi: 10.1196/annals.1301.024

Gunnar, M. R., and Cheatham, C. L. (2003). Brain and behavior interface: Stress and the developing brain. Infant Ment. Health J. 24, 195-211. doi: 10.1002/imhj.10052

Gunnar, M. R., and Donzella, B. (2002). Social regulation of the cortisol levels in early human development. Psychoneuroendocrinology 27, 199-220. doi: 10.1016/S0306-4530(01)00045-2

Gutteling, B. M., de Weerth, C., and Buitelaar, J. K. (2005). Prenatal stress and children's cortisol reaction to the first day of school. Psychoneuroendocrinology 30, 541-549. doi: 10.1016/j.psyneuen.2005.01.002 
Hatakeyama, S., Suzuki, A., Yoshizumi, N., Sato, M., and Nishiya, I. (1991). Glucocorticoid-induced G1 arrest and the release effect of epidermal growth factor on the human salivary gland adenocarcinoma cell. Cell Biol. Int. Rep. 15, 55-65. doi: 10.1016/0309-1651(91)90082-T

Heidbreder, C. A., and Groenewegen, H. J. (2003). The medial prefrontal cortex in the rat: evidence for a dorso-ventral distinction based upon functional and anatomical characteristics. Neurosci. Biobehav. Rev. 27, 555-579. doi: 10.1016/j.neubiorev.2003.09.003

Heijtz, R. D., Fuchs, E., Feldon, J., Pryce, C. R., and Forssberg, H. (2010). Effects of antenatal dexamethasone treatment on glucocorticoid receptor and calcyon gene expression in the prefrontal cortex of neonatal and adult common marmoset monkeys. Behav. Brain Funct. 6:18. doi: 10.1186/1744-9081-6-18

Helmeke, C., Ovtscharoff, W. Jr., Poeggel, G., and Braun, K. (2008). Imbalance of immunohistochemically characterized interneuron populations in the adolescent and adult rodent medial prefrontal cortex after repeated exposure to neonatal separation stress. Neuroscience 152, 18-28. doi: 10.1016/j.neuroscience.2007.12.023

Helmeke, C., Poeggel, G., and Braun, K. (2001). Differential emotional experience induces elevated spine densities on basal dendrites of pyramidal neurons in the anterior cingulate cortex of Octodon degus. Neuroscience 104, 927-931. doi: 10.1016/S0306-4522(01)00201-9

Henckens, M. J., Deussing, J. M., and Chen, A. (2016). Region-specific roles of the corticotropin-releasing factor-urocortin system in stress. Nat. Rev. Neurosci. 17, 636-651. doi: 10.1038/nrn.2016.94

Henry, C., Kabbaj, M., Simon, H., Moal, M., and MacCari, S. (1994). Prenatal stress increases the hypothalamo-pituitary-adrenal axis response in young and adult rats. J. Neuroendocrinol. 6, 341-345. doi: 10.1111/j.1365-2826.1994.tb00591.x

Hensch, T. K. (2005). Critical period plasticity in local cortical circuits. Nat. Rev. Neurosci. 6, 877-888. doi: 10.1038/nrn1787

Herman, J. P., and Cullinan, W. E. (1997). Neurocircuitry of stress: central control of the hypothalamo-pituitary-adrenocortical axis. Trends Neurosci. 20, 78-84. doi: 10.1016/S0166-2236(96)10069-2

Herman, J. P., Cullinan, W. E., Morano, M. I., Akil, H., and Watson, S. J. (1995). Contribution of the ventral subiculum to inhibitory regulation of the hypothalamo-pituitary-adrenocortical axis. J. Neuroendocrinol. 7, 475-482. doi: 10.1111/j.1365-2826.1995.tb00784.x

Herman, J. P., Figueiredo, H., Mueller, N. K., Ulrich-Lai, Y., Ostrander, M. M., Choi, D. C., et al. (2003). Central mechanisms of stress integration: hierarchical circuitry controlling hypothalamo-pituitary-adrenocortical responsiveness. Front. Neuroendocrinol. 24, 151-180. doi: 10.1016/j.yfrne.2003. 07.001

Herman, J. P., Schäfer, M. K., Young, E. A., Thompson, R., Douglass, J., Akil, H., et al. (1989). Evidence for hippocampal regulation of neuroendocrine neurons of the hypothalamo-pituitary-adrenocortical axis. J. Neurosci. 9, 3072-3082.

Hosseini-sharifabad, M., and Hadinedoushan, H. (2007). Prenatal stress induces learning deficits and is associated with a decrease in granules and ca3 cell dendritic tree size in rat hippocampus. Anat. Sci. Int. 82, 211. doi: 10.1111/j.1447-073X.2007.00186.x

Huang, C. C., Chou, P. H., Yang, C. H., and Hsu, K. S. (2005). Neonatal isolation accelerates the developmental switch in the signalling cascades for long-term potentiation induction. J. Physiol. 569(Pt 3), 789-799. doi: 10.1113/jphysiol.2005.098160

Hui, J.-J., Zhang, Z.-J., Liu, S.-S., Xi, G.-J., Zhang, X.-R., Teng, G.-J., et al. (2011). Hippocampal neurochemistry is involved in the behavioural effects of neonatal maternal separation and their reversal by post-weaning environmental enrichment: a magnetic resonance study. Behav. Brain Res. 217, 122-127. doi: 10.1016/j.bbr.2010.10.014

Hulshof, H. J., Novati, A., Sgoifo, A., Luiten, P. G. M., den Boer, J. A., and Meerlo, P. (2011). Maternal separation decreases adult hippocampal cell proliferation and impairs cognitive performance but has little effect on stress sensitivity and anxiety in adult Wistar rats. Behav. Brain Res. 216, 552-560. doi: 10.1016/j.bbr.2010.08.038

Huot, R. L., Gonzalez, M. E., Ladd, C. O., Thrivikraman, K. V., and Plotsky, P. M. (2004). Foster litters prevent hypothalamic-pituitary-adrenal axis sensitization mediated by neonatal maternal separation. Psychoneuroendocrinology 29, 279-289. doi: 10.1016/S0306-4530(03)00028-3

Huot, R. L., Plotsky, P. M., Lenox, R. H., and McNamara, R. K. (2002). Neonatal maternal separation reduces hippocampal mossy fiber density in adult Long Evans rats. Brain Res. 950, 52-63. doi: 10.1016/S0006-8993(02)02985-2
Insel, T. R., Battaglia, G., Fairbanks, D. W., and De Souza, E. B. (1988). The ontogeny of brain receptors for corticotropin-releasing factor and the development of their functional association with adenylate cyclase. J. Neurosci. $8,4151-4158$.

Irles, C., Nava-Kopp, A. T., Morán, J., and Zhang, L. (2014). Neonatal maternal separation up-regulates protein signalling for cell survival in rat hypothalamus. Stress 17, 275-284. doi: 10.3109/10253890.2014.913017

Ishiwata, H., Shiga, T., and Okado, N. (2005). Selective serotonin reuptake inhibitor treatment of early postnatal mice reverses their prenatal stress-induced brain dysfunction. Neuroscience 133, 893-901. doi: 10.1016/j.neuroscience.2005.03.048

Ivy, A. S., Brunson, K. L., Sandman, C., and Baram, T. Z. (2008). Dysfunctional nurturing behavior in rat dams with limited access to nesting material: a clinically relevant model for early-life stress. Neuroscience 154, 1132-1142. doi: 10.1016/j.neuroscience.2008.04.019

Ivy, A. S., Rex, C. S., Chen, Y., Dubé, C., Maras, P. M., Grigoriadis, D. E., et al. (2010). Hippocampal dysfunction and cognitive impairments provoked by chronic early-life stress involve excessive activation of CRH receptors. J. Neurosci. 30, 13005-13015. doi: 10.1523/JNEUROSCI.1784-10.2010

Jaferi, A., and Bhatnagar, S. (2007). Corticotropin-releasing hormone receptors in the medial prefrontal cortex regulate hypothalamic-pituitary-adrenal activity and anxiety-related behavior regardless of prior stress experience. Brain Res. 1186, 212-223. doi: 10.1016/j.brainres.2007.07.100

Jensen Peña, C., Monk, C., and Champagne, F. A. (2012). Epigenetic effects of prenatal stress on 11beta-hydroxysteroid dehydrogenase- 2 in the placenta and fetal brain. PLoS ONE 7:e39791. doi: 10.1371/journal.pone.0039791

Joëls, M. (2008). Functional actions of corticosteroids in the hippocampus. Eur. J. Pharmacol. 583, 312-321. doi: 10.1016/j.ejphar.2007.11.064

Joëls, M., and Baram, T. Z. (2009). The neuro-symphony of stress. Nat. Rev. Neurosci. 10, 459-466. doi: 10.1038/nrn2632

Jovanovic, T., Blanding, N. Q., Norrholm, S. D., Duncan, E., Bradley, B., and Ressler, K. J. (2009). Childhood abuse is associated with increased startle reactivity in adulthood. Depress. Anxiety 26, 1018-1026. doi: 10.1002/da.20599

Judo, C., Matsumoto, M., Yamazaki, D., Hiraide, S., Yanagawa, Y., Kimura, S., et al. (2010). Early stress exposure impairs synaptic potentiation in the rat medial prefrontal cortex underlying contextual fear extinction. Neuroscience 169, 1705-1714. doi: 10.1016/j.neuroscience.2010.06.035

Kajantie, E., and Phillips, D. I. (2006). The effects of sex and hormonal status on the physiological response to acute psychosocial stress. Psychoneuroendocrinology 31, 151-178. doi: 10.1016/j.psyneuen.2005.07.002

Kalinichev, M., Easterling, K. W., Plotsky, P. M., and Holtzman, S. G. (2002). Long-lasting changes in stress-induced corticosterone response and anxiety-like behaviors as a consequence of neonatal maternal separation in Long-Evans rats. Pharmacol. Biochem. Behav. 73, 131-140. doi: 10.1016/S0091-3057(02)00781-5

Kawamura, T., Chen, J., Takahashi, T., Ichitani, Y., and Nakahara, D. (2006). Prenatal stress suppresses cell proliferation in the early developing brain. Neuroreport 17, 1515-1518. doi: 10.1097/01.wnr.0000236849.53682.6d

Kehoe, P., and Bronzino, J. D. (1999). Neonatal stress alters LTP in freely moving male and female adult rats. Hippocampus 9, 651-658. doi: 10.1002/(SICI)1098-1063(1999)9:6<651::AID-HIPO6>3.0.CO;2-P

Kehoe, P., Hoffman, J. H., Austin-LaFrance, R. J., and Bronzino, J. D. (1995). Neonatal isolation enhances hippocampal dentate response to tetanization in freely moving juvenile male rats. Exp. Neurol. 136, 89-97. doi: 10.1006/exnr.1995.1086

Keller-Wood, M., Powers, M. J., Gersting, J. A., Ali, N., and Wood, C. E. (2006). Genomic analysis of neuroendocrine development of fetal brainpituitary-adrenal axis in late gestation. Physiol. Genomics 24, 218-224. doi: 10.1152/physiolgenomics.00176.2005

Kiank, C., Mundt, A., and Schuett, C. (2009). Mild postnatal separation stress reduces repeated stress-induced immunosuppression in adult BALB/c mice. Neuro Endocrinol. Lett. 30, 761-768.

Koehl, M., Darnaudéry, M., Dulluc, J., Van Reeth, O., Moal, M. L., and Maccari, S. (1999). Prenatal stress alters circadian activity of hypothalamo-pituitary-adrenal axis and hippocampal corticosteroid receptors in adult rats of both gender. J. Neurobiol. 40, 302-315. doi: 10.1002/(SICI)1097-4695(19990905)40:3 <302::AID-NEU3 > 3.0.CO;2-7

Koenig, J. I., Elmer, G. I., Shepard, P. D., Lee, P. R., Mayo, C., Joy, B., et al. (2005). Prenatal exposure to a repeated variable stress paradigm elicits behavioral and 
neuroendocrinological changes in the adult offspring: potential relevance to schizophrenia. Behav. Brain Res. 156, 251-261. doi: 10.1016/j.bbr.2004.05.030

Kolb, B., Mychasiuk, R., Muhammad, A., Li, Y., Frost, D. O., and Gibb, R. (2012). Experience and the developing prefrontal cortex. Proc. Natl. Acad. Sci. U.S.A. 109(Suppl. 2), 17186-17193. doi: 10.1073/pnas.1121251109

Kolber, B. J., Roberts, M. S., Howell, M. P., Wozniak, D. F., Sands, M. S., and Muglia, L. J. (2008). Central amygdala glucocorticoid receptor action promotes fear-associated CRH activation and conditioning. Proc. Natl. Acad. Sci. U.S.A. 105, 12004-12009. doi: 10.1073/pnas.0803216105

Korosi, A., Shanabrough, M., McClelland, S., Liu, Z.-W., Borok, E., Gao, X.-B., et al. (2010). Early-life experience reduces excitation to stress-responsive hypothalamic neurons and reprograms the expression of corticotropin-releasing hormone. J. Neurosci. 30, 703-713. doi: 10.1523/JNEUROSCI.4214-09.2010

Kosten, T. A., Karanian, D. A., Yeh, J., Haile, C. N., Kim, J. J., Kehoe, P., et al. (2007). Memory impairments and hippocampal modifications in adult rats with neonatal isolation stress experience. Neurobiol. Learn. Mem. 88, 167-176. doi: 10.1016/j.nlm.2007.03.011

Kraszpulski, M., Dickerson, P. A., and Salm, A. K. (2006). Prenatal stress affects the developmental trajectory of the rat amygdala. Stress 9, 85-95. doi: 10.1080/10253890600798109

Krugers, H. J., Oomen, C. A., Gumbs, M., Li, M., Velzing, E. H., Joels, M., et al. (2012). Maternal deprivation and dendritic complexity in the basolateral amygdala. Neuropharmacology 62, 534-537. doi: 10.1016/j.neuropharm.2011.09.022

Kuma, H., Miki, T., Matsumoto, Y., Gu, H., Li, H.-P., Kusaka, T., et al. (2004). Early maternal deprivation induces alterations in brain-derived neurotrophic factor expression in the developing rat hippocampus. Neurosci. Lett. 372, 68-73. doi: 10.1016/j.neulet.2004.09.012

Labonte, B., Yerko, V., Gross, J., Mechawar, N., Meaney, M. J., Szyf, M., et al. (2012). Differential glucocorticoid receptor exon 1(B), 1(C), and 1(H) expression and methylation in suicide completers with a history of childhood abuse. Biol. Psychiatry 72, 41-48. doi: 10.1016/j.biopsych.2012.01.034

Ladd, C. O., Huot, R. L., Thrivikraman, K. V., Nemeroff, C. B., and Plotsky, P. M. (2004). Long-term adaptations in glucocorticoid receptor and mineralocorticoid receptor mrna and negative feedback on the hypothalamopituitary-adrenal axis following neonatal maternal separation. Biol. Psychiatry 55, 367-375. doi: 10.1016/j.biopsych.2003.10.007

Ladd, C. O., Owens, M. J., and Nemeroff, C. (1996). Persistent changes in corticotropin-releasing factor neuronal systems induced by maternal deprivation. Endocrinology 137, 1212-1218.

Ladd, C. O., Thrivikraman, K. V., Huot, R. L., and Plotsky, P. M. (2005). Differential neuroendocrine responses to chronic variable stress in adult Long Evans rats exposed to handling-maternal separation as neonates. Psychoneuroendocrinology 30, 520-533. doi: 10.1016/j.psyneuen.2004. 12.004

Lajud, N., Roque, A., Cajero, M., Gutiérrez-Ospina, G., and Torner, L. (2012). Periodic maternal separation decreases hippocampal neurogenesis without affecting basal corticosterone during the stress hyporesponsive period, but alters HPA axis and coping behavior in adulthood. Psychoneuroendocrinology 37, 410-420. doi: 10.1016/j.psyneuen.2011.07.011

Laloux, C., Mairesse, J., Van Camp, G., Giovine, A., Branchi, I., Bouret, S., et al. (2012). Anxiety-like behaviour and associated neurochemical and endocrinological alterations in male pups exposed to prenatal stress. Psychoneuroendocrinology 37, 1646-1658. doi: 10.1016/j.psyneuen.2012.02.010

Laviola, G., Rea, M., Morley-Fletcher, S., Di Carlo, S., Bacosi, A., De Simone, R., et al. (2004). Beneficial effects of enriched environment on adolescent rats from stressed pregnancies. Eur. J. Neurosci. 20, 1655-1664. doi: 10.1111/j.1460-9568.2004.03597.x

LeDoux, J. E. (1994). The amygdala: contributions to fear and stress. Semin. Neurosci. 6, 231-237. doi: 10.1006/smns.1994.1030

LeDoux, J. E., Iwata, J., Cicchetti, P., and Reis, D. J. (1988). Different projections of the central amygdaloid nucleus mediate autonomic and behavioral correlates of conditioned fear. J. Neurosci. 8, 2517-2529.

Lee, P. R., Brady, D. L., Shapiro, R. A., Dorsa, D. M., and Koenig, J. I. (2007). Prenatal stress generates deficits in rat social behavior: reversal by oxytocin. Brain Res. 1156, 152-167. doi: 10.1016/j.brainres.2007.04.042

Lee, S. W., Yoo, J. H., Kim, K. W., Lee, J. S., Kim, D., Park, H., et al. (2015). Aberrant function of frontoamygdala circuits in adolescents with previous verbal abuse experiences. Neuropsychologia 79(Pt A), 76-85. doi: 10.1016/j.neuropsychologia.2015.10.029

Lehmann, J., Russig, H., Feldon, J., and Pryce, C. R. (2002). Effect of a single maternal separation at different pup ages on the corticosterone stress response in adult and aged rats. Pharmacol. Biochem. Behav. 73, 141-145. doi: 10.1016/S0091-3057(02)00788-8

Lemaire, V., Koehl, M., Le Moal, M., and Abrous, D. N. (2000). Prenatal stress produces learning deficits associated with an inhibition of neurogenesis in the hippocampus. Proc. Natl. Acad. Sci. U.S.A. 97, 11032-11037. doi: 10.1073/pnas.97.20.11032

Leussis, M. P., Lawson, K., Stone, K., and Andersen, S. L. (2008). The enduring effects of an adolescent social stressor on synaptic density, part II: poststress reversal of synaptic loss in the cortex by adinazolam and MK-801. Synapse 62, 185-192. doi: 10.1002/syn.20483

Leventopoulos, M., Rüedi-Bettschen, D., Knuesel, I., Feldon, J., Pryce, C. R., and Opacka-Juffry, J. (2007). Long-term effects of early life deprivation on brain glia in Fischer rats. Brain Res. 1142, 119-126. doi: 10.1016/j.brainres.2007.01.039

Levine, S. (1994). The ontogeny of the hypothalamic-pituitary-adrenal axis. The influence of maternal factorsa. Ann. N.Y. Acad. Sci. 746, 275-288. doi: 10.1111/j.1749-6632.1994.tb39245.x

Levine, S., Huchton, D. M., Wiener, S. G., and Rosenfeld, P. (1991). Time course of the effect of maternal deprivation on the hypothalamic-pituitary-adrenal axis in the infant rat. Dev. Psychobiol. 24, 547-558. doi: 10.1002/dev.420240803

Levitt, N. S., Lindsay, R. S., Holmes, M. C., and Seckl, J. R. (1996). Dexamethasone in the last week of pregnancy attenuates hippocampal glucocorticoid receptor gene expression and elevates blood pressure in the adult offspring in the rat. Neuroendocrinology 64, 412-418. doi: 10.1159/000127146

Liao, X. M., Yang, X. D., Jia, J., Li, J. T., Xie, X. M., Su, Y. A., et al. (2014). Blockade of corticotropin-releasing hormone receptor 1 attenuates early-life stressinduced synaptic abnormalities in the neonatal hippocampus. Hippocampus 24, 528-540. doi: 10.1002/hipo.22254

Liaudat, A. C., Rodríguez, N., Chen, S., Romanini, M. C., Vivas, A., Rolando, A., et al. (2015). Adrenal response of male rats exposed to prenatal stress and early postnatal stimulation. Biotech. Histochem. 90, 432-438. doi: 10.3109/10520295.2015.1019926

Lin, Y. C., and Koleske, A. J. (2010). Mechanisms of synapse and dendrite maintenance and their disruption in psychiatric and neurodegenerative disorders. Annu. Rev. Neurosci. 33, 349-378. doi: 10.1146/annurev-neuro-060909-153204

Lippmann, M., Bress, A., Nemeroff, C. B., Plotsky, P. M., and Monteggia, L. M. (2007). Long-term behavioural and molecular alterations associated with maternal separation in rats. Eur. J. Neurosci. 25, 3091-3098. doi: 10.1111/j.1460-9568.2007.05522.x

Liston, C., and Gan, W. B. (2011). Glucocorticoids are critical regulators of dendritic spine development and plasticity in vivo. Proc. Natl. Acad. Sci. U.S.A. 108, 16074-16079. doi: 10.1073/pnas.1110444108

Liu, D., Caldji, C., Sharma, S., Plotsky, P. M., and Meaney, M. J. (2000a). Influence of neonatal rearing conditions on stress-induced adrenocorticotropin responses and norepinepherine release in the hypothalamic paraventricular nucleus. J. Neuroendocrinol. 12, 5-12. doi: 10.1046/j.1365-2826.2000.00422.x

Liu, D., Diorio, J., Day, J. C., Francis, D. D., and Meaney, M. J. (2000b). Maternal care, hippocampal synaptogenesis and cognitive development in rats. Nat. Neurosci. 3, 799-806. doi: 10.1038/77702

Liu, D., Diorio, J., Tannenbaum, B., Caldji, C., Francis, D., Freedman, A., et al. (1997). Maternal care, hippocampal glucocorticoid receptors, and hypothalamic-pituitary-adrenal responses to stress. Science 277, 1659-1662. doi: 10.1126/science.277.5332.1659

Llorente, R., Miguel-Blanco, C., Aisa, B., Lachize, S., Borcel, E., Meijer, O. C., et al. (2011). Long term sex-dependent psychoneuroendocrine effects of maternal deprivation and juvenile unpredictable stress in rats. J. Neuroendocrinol. 23, 329-344. doi: 10.1111/j.1365-2826.2011.02109.x

Loi, M., Mossink, J. C., Meerhoff, G. F., Den Blaauwen, J. L., Lucassen, P. J., and Joëls, M. (2017). Effects of early-life stress on cognitive function and hippocampal structure in female rodents. Neuroscience 342, 101-119. doi: 10.1016/j.neuroscience.2015.08.024

Lolait, S. J., Stewart, L. Q., Jessop, D. S., Young, W. S., and O'Carroll, A.-M. (2007). The hypothalamic-pituitary-adrenal axis response to stress in mice lacking functional vasopressin V1b receptors. Endocrinology 148, 849-856. doi: 10.1210/en.2006-1309 
Luecken, L. J., Hagan, M. J., Wolchik, S. A., Sandler, I. N., and Tein, J. Y. (2016). A longitudinal study of the effects of child-reported maternal warmth on cortisol stress response 15 years after parental divorce. Psychosom. Med. 78, 163-170. doi: 10.1097/PSY.0000000000000251

Lukas, M., Bredewold, R., Landgraf, R., Neumann, I. D., and Veenema, A. H. (2011). Early life stress impairs social recognition due to a blunted response of vasopressin release within the septum of adult male rats. Psychoneuroendocrinology 36, 843-853. doi: 10.1016/j.psyneuen.2010.11.007

Lupien, S. J., McEwen, B. S., Gunnar, M. R., and Heim, C. (2009). Effects of stress throughout the lifespan on the brain, behaviour and cognition. Nat. Rev. Neurosci. 10, 434-445. doi: 10.1038/nrn2639

Maccari, S., Krugers, H. J., Morley-Fletcher, S., Szyf, M., and Brunton, P. J. (2014). The consequences of early-life adversity: neurobiological, behavioural and epigenetic adaptations. J. Neuroendocrinol. 26, 707-723. doi: 10.1111/jne.12175

Maccari, S., Piazza, P. V., Kabbaj, M., Barbazanges, A., Simon, H., and Le Moal, M. (1995). Adoption reverses the long-term impairment in glucocorticoid feedback induced by prenatal stress. J. Neurosci. 15, 110-116.

MacMillan, H. L., Fleming, J. E., Streiner, D. L., Lin, E., Boyle, M. H., Jamieson, E., et al. (2001). Childhood abuse and lifetime psychopathology in a community sample. Am. J. Psychiatry 158, 1878-1883. doi: 10.1176/appi.ajp.158.11.1878

Macrì, S., Chiarotti, F., and Wurbel, H. (2008). Maternal separation and maternal care act independently on the development of HPA responses in male rats. Behav. Brain Res. 191, 227-234. doi: 10.1016/j.bbr.2008.03.031

Madhyastha, S., Sekhar, S., and Rao, G. (2013). Resveratrol improves postnatal hippocampal neurogenesis and brain derived neurotrophic factor in prenatally stressed rats. Int. J. Dev. Neurosci. 31, 580-585. doi: 10.1016/j.ijdevneu.2013.06.010

Maercker, A., Michael, T., Fehm, L., Becker, E. S., and Margraf, J. (2004). Age of traumatisation as a predictor of post-traumatic stress disorder or major depression in young women. Br. J. Psychiatry 184, 482-487. doi: 10.1192/bjp.184.6.482

Mairesse, J., Lesage, J., Breton, C., Bréant, B., Hahn, T., Darnaudéry, M., et al. (2007). Maternal stress alters endocrine function of the fetoplacental unit in rats. Am. J. Physiol. Endocrinol. Metab. 292, 1526-1533. doi: 10.1152/ajpendo.00574.2006

Majzoub, J. A., Emanuel, R., Adler, G., Martinez, C., Robinson, B., and Wittert, G. (1993). Second messenger regulation of mRNA for corticotropin-releasing factor. Ciba Found. Symp. 172, 30-43; discussion: 43-58.

Makino, S., Gold, P. W., and Schulkin, J. (1994). Corticosterone effects on corticotropin-releasing hormone mRNA in the central nucleus of the amygdala and the parvocellular region of the paraventricular nucleus of the hypothalamus. Brain Res. 640, 105-112. doi: 10.1016/0006-8993(94)91862-7

Mandyam, C. D., Crawford, E. F., Eisch, A. J., Rivier, C. L., and Richardson, H. N. (2008). Stress experienced in utero reduces sexual dichotomies in neurogenesis, microenvironment, and cell death in the adult rat hippocampus. Dev. Neurobiol. 68, 575-589. doi: 10.1002/dneu.20600

Maras, P. M., and Baram, T. Z. (2012). Sculpting the hippocampus from within: stress, spines, and CRH. Trends Neurosci. 35, 315-324. doi: 10.1016/j.tins.2012.01.005

Markham, J. A., Taylor, A. R., Taylor, S. B., Bell, D. B., and Koenig, J. I. (2010). Characterization of the cognitive impairments induced by prenatal exposure to stress in the rat. Front. Behav. Neurosci. 4:173. doi: 10.3389/fnbeh.2010.00173

Marmendal, M., Eriksson, C. J. P., and Fahlke, C. (2006). Early deprivation increases exploration and locomotion in adult male Wistar offspring. Pharmacol. Biochem. Behav. 85, 535-544. doi: 10.1016/j.pbb.2006.10.005

Martínez-Téllez, R. I., Hernández-Torres, E., Gamboa, C., and Flores, G. (2009). Prenatal stress alters spine density and dendritic length of nucleus accumbens and hippocampus neurons in rat offspring. Synapse 63, 794-804. doi: 10.1002/syn.20664

Masson, M., Bussieres, E.-L., East-Richard, C., R-Mercier, A., and Cellard, C. (2015). Neuropsychological profile of children, adolescents and adults experiencing maltreatment: a meta-analysis. Clin. Neuropsychol. 29, 573-594. doi: 10.1080/13854046.2015.1061057

Matthews, S. G. (2002). Early programming of the hypothalamopituitary-adrenal axis. Trends Endocrinol. Metab. 13, 373-380. doi: 10.1016/S1043-2760(02)00690-2

McCormick, C. M., Kehoe, P., and Kovacs, S. (1998). Corticosterone release in response to repeated, short episodes of neonatal isolation: evidence of sensitization. Int. J. Dev. Neurosci. 16, 175-185. doi: 10.1016/S0736-5748(98)00026-4

McCormick, C. M., Mathews, I. Z., Thomas, C., and Waters, P. (2010). Investigations of HPA function and the enduring consequences of stressors in adolescence in animal models. Brain Cogn. 72, 73-85. doi: 10.1016/j.bandc.2009.06.003

McCormick, C. M., Smythe, J. W., Sharma, S., and Meaney, M. J. (1995). Sexspecific effects of prenatal stress on hypothalamic-pituitary-adrenal responses to stress and brain glucocorticoid receptor density in adult rats. Dev. Brain Res. 84, 55-61. doi: 10.1016/0165-3806(94)00153-Q

McEwen, B. S. (2003). Mood disorders and allostatic load. Biol. Psychiatry 54, 200-207. doi: 10.1016/S0006-3223(03)00177-X

McEwen, B. S. (2007). Physiology and neurobiology of stress and adaptation: central role of the brain. Physiol. Rev. 87, 873-904. doi: 10.1152/physrev.00041.2006

McGowan, P. O. (2013). Epigenomic mechanisms of early adversity and hpa dysfunction: considerations for PTSD research. Front. Psychiatry 4:110. doi: 10.3389/fpsyt.2013.00110

McGowan, P. O., Sasaki, A., D’Alessio, A. C., Dymov, S., Labonté, B., Szyf, M., et al. (2009). Epigenetic regulation of the glucocorticoid receptor in human brain associates with childhood abuse. Nat. Neurosci. 12, 342-348. doi: $10.1038 / \mathrm{nn} .2270$

McGowan, P. O., Suderman, M., Sasaki, A., Huang, T. C., Hallett, M., Meaney, M. J., et al. (2011). Broad epigenetic signature of maternal care in the brain of adult rats. PLoS ONE 6:e14739. doi: 10.1371/journal.pone.0014739

McKay, L. I., and Cidlowski, J. A. (2003). "Physiologic and pharmacologic effects of corticosteroids," in Holland-Frei Cancer Medicine, 6th Edn., eds D. W. Kufe, R. E. Pollock, R. R. Weichselbaum, R. C. Bast, T. S. Gansler, J. F. Holland, and E. Frei (Hamilton, ON: B.C. Decker).

McLaughlin, R. J., Verlezza, S., Gray, J. M., Hill, M. N., and Walker, C.-D. (2016). Inhibition of anandamide hydrolysis dampens the neuroendocrine response to stress in neonatal rats subjected to suboptimal rearing conditions. Stress 19, 114-124. doi: 10.3109/10253890.2015.1117448

Meaney, M. J., Aitken, D. H., Bodnoff, S. R., Iny, L. J., Tatarewicz, J. E., and Sapolsky, R. M. (1985a). Early postnatal handling alters glucocorticoid receptor concentrations in selected brain regions. Behav. Neurosci. 99, 765-770. doi: 10.1037/0735-7044.99.4.765

Meaney, M. J., Sapolsky, R. M., and McEwen, B. S. (1985b). The development of the glucocorticoid receptor system in the rat limbic brain. I. Ontogeny and autoregulation. Brain Res. 350, 159-164. doi: 10.1016/0165-3806(85) 90259-7

Mehta, M., and Schmauss, C. (2011). Strain-specific cognitive deficits in adult mice exposed to early life stress. Behav. Neurosci. 125, 29-36. doi: 10.1037/a0021952

Meyer, J. S. (1983). Early adrenalectomy stimulates subsequent growth and development of the rat brain. Exp. Neurol. 82, 432-446. doi: 10.1016/0014-4886(83)90415-6

Michelsen, K. A., van den Hove, D. L., Schmitz, C., Segers, O., Prickaerts, J., and Steinbusch, H. W. (2007). Prenatal stress and subsequent exposure to chronic mild stress influence dendritic spine density and morphology in the rat medial prefrontal cortex. BMC Neurosci. 8:107. doi: 10.1186/1471-2202-8-107

Mirescu, C., Peters, J. D., and Gould, E. (2004). Early life experience alters response of adult neurogenesis to stress. Nat. Neurosci. 7, 841-846. doi: 10.1038/nn1290

Monroy, E., Hernández-Torres, E., and Flores, G. (2010). Maternal separation disrupts dendritic morphology of neurons in prefrontal cortex, hippocampus, and nucleus accumbens in male rat offspring. J. Chem. Neuroanat. 40, 93-101. doi: 10.1016/j.jchemneu.2010.05.005

Moriceau, S., Shionoya, K., Jakubs, K., and Sullivan, R. M. (2009). Early-life stress disrupts attachment learning: the role of amygdala corticosterone, locus ceruleus corticotropin releasing hormone, and olfactory bulb norepinephrine. J. Neurosci. 29, 15745-15755. doi: 10.1523/JNEUROSCI.4106-09.2009

Moriceau, S., Wilson, D. A., Levine, S., and Sullivan, R. M. (2006). Dual circuitry for odor-shock conditioning during infancy: corticosterone switches between fear and attraction via amygdala. J. Neurosci. 26, 6737-6748. doi: 10.1523/JNEUROSCI.0499-06.2006

Morley-Fletcher, S., Mairesse, J., Soumier, A., Banasr, M., Fagioli, F., Gabriel, C., et al. (2011). Chronic agomelatine treatment corrects behavioral, cellular, and biochemical abnormalities induced by prenatal stress in rats. Psychopharmacology 217, 301-313. doi: 10.1007/s00213-011-2280-x 
Moussaoui, N., Jacobs, J. P., Larauche, M., Biraud, M., Million, M., Mayer, E., et al. (2017). Chronic early-life stress in rat pups alters basal corticosterone, intestinal permeability, and fecal microbiota at weaning: influence of sex. $J$. Neurogastroenterol. Motil. 23, 135-143. doi: 10.5056/jnm16105

Moussaoui, N., Larauche, M., Biraud, M., Molet, J., Million, M., Mayer, E., et al. (2016). Limited nesting stress alters maternal behavior and in vivo intestinal permeability in male wistar pup rats. PLOS ONE 11:e0155037. doi: 10.1371/journal.pone.0155037

Mueller, B. R., and Bale, T. L. (2008). Sex-specific programming of offspring emotionality after stress early in pregnancy. J. Neurosci. 28, 9055-9065. doi: 10.1523/JNEUROSCI.1424-08.2008

Muhammad, A., Carroll, C., and Kolb, B. (2012). Stress during development alters dendritic morphology in the nucleus accumbens and prefrontal cortex. Neuroscience 216, 103-109. doi: 10.1016/j.neuroscience.2012.04.041

Murgatroyd, C., Patchev, A. V., Wu, Y., Micale, V., Bockmuhl, Y., Fischer, D., et al. (2009). Dynamic DNA methylation programs persistent adverse effects of early-life stress. Nat. Neurosci. 12, 1559-1566. doi: 10.1038/nn.2436

Murmu, M. S., Salomon, S., Biala, Y., Weinstock, M., Braun, K., and Bock, J. (2006). Changes of spine density and dendritic complexity in the prefrontal cortex in offspring of mothers exposed to stress during pregnancy. Eur. J. Neurosci. 24, 1477-1487. doi: 10.1111/j.1460-9568.2006.05024.x

Murphy, B. E. P. (1973). Steroid arteriovenous differences in umbilical cord plasma: evidence of cortisol production by the human fetus in early gestation. J. Clin. Endocrinol. Metab. 36, 1037-1038. doi: 10.1210/jcem-36-5-1037

Mychasiuk, R., Gibb, R., and Kolb, B. (2012). Prenatal stress alters dendritic morphology and synaptic connectivity in the prefrontal cortex and hippocampus of developing offspring. Synapse 66, 308-314. doi: $10.1002 /$ syn. 21512

Mychasiuk, R., Ilnytskyy, S., Kovalchuk, O., Kolb, B., and Gibb, R. (2011). Intensity matters: brain, behaviour and the epigenome of prenatally stressed rats. Neuroscience 180, 105-110. doi: 10.1016/j.neuroscience.2011.02.026

Naninck, E. F., Hoeijmakers, L., Kakava-Georgiadou, N., Meesters, A., Lazic, S. E., Lucassen, P. J., et al. (2015). Chronic early life stress alters developmental and adult neurogenesis and impairs cognitive function in mice. Hippocampus 25, 309-328. doi: 10.1002/hipo.22374

Nederhof, E., and Schmidt, M. V. (2012). Mismatch or cumulative stress: toward an integrated hypothesis of programming effects. Physiol. Behav. 106, 691-700. doi: 10.1016/j.physbeh.2011.12.008

Negrón-Oyarzo, I., Neira, D., Espinosa, N., Fuentealba, P., and Aboitiz, F. (2015). Prenatal stress produces persistence of remote memory and disrupts functional connectivity in the hippocampal-prefrontal cortex axis. Cereb. Cortex 25, 3132-3143. doi: 10.1093/cercor/bhu108

Noorlander, C. W., De Graan, P. N. E., Middeldorp, J., Van Beers, J. J. B. C., and Visser, G. H. A. (2006). Ontogeny of hippocampal corticosteroid receptors: effects of antenatal glucocorticoids in human and mouse. J. Comp. Neurol. 499, 924-932. doi: 10.1002/cne.21162

Nowicka, D., Soulsby, S., Skangiel-Kramska, J., and Glazewski, S. (2009). Parvalbumin-containing neurons, perineuronal nets and experiencedependent plasticity in murine barrel cortex. Eur. J. Neurosci. 30, 2053-2063. doi: $10.1111 / j .1460-9568.2009 .06996 . x$

Nugent, N. R., Tyrka, A. R., Carpenter, L. L., and Price, L. H. (2011). Geneenvironment interactions: early life stress and risk for depressive and anxiety disorders. Psychopharmacology 214, 175-196. doi: 10.1007/s00213-010-2151-x

O'Connor, T. G., Ben-Shlomo, Y., Heron, J., Golding, J., Adams, D., and Glover, V. (2005). Prenatal anxiety predicts individual differences in cortisol in pre-adolescent children. Biol. Psychiatry 58, 211-217. doi: 10.1016/j.biopsych.2005.03.032

Ohkawa, T., Rohde, W., Takeshita, S., Dörner, G., Arai, K., and Okinaga, S. (1991). Effect of an acute maternal stress on the fetal hypothalamo-pituitary-adrenal system in late gestational life of the rat. Exp. Clin. Endocrinol. Diab. 98, 123-129. doi: 10.1055/s-0029-1211108

Oitzl, M. S., Champagne, D. L., van der Veen, R., and de Kloet, E. R. (2010). Brain development under stress: hypotheses of glucocorticoid actions revisited. Neurosci. Biobehav. Rev. 34, 853-866. doi: 10.1016/j.neubiorev.2009.07.006

O'Malley, D., Dinan, T. G., and Cryan, J. F. (2011). Neonatal maternal separation in the rat impacts on the stress responsivity of central corticotropinreleasing factor receptors in adulthood. Psychopharmacology 214, 221-229. doi: $10.1007 /$ s00213-010-1885-9
Ono, M., Kikusui, T., Sasaki, N., Ichikawa, M., Mori, Y., and Murakami-Murofushi, K. (2008). Early weaning induces anxiety and precocious myelination in the anterior part of the basolateral amygdala of male Balb/c mice. Neuroscience 156, 1103-1110. doi: 10.1016/j.neuroscience.2008.07.078

Oomen, C. A., Girardi, C. E., Cahyadi, R., Verbeek, E. C., Krugers, H., Joëls, M., et al. (2009). Opposite effects of early maternal deprivation on neurogenesis in male versus female rats. PLoS ONE 4:e3675. doi: 10.1371/journal.pone. 0003675

Oomen, C. A., Soeters, H., Audureau, N., Vermunt, L., van Hasselt, F. N., Manders, E. M., et al. (2011). Early maternal deprivation affects dentate gyrus structure and emotional learning in adult female rats. Psychopharmacology 214, 249-260. doi: 10.1007/s00213-010-1922-8

Oomen, C. A., Soeters, H., Audureau, N., Vermunt, L., van Hasselt, F. N., Manders, E. M., et al. (2010). Severe early life stress hampers spatial learning and neurogenesis, but improves hippocampal synaptic plasticity and emotional learning under high-stress conditions in adulthood. J. Neurosci. 30, 6635-6645. doi: 10.1523/JNEUROSCI.0247-10.2010

Ovtscharoff, W. Jr., and Braun, K. (2001). Maternal separation and social isolation modulate the postnatal development of synaptic composition in the infralimbic cortex of Octodon degus. Neuroscience 104, 33-40. doi: 10.1016/S0306-4522(01)00059-8

Pariante, C. M. (2006). The glucocorticoid receptor: part of the solution or part of the problem? J. Psychopharmacol. 20, 79-84. doi: 10.1177/1359786806066063

Pariante, C. M., and Lightman, S. L. (2008). The HPA axis in major depression: classical theories and new developments. Trends Neurosci. 31, 464-468. doi: 10.1016/j.tins.2008.06.006

Penke, Z., Felszeghy, K., Fernette, B., Sage, D., Nyakas, C., and Burlet, A. (2001). Postnatal maternal deprivation produces long-lasting modifications of the stress response, feeding and stress-related behaviour in the rat. Eur. J. Neurosci. 14, 747-755. doi: 10.1046/j.0953-816x.2001.01691.x

Pérez-Laso, C., Segovia, S., Martín, J. L. R., Ortega, E., Gómez, F., and Del Cerro, M. C. R. (2008). Environmental prenatal stress alters sexual dimorphism of maternal behavior in rats. Behav. Brain Res. 187, 284-288. doi: 10.1016/j.bbr.2007.09.029

Peters, D. A. (1982). Prenatal stress: effects on brain biogenic amine and plasma corticosterone levels. Pharmacol. Biochem. Behav. 17, 721-725. doi: 10.1016/0091-3057(82)90353-7

Pitzer, M., Jennen-Steinmetz, C., Esser, G., Schmidt, M. H., and Laucht, M. (2011). Prediction of preadolescent depressive symptoms from child temperament, maternal distress, and gender: results of a prospective, longitudinal study. $J$. Dev. Behav. Pediatr. 32, 18-26. doi: 10.1097/DBP.0b013e3181f4a474

Pizzorusso, T., Medini, P., Berardi, N., Chierzi, S., Fawcett, J. W., and Maffei, L. (2002). Reactivation of ocular dominance plasticity in the adult visual cortex. Science 298, 1248-1251. doi: 10.1126/science.1072699

Plotsky, P. M., and Meaney, M. J. (1993). Early, postnatal experience alters hypothalamic corticotropin-releasing factor (CRF) mRNA, median eminence CRF content and stress-induced release in adult rats. Mol. Brain Res. 18, 195-200. doi: 10.1016/0169-328X(93)90189-V

Plotsky, P. M., Thrivikraman, K. V., Nemeroff, C. B., Caldji, C., Sharma, S., and Meaney, M. J. (2005). Long-term consequences of neonatal rearing on central corticotropin-releasing factor systems in adult male rat offspring. Neuropsychopharmacology 30, 2192-2204. doi: 10.1038/sj.npp. 1300769

Pollak, S. D., Messner, M., Kistler, D. J., and Cohn, J. F. (2009). Development of perceptual expertise in emotion recognition. Cognition 110, 242-247. doi: 10.1016/j.cognition.2008.10.010

Pollak, S. D., and Sinha, P. (2002). Effects of early experience on children's recognition of facial displays of emotion. Dev. Psychol. 38, 784-791. doi: 10.1037/0012-1649.38.5.784

Pollak, S. D., and Tolley-Schell, S. A. (2003). Selective attention to facial emotion in physically abused children. J. Abnorm. Psychol. 112, 323-338. doi: 10.1037/0021-843X.112.3.323

Pryce, C. R. (2008). Postnatal ontogeny of expression of the corticosteroid receptor genes in mammalian brains: inter-species and intra-species differences. Brain Res. Rev. 57, 596-605. doi: 10.1016/j.brainresrev.2007.08.005

Pryce, C. R., Bettschen, D., and Feldon, J. (2001). Comparison of the effects of early handling and early deprivation on maternal care in the rat. Dev. Psychobiol. 38, 239-251. doi: 10.1002/dev.1018 
Pryce, C. R., Bettschen, D., Nanz-Bahr, N. I., and Feldon, J. (2003). Comparison of the effects of early handling and early deprivation on conditioned stimulus, context, and spatial learning and memory in adult rats. Behav. Neurosci. 117, 883-893. doi: 10.1037/0735-7044.117.5.883

Radley, J. J., Arias, C. M., and Sawchenko, P. E. (2006). Regional differentiation of the medial prefrontal cortex in regulating adaptive responses to acute emotional stress. J. Neurosci. 26, 12967-12976. doi: 10.1523/JNEUROSCI.4297-06.2006

Rana, S., Pugh, P. C., Jackson, N., Clinton, S. M., and Kerman, I. A. (2015). Inborn stress reactivity shapes adult behavioral consequences of early-life maternal separation stress. Neurosci. Lett. 584, 146-150. doi: 10.1016/j.neulet.2014.10.011

Rees, S. L., Steiner, M., and Fleming, A. S. (2006). Early deprivation, but not maternal separation, attenuates rise in corticosterone levels after exposure to a novel environment in both juvenile and adult female rats. Behav. Brain Res. 175, 383-391. doi: 10.1016/j.bbr.2006.09.013

Refojo, D., and Holsboer, F. (2009). CRH signaling. Molecular specificity for drug targeting in the CNS. Ann. N.Y. Acad. Sci. 1179, 106-119. doi: 10.1111/j.1749-6632.2009.04983.x

Renard, G. M., Rivarola, M. A., and Suarez, M. M. (2007). Sexual dimorphism in rats: effects of early maternal separation and variable chronic stress on pituitary-adrenal axis and behavior. Int. J. Dev. Neurosci. 25, 373-379. doi: 10.1016/j.ijdevneu.2007.07.001

Renard, G. M., Rivarola, M. A., and Suarez, M. M. (2010). Genderdependent effects of early maternal separation and variable chronic stress on vasopressinergic activity and glucocorticoid receptor expression in adult rats. Dev. Neurosci. 32, 71-80. doi: 10.1159/000280102

Reul, J. M., and de Kloet, E. R. (1985). Two receptor systems for corticosterone in rat brain: microdistribution and differential occupation. Endocrinology 117, 2505-2511. doi: 10.1210/endo-117-6-2505

Rhees, R. W., Lephart, E. D., and Eliason, D. (2001). Effects of maternal separation during early postnatal development on male sexual behavior and female reproductive function. Behav. Brain Res. 123, 1-10. doi: 10.1016/S0166-4328(00)00381-8

Rice, C. J., Sandman, C. A., Lenjavi, M. R., and Baram, T. Z. (2008). A novel mouse model for acute and long-lasting consequences of early life stress. Endocrinology 149, 4892-4900. doi: 10.1210/en.2008-0633

Roceri, M., Cirulli, F., Pessina, C., Peretto, P., Racagni, G., and Riva, M. A. (2004). Postnatal repeated maternal deprivation produces age-dependent changes of brain-derived neurotrophic factor expression in selected rat brain regions. Biol. Psychiatry 55, 708-714. doi: 10.1016/j.biopsych.2003.12.011

Rohleder, N., Joksimovic, L., Wolf, J. M., and Kirschbaum, C. (2004). Hypocortisolism and increased glucocorticoid sensitivity of pro-Inflammatory cytokine production in Bosnian war refugees with posttraumatic stress disorder. Biol. Psychiatry 55, 745-751. doi: 10.1016/j.biopsych.2003.11.018

Romano-López, A., Mendez-Diaz, M., Garcia, F. G., Regalado-Santiago, C., RuizContreras, A. E., and Prospero-Garcia, O. (2016). Maternal separation and early stress cause long-lasting effects on dopaminergic and endocannabinergic systems and alters dendritic morphology in the nucleus accumbens and frontal cortex in rats. Dev. Neurobiol. 76, 819-831. doi: 10.1002/dneu. 22361

Romeo, R. D., Mueller, A., Sisti, H. M., Ogawa, S., McEwen, B. S., and Brake, W. G. (2003). Anxiety and fear behaviors in adult male and female C57BL/6 mice are modulated by maternal separation. Horm. Behav. 43, 561-567. doi: 10.1016/S0018-506X(03)00063-1

Roth, T. L., Lubin, F. D., Funk, A. J., and Sweatt, J. D. (2009). Lasting epigenetic influence of early-life adversity on the BDNF gene. Biol. Psychiatry 65, 760-769. doi: 10.1016/j.biopsych.2008.11.028

Rüedi-Bettschen, D., Pedersen, E.-M., Feldon, J., and Pryce, C. R. (2005). Early deprivation under specific conditions leads to reduced interest in reward in adulthood in Wistar rats. Behav. Brain Res. 156, 297-310. doi: 10.1016/j.bbr.2004.06.001

Rüedi-Bettschen, D., Zhang, W., Russig, H., Ferger, B., Weston, A., Pedersen, E.-M., et al. (2006). Early deprivation leads to altered behavioural, autonomic and endocrine responses to environmental challenge in adult Fischer rats. Eur. J. Neurosci. 24, 2879-2893. doi: 10.1111/j.1460-9568.2006.05158.x

Ryan, S. J., Ehrlich, D. E., and Rainnie, D. G. (2016). Morphology and dendritic maturation of developing principal neurons in the rat basolateral amygdala. Brain Struct. Funct. 221, 839-854. doi: 10.1007/s00429-014-0939-x
Sadler, T. R., Nguyen, P. T., Yang, J., Givrad, T. K., Mayer, E. A., Maarek, J. M., et al. (2011). Antenatal maternal stress alters functional brain responses in adult offspring during conditioned fear. Brain Res. 1385, 163-174. doi: 10.1016/j.brainres.2011.01.104

Salm, A. K., Pavelko, M., Krouse, E. M., Webster, W., Kraszpulski, M., and Birkle, D. L. (2004). Lateral amygdaloid nucleus expansion in adult rats is associated with exposure to prenatal stress. Dev. Brain Res. 148, 159-167. doi: 10.1016/j.devbrainres.2003.11.005

Sánchez, I., Goya, L., Vallerga, A. K., and Firestone, G. L. (1993). Glucocorticoids reversibly arrest rat hepatoma cell growth by inducing an early G1 block in cell cycle progression. Cell Growth Differ. 4, 215-225.

Sandi, C., and Haller, J. (2015). Stress and the social brain: behavioural effects and neurobiological mechanisms. Nat. Rev. Neurosci. 16, 290-304. doi: $10.1038 / \mathrm{nrn} 3918$

Santarelli, S., Lesuis, S. L., Wang, X. D., Wagner, K. V., Hartmann, J., Labermaier, C., et al. (2014). Evidence supporting the match/mismatch hypothesis of psychiatric disorders. Eur. Neuropsychopharmacol. 24, 907-918. doi: 10.1016/j.euroneuro.2014.02.002

Sapolsky, R. M., and Meaney, M. J. (1986). Maturation of the adrenocortical stress response: neuroendocrine control mechanisms and the stress hyporesponsive period. Brain Res. Rev. 11, 65-76. doi: 10.1016/0165-0173(86)90010-X

Sapolsky, R. M., McEwen, B. S., and Rainbow, T. C. (1983). Quantitative autoradiography of $[3 \mathrm{H}]$ corticosterone receptors in rat brain. Brain Res. 271, 331-334. doi: 10.1016/0006-8993(83)90295-0

Sapolsky, R. M., Meaney, M. J., and McEwen, B. S. (1985). The development of the glucocorticoid receptor system in the rat limbic brain. III. Negative-feedback regulation. Dev. Brain Res. 18, 169-173. doi: 10.1016/0165-3806(85)90261-5

Sarrieau, A., Sharma, S., and Meaney, M. J. (1988). Postnatal development and environmental regulation of hippocampal glucocorticoid and mineralocorticoid receptors. Brain Res. 471, 158-162. doi: 10.1016/0165-3806(88)90162-9

Schierloh, A., Deussing, J., Wurst, W., Zieglgansberger, W., and Rammes, G. (2007). Corticotropin-releasing factor (CRF) receptor type 1dependent modulation of synaptic plasticity. Neurosci. Lett. 416, 82-86. doi: 10.1016/j.neulet.2007.01.047

Schmidt, M., Enthoven, L., van der Mark, M., Levine, S., de Kloet, E. R., and Oitzl, M. S. (2003). The postnatal development of the hypothalamicpituitary-adrenal axis in the mouse. Int. J. Dev. Neurosci. 21, 125-132. doi: 10.1016/S0736-5748(03)00030-3

Schmidt, M., Enthoven, L., Van Woezik, J. H. G., Levine, S., De Kloet, E. R., and Oitzl, M. S. (2004). The dynamics of the hypothalamic-pituitaryadrenal axis during maternal deprivation. J. Neuroendocrinol. 16, 52-57. doi: 10.1111/j.1365-2826.2004.01123.x

Schubert, D., Martens, G. J., and Kolk, S. M. (2015). Molecular underpinnings of prefrontal cortex development in rodents provide insights into the etiology of neurodevelopmental disorders. Mol. Psychiatry 20, 795-809. doi: $10.1038 / \mathrm{mp} .2014 .147$

Schulkin, J. (2006). Angst and the amygdala. Dialogues Clin. Neurosci. 8, 407-416.

Scott, R. E., and Pintar, J. E. (1993). Developmental regulation of proopiomelanocortin gene expression in the fetal and neonatal rat pituitary. Mol. Endocrinol. 7, 585-596.

Seckl, J. R. (2008). Glucocorticoids, developmental 'programming' and the risk of affective dysfunction. Prog. Brain Res. 167, 17-34. doi: 10.1016/S0079-6123(07)67002-2

Seidel, K., Helmeke, C., Poeggel, G., and Braun, K. (2008). Repeated neonatal separation stress alters the composition of neurochemically characterized interneuron subpopulations in the rodent dentate gyrus and basolateral amygdala. Dev. Neurobiol. 68, 1137-1152. doi: 10.1002/dneu.20651

Shackman, J. E., Shackman, A. J., and Pollak, S. D. (2007). Physical abuse amplifies attention to threat and increases anxiety in children. Emotion 7, 838-852. doi: $10.1037 / 1528-3542.7 .4 .838$

Shams, M., Kilby, M. D., Somerset, D. A., Howie, A. J., Gupta, A., Wood, P. J., et al. (1998). 11Beta-hydroxysteroid dehydrogenase type 2 in human pregnancy and reduced expression in intrauterine growth restriction. Hum. Reprod. 13, 799-804. doi: 10.1093/humrep/13.4.799

Silberman, D. M., Acosta, G. B., and Zorrilla Zubilete, M. A. (2016). Long-term effects of early life stress exposure: role of epigenetic mechanisms. Pharmacol. Res. 109, 64-73. doi: 10.1016/j.phrs.2015.12.033 
Slotten, H. A., Kalinichev, M., Hagan, J. J., Marsden, C. A., and Fone, K. C. F. (2006). Long-lasting changes in behavioural and neuroendocrine indices in the rat following neonatal maternal separation: gender-dependent effects. Brain Res. 1097, 123-132. doi: 10.1016/j.brainres.2006.04.066

Smith, M. A., Kim, S.-Y., van Oers, H. J., and Levine, S. (1997). Maternal deprivation and stress induce immediate early genes in the infant rat brain. Endocrinology 138, 4622-4628. doi: 10.1210/endo.138.11.5529

Son, G. H., Geum, D., Chung, S., Kim, E. J., Jo, J. H., Kim, C. M., et al. (2006). Maternal stress produces learning deficits associated with impairment of NMDA receptor-mediated synaptic plasticity. J. Neurosci. 26, 3309-3318. doi: 10.1523/JNEUROSCI.3850-05.2006

Sotnikov, S., Wittmann, A., Bunck, M., Bauer, S., Deussing, J., Schmidt, M., et al. (2014). Blunted HPA axis reactivity reveals glucocorticoid system dysbalance in a mouse model of high anxiety-related behavior. Psychoneuroendocrinology 48, 41-51. doi: 10.1016/j.psyneuen.2014.06.006

Sowa, J., Bobula, B., Glombik, K., Slusarczyk, J., Basta-Kaim, A., and Hess, G. (2015). Prenatal stress enhances excitatory synaptic transmission and impairs long-term potentiation in the frontal cortex of adult offspring rats. PLOS ONE 10:e0119407. doi: 10.1371/journal.pone.0119407

Stanton, M. E., Gutierrez, Y. R., and Levine, S. (1988). Maternal deprivation potentiates pituitary-adrenal stress responses in infant rats. Behav. Neurosci. 102, 692-700. doi: 10.1037/0735-7044.102.5.692

St-Cyr, S., and McGowan, P. O. (2015). Programming of stress-related behavior and epigenetic neural gene regulation in mice offspring through maternal exposure to predator odor. Front. Behav. Neurosci. 9:145. doi: 10.3389/fnbeh.2015.00145

Steckler, T., and Holsboer, F. (1999). Corticotropin-releasing hormone receptor subtypes and emotion. Biol. Psychiatry 46, 1480-1508. doi: 10.1016/S0006-3223(99)00170-5

Stratakis, C. A., and Chrousos, G. P. (1995). Neuroendocrinology and pathophysiology of the stress system. Ann. N.Y. Acad. Sci. 771, 1-18. doi: 10.1111/j.1749-6632.1995.tb44666.x

Sullivan, R. M., and Holman, P. J. (2010). Transitions in sensitive period attachment learning in infancy: the role of corticosterone. Neurosci. Biobehav. Rev. 34, 835-844. doi: 10.1016/j.neubiorev.2009.11.010

Sullivan, R. M., Landers, M., Yeaman, B., and Wilson, D. A. (2000). Good memories of bad events in infancy. Nature 407, 38-39. doi: 10.1038/35024156

Sutanto, W., Rosenfeld, P., de Kloet, E. R., and Levine, S. (1996). Longterm effects of neonatal maternal deprivation and ACTH on hippocampal mineralocorticoid and glucocorticoid receptors. Dev. Brain Res. 92, 156-163. doi: 10.1016/0165-3806(95)00213-8

Swanson, L. W., and Simmons, D. M. (1989). Differential steroid hormone and neural influences on peptide mRNA levels in CRH cells of the paraventricular nucleus: a hybridization histochemical study in the rat. J. Comp. Neurol. 285, 413-435. doi: 10.1002/cne.902850402

Szuran, T. F., Pliška, V., Pokorny, J., and Welzl, H. (2000). Prenatal stress in rats: effects on plasma corticosterone, hippocampal glucocorticoid receptors, and maze performance. Physiol. Behav. 71, 353-362. doi: 10.1016/S0031-9384(00)00351-6

Teicher, M. H., Tomoda, A., and Andersen, S. L. (2006). Neurobiological consequences of early stress and childhood maltreatment: are results from human and animal studies comparable? Ann. N.Y. Acad. Sci. 1071, 313-323. doi: 10.1196/annals.1364.024

Tobe, I., Ishida, Y., Tanaka, M., Endoh, H., Fujioka, T., and Nakamura, S. (2005). Effects of repeated maternal stress on FOS expression in the hypothalamic paraventricular nucleus of fetal rats. Neuroscience 134, 387-395. doi: 10.1016/j.neuroscience.2005.04.023

Tolin, D. F., and Foa, E. B. (2006). Sex differences in trauma and posttraumatic stress disorder: a quantitative review of 25 years of research. Psychol. Bull. 132:959. doi: 10.1037/0033-2909.132.6.959

Tollenaar, M. S., Beijers, R., Jansen, J., Riksen-Walraven, J. M., and de Weerth, C. (2011). Maternal prenatal stress and cortisol reactivity to stressors in human infants. Stress 14, 53-65. doi: 10.3109/10253890.2010. 499485

Trujillo, V., Durando, P. E., and Suarez, M. M. (2016). Maternal separation in early life modifies anxious behavior and Fos and glucocorticoid receptor expression in limbic neurons after chronic stress in rats: effects of tianeptine. Stress 19, 91-103. doi: 10.3109/10253890.2015.1105958
Uchida, S., Hara, K., Kobayashi, A., Funato, H., Hobara, T., Otsuki, K., et al. (2010). Early life stress enhances behavioral vulnerability to stress through the activation of REST4-mediated gene transcription in the medial prefrontal cortex of rodents. J. Neurosci. 30, 15007-15018. doi: 10.1523/JNEUROSCI.1436-10.2010

Ulrich-Lai, Y. M., and Herman, J. P. (2009). Neural regulation of endocrine and autonomic stress responses. Nat. Rev. Neurosci. 10, 397-409. doi: 10.1038/nrn2647

Uribe-Marino, A., Gassen, N. C., Wiesbeck, M. F., Balsevich, G., Santarelli, S., Solfrank, B., et al. (2016). Prefrontal cortex corticotropin-releasing factor receptor 1 conveys acute stress-induced executive dysfunction. Biol. Psychiatry 80, 743-753. doi: 10.1016/j.biopsych.2016.03.2106

Vallée, M., Mayo, W., Dellu, F., Le Moal, M., Simon, H., and Maccari, S. (1997). Prenatal stress induces high anxiety and postnatal handling induces low anxiety in adult offspring: correlation with stress-induced corticosterone secretion. $J$. Neurosci. 17, 2626-2636.

Vallée, M., Mayo, W., Maccari, S., Le Moal, M., and Simon, H. (1996). Long-term effects of prenatal stress and handling on metabolic parameters: relationship to corticosterone secretion response. Brain Res. 712, 287-292. doi: 10.1016/0006-8993(95)01459-4

van der Doelen, R. H., Arnoldussen, I. A., Ghareh, H., van Och, L., Homberg, J. R., and Kozicz, T. (2015). Early life adversity and serotonin transporter gene variation interact to affect DNA methylation of the corticotropin-releasing factor gene promoter region in the adult rat brain. Dev. Psychopathol. 27, 123-135. doi: 10.1017/S0954579414001345

van der Doelen, R. H., Kozicz, T., and Homberg, J. R. (2013). Adaptive fitness; early life adversity improves adult stress coping in heterozygous serotonin transporter knockout rats. Mol. Psychiatry 18, 1244-1245. doi: $10.1038 / \mathrm{mp} .2012 .186$

van Oers, H. J. J., de Kloet, E. R., and Levine, S. (1997). Persistent, but paradoxical, effects on HPA regulation of infants maternally deprived at different ages. Stress 1, 249-261. doi: 10.3109/10253899709013745

van Oers, H. J., de Kloet, E. R., and Levine, S. (1998b). Early vs. late maternal deprivation differentially alters the endocrine and hypothalamic responses to stress. Dev. Brain Res. 111, 245-252. doi: 10.1016/S0165-3806(98)00143-6

van Oers, H. J., de Kloet, E. R., Whelan, T., and Levine, S. (1998a). Maternal deprivation effect on the infant's neural stress markers is reversed by tactile stimulation and feeding but not by suppressing corticosterone. J. Neurosci. 18, 10171-10179.

Van Pett, K., Viau, V., Bittencourt, J. C., Chan, R. K., Li, H. Y., Arias, C., et al. (2000). Distribution of mRNAs encoding CRF receptors in brain and pituitary of rat and mouse. J. Comp. Neurol. 428, 191-212. doi: 10.1002/1096-9861(20001211)428:2<191::AID-CNE1>3.0.CO;2-U

Van Waes, V., Enache, M., Dutriez, I., Lesage, J., Morley-Fletcher, S., Vinner, E., et al. (2006). Hypo-response of the hypothalamic-pituitary-adrenocortical axis after an ethanol challenge in prenatally stressed adolescent male rats. Eur. J. Neurosci. 24, 1193-1200. doi: 10.1111/j.1460-9568.2006.04973.x

Varghese, F. P., and Brown, E. S. (2001). The hypothalamic-pituitary-adrenal axis in major depressive disorder: a brief primer for primary care physicians. Prim. Care Companion J. Clin. Psychiatry 3, 151-155. doi: 10.4088/PCC.v03n0401

Vazquez, D. M., Bailey, C., Dent, G. W., Okimoto, D. K., Steffek, A., López, J. F., et al. (2006). Brain corticotropin-releasing hormone (CRH) circuits in the developing rat: effect of maternal deprivation. Brain Res. 1121, 83-94. doi: 10.1016/j.brainres.2006.08.104

Vázquez, D. M., Eskandari, R., Phelka, A., and López, J. F. (2003). Impact of maternal deprivation on brain corticotropin-releasing hormone circuits: prevention of $\mathrm{CRH}$ receptor-2 mRNA changes by desipramine treatment. Neuropsychopharmacology 28, 898-909. doi: 10.1038/sj.npp.1300126

Vázquez, D. M., Van Oers, H., Levine, S., and Akil, H. (1996). Regulation of glucocorticoid and mineralocorticoid receptor mRNAs in the hippocampus of the maternally deprived infant rat. Brain Res. 731, 79-90. doi: 10.1016/0006-8993(96)00465-9

Veenema, A. H., and Neumann, I. D. (2009). Maternal separation enhances offensive play-fighting, basal corticosterone and hypothalamic vasopressin mRNA expression in juvenile male rats. Psychoneuroendocrinology 34, 463-467. doi: 10.1016/j.psyneuen.2008.10.017

Veenema, A. H., Blume, A., Niederle, D., Buwalda, B., and Neumann, I. D. (2006). Effects of early life stress on adult male aggression and 
hypothalamic vasopressin and serotonin. Eur. J. Neurosci. 24, 1711-1720. doi: 10.1111/j.1460-9568.2006.05045.x

Veenema, A. H., Bredewold, R., and Neumann, I. D. (2007). Opposite effects of maternal separation on intermale and maternal aggression in C57BL/6 mice: link to hypothalamic vasopressin and oxytocin immunoreactivity. Psychoneuroendocrinology 32, 437-450. doi: 10.1016/j.psyneuen.2007.02.008

Vintermyr, O. K., Mellgren, G., Boe, R., and Doskeland, S. O. (1989). Cyclic adenosine monophosphate acts synergistically with dexamethasone to inhibit the entrance of cultured adult rat hepatocytes into S-phase: with a note on the use of nucleolar and extranucleolar [3H]-thymidine labelling patterns to determine rapid changes in the rate of onset of DNA replication. J. Cell. Physiol. 141, 371-382. doi: 10.1002/jcp. 1041410219

Walker, C.-D., Perrin, M., Vale, W., and Rivier, C. (1986a). Ontogeny of the stress response in the rat: role of the pituitary and the hypothalamus*. Endocrinology 118, 1445-1451. doi: 10.1210/endo-118-4-1445

Walker, C.-D., Sapolsky, R. M., Meaney, M. J., Vale, W. W., and Rivier, C. L. (1986b). Increased pituitary sensitivity to glucocorticoid feedback during the stress nonresponsive period in the neonatal rat*. Endocrinology 119, 1816-1821. doi: 10.1210/endo-119-4-1816

Wang, A., Nie, W., Li, H., Hou, Y., Yu, Z., Fan, Q., et al. (2014). Epigenetic upregulation of corticotrophin-releasing hormone mediates postnatal maternal separation-induced memory deficiency. PLoS ONE 9:e94394. doi: 10.1371/journal.pone.0094394

Wang, H., Meyer, K., and Korz, V. (2013). Stress induced hippocampal mineralocorticoid and estrogen receptor beta gene expression and long-term potentiation in male adult rats is sensitive to early-life stress experience. Psychoneuroendocrinology 38, 250-262. doi: 10.1016/j.psyneuen.2012.06.004

Wang, X. D., Labermaier, C., Holsboer, F., Wurst, W., Deussing, J. M., Müller, M. B., et al. (2012). Early-life stress-induced anxiety-related behavior in adult mice partially requires forebrain corticotropin-releasing hormone receptor 1. Eur. J. Neurosci. 36, 2360-2367. doi: 10.1111/j.1460-9568.2012.08148.x

Wang, X. D., Rammes, G., Kraev, I., Wolf, M., Liebl, C., Scharf, S. H., et al. (2011). Forebrain $\mathrm{CRF}(1)$ modulates early-life stress-programmed cognitive deficits. J. Neurosci. 31, 13625-13634. doi: 10.1523/JNEUROSCI.2259-11.2011

Wang, X., Meng, F.-S., Liu, Z.-Y., Fan, J.-M., Hao, K., Chen, X.-Q., et al. (2013). Gestational hypoxia induces sex-differential methylation of Crhr1 linked to anxiety-like behavior. Mol. Neurobiol. 48, 544-555. doi: 10.1007/s12035-013-8444-4

Ward, H. E., Johnson, E. A., Salm, A. K., and Birkle, D. L. (2000). Effects of prenatal stress on defensive withdrawal behavior and corticotropin releasing factor systems in rat brain. Physiol. Behav. 70, 359-366. doi: 10.1016/S0031-9384(00)00270-5

Weaver, I. C., Cervoni, N., Champagne, F. A., D’Alessio, A. C., Sharma, S., Seckl, J. R., et al. (2004). Epigenetic programming by maternal behavior. Nat. Neurosci. 7, 847-854. doi: $10.1038 / \mathrm{nn} 1276$

Weinstock, M. (2008). The long-term behavioural consequences of prenatal stress. Neurosci. Biobehav. Rev. 32, 1073-1086. doi: 10.1016/j.neubiorev.2008.03.002

Weinstock, M., Matlina, E., Maor, G. I., Rosen, H., and McEwen, B. S. (1992). Prenatal stress selectively alters the reactivity of the hypothalamicpituitary adrenal system in the female rat. Brain Res. 595, 195-200. doi: 10.1016/0006-8993(92)91049-K

Weinstock, M., Poltyrev, T., Schorer-Apelbaum, D., Men, D., and McCarty, R. (1998). Effect of prenatal stress on plasma corticosterone and catecholamines in response to footshock in rats. Physiol. Behav. 64, 439-444. doi: 10.1016/S0031-9384(98)00056-0

Welberg, L. A. M., Seckl, J. R., and Holmes, M. C. (2000). Inhibition of $11 \beta$-hydroxysteroid dehydrogenase, the foeto-placental barrier to maternal glucocorticoids, permanently programs amygdala GR mRNA expression and anxiety-like behaviour in the offspring. Eur. J. Neurosci. 12, 1047-1054. doi: 10.1046/j.1460-9568.2000.00958.x

Welberg, L. A. M., Seckl, J. R., and Holmes, M. C. (2001). Prenatal glucocorticoid programming of brain corticosteroid receptors and corticotrophin-releasing hormone: possible implications for behaviour. Neuroscience 104, 71-79. doi: 10.1016/S0306-4522(01)00065-3

Wigger, A., and Neumann, I. D. (1999). Periodic maternal deprivation induces gender-dependent alterations in behavioral and neuroendocrine responses to emotional stress in adult rats. Physiol. Behav. 66, 293-302. doi: 10.1016/S0031-9384(98)00300-X
Wilson, M. A. (1996). GABA physiology: modulation by benzodiazepines and hormones. Crit. Rev. Neurobiol. 10, 1-37. doi: 10.1615/CritRevNeurobiol.v10.i1.10

Workel, J. O., Oitzl, M. S., Fluttert, M., Lesscher, H., Karssen, A., and de Kloet, E. R. (2001). Differential and age-dependent effects of maternal deprivation on the hypothalamic-pituitary-adrenal axis of brown norway rats from youth to senescence. J. Neuroendocrinol. 13, 569-580. doi: 10.1046/j.1365-2826.2001.00668.x

Wu, Y., Patchev, A. V., Daniel, G., Almeida, O. F., and Spengler, D. (2014). Early-life stress reduces DNA methylation of the Pomc gene in male mice. Endocrinology 155, 1751-1762. doi: 10.1210/en.2013-1868

Xiong, G. J., Yang, Y., Wang, L. P., Xu, L., and Mao, R. R. (2014). Maternal separation exaggerates spontaneous recovery of extinguished contextual fear in adult female rats. Behav. Brain Res. 269, 75-80. doi: 10.1016/j.bbr.2014.04.015

Xu, L., Sun, Y., Gao, L., Cai, Y.-Y., and Shi, S.-X. (2014). Prenatal restraint stress is associated with demethylation of Corticotrophin Releasing Hormone (CRH) promoter and enhances $\mathrm{CRH}$ transcriptional responses to stress in adolescent rats. Neurochem. Res. 39, 1193-1198. doi: 10.1007/s11064-014-1296-0

Yan, X. X., Toth, Z., Schultz, L., Ribak, C. E., and Baram, T. Z. (1998). Corticotropin-releasing hormone (CRH)-containing neurons in the immature rat hippocampal formation: light and electron microscopic features and colocalization with glutamate decarboxylase and parvalbumin. Hippocampus 8, 231-243. doi: 10.1002/(SICI)1098-1063(1998)8:3<231::AID-HIPO6> 3.0.CO;2-M

Yang, J., Han, H., Cao, J., Li, L., and Xu, L. (2006a). Prenatal stress modifies hippocampal synaptic plasticity and spatial learning in young rat offspring. Hippocampus 16, 431-436. doi: 10.1002/hipo.20181

Yang, J., Hou, C., Ma, N., Liu, J., Zhang, Y., Zhou, J., et al. (2007). Enriched environment treatment restores impaired hippocampal synaptic plasticity and cognitive deficits induced by prenatal chronic stress. Neurobiol. Learn. Mem. 87, 257-263. doi: 10.1016/j.nlm.2006.09.001

Yang, J., Li, W., Liu, X., Li, Z., Li, H., Yang, G., et al. (2006b). Enriched environment treatment counteracts enhanced addictive and depressive-like behavior induced by prenatal chronic stress. Brain Res. 1125, 132-137. doi: 10.1016/j.brainres.2006.10.028

Yehuda, R., Yang, R.-K., Buchsbaum, M. S., and Golier, J. A. (2006). Alterations in cortisol negative feedback inhibition as examined using the ACTH response to cortisol administration in PTSD. Psychoneuroendocrinology 31, 447-451. doi: 10.1016/j.psyneuen.2005.10.007

Yi, S. J., and Baram, T. Z. (1993). Methods for implanting steroid-containing cannulae into the paraventricular nucleus of neonatal rats. J. Pharmacol. Toxicol. Methods 30, 97-102. doi: 10.1016/1056-8719(93)90012-4

Yi, S.-J., Masters, J. N., and Baram, T. Z. (1994). Glucocorticoid receptor mRNA ontogeny in the fetal and postnatal rat forebrain. Mol. Cell. Neurosci. 5, 385. doi: 10.1006/mcne.1994.1048

Zalosnik, M. I., Pollano, A., Trujillo, V., Suarez, M. M., and Durando, P. E. (2014). Effect of maternal separation and chronic stress on hippocampal-dependent memory in young adult rats: evidence for the match-mismatch hypothesis. Stress 17, 445-450. doi: 10.3109/10253890.2014.936005

Zelena, D., Barna, I., Pintér, O., Klausz, B., Varga, J., and Makara, G. B. (2011). Congenital absence of vasopressin and age-dependent changes in ACTH and corticosterone stress responses in rats. Stress 14, 420-430. doi: 10.3109/10253890.2011.552991

Zelena, D., Stocker, B., Barna, I., Tóth, Z. E., and Makara, G. B. (2015). Vasopressin deficiency diminishes acute and long-term consequences of maternal deprivation in male rat pups. Psychoneuroendocrinology 51, 378-391. doi: 10.1016/j.psyneuen.2014.10.018

Zhang, L., Hernandez, V., Liu, B., Medina, M., Nava-Kopp, A., Irles, C., et al. (2012). Hypothalamic vasopressin system regulation by maternal separation: its impact on anxiety in rats. Neuroscience 215, 135-148. doi: 10.1016/j.neuroscience.2012.03.046

Zhang, T. Y., Chretien, P., Meaney, M. J., and Gratton, A. (2005). Influence of naturally occurring variations in maternal care on prepulse inhibition of acoustic startle and the medial prefrontal cortical dopamine response to stress in adult rats. J. Neurosci. 25, 1493-1502. doi: 10.1523/JNEUROSCI.3293-04.2005

Zhang, X., Wang, B., Jin, J., An, S., Zeng, Q., Duan, Y., et al. (2014). Early deprivation reduced anxiety and enhanced memory in adult 
male rats. Brain Res. Bull. 108, 44-50. doi: 10.1016/j.brainresbull.2014. 08.005

Zhang, Z. W. (2004). Maturation of layer V pyramidal neurons in the rat prefrontal cortex: intrinsic properties and synaptic function. J. Neurophysiol. 91, 1171-1182. doi: 10.1152/jn.00855.2003

Zilles, K., Qu, M., and Schleicher, A. (1993). Regional distribution and heterogeneity of alpha-adrenoceptors in the rat and human central nervous system. J. Hirnforsch. 34, 123-132.

Zohar, I., and Weinstock, M. (2011). Differential effect of prenatal stress on the expression of cortiocotrophin-releasing hormone and its receptors in the hypothalamus and amygdala in male and female rats. J. Neuroendocrinol. 23, 320-328. doi: 10.1111/j.1365-2826.2011.02117.x

Zovkic, I. B., Guzman-Karlsson, M. C., and Sweatt, J. D. (2013). Epigenetic regulation of memory formation and maintenance. Learn. Mem. 20, 61-74. doi: $10.1101 / \mathrm{lm} .026575 .112$

Zucchi, F. C., Yao, Y., Ward, I. D., Ilnytskyy, Y., Olson, D. M., Benzies, K., et al. (2013). Maternal stress induces epigenetic signatures of psychiatric and neurological diseases in the offspring. PLOS ONE 8:e56967. doi: 10.1371/journal.pone.0056967
Zuena, A. R., Mairesse, J., Casolini, P., Cinque, C., Alema, G. S., Morley-Fletcher, S., et al. (2008). Prenatal restraint stress generates two distinct behavioral and neurochemical profiles in male and female rats. PLoS ONE 3:e2170. doi: 10.1371/journal.pone.0002170

Zuloaga, D. G., Carbone, D. L., Hiroi, R., Chong, D. L., and Handa, R. J. (2011). Dexamethasone induces apoptosis in the developing rat amygdala in an age-, region-, and sex-specific manner. Neuroscience 199, 535-547. doi: 10.1016/j.neuroscience.2011.09.052

Conflict of Interest Statement: The authors declare that the research was conducted in the absence of any commercial or financial relationships that could be construed as a potential conflict of interest.

Copyright (c) 2017 van Bodegom, Homberg and Henckens. This is an open-access article distributed under the terms of the Creative Commons Attribution License (CC $B Y)$. The use, distribution or reproduction in other forums is permitted, provided the original author(s) or licensor are credited and that the original publication in this journal is cited, in accordance with accepted academic practice. No use, distribution or reproduction is permitted which does not comply with these terms. 